University of New Hampshire

University of New Hampshire Scholars' Repository

$3-24-2020$

\title{
New Hampshire Coastal Flood Risk Summary, Part II: Guidance for Using Scientific Projections
}

New Hampshire Coastal Flood Risk Science and Technical Advisory Panel

Follow this and additional works at: https://scholars.unh.edu/ersc

\section{Recommended Citation}

NH Coastal Flood Risk Science and Technical Advisory Panel (2020). New Hampshire Coastal Flood Risk Summary, Part II: Guidance for Using Scientific Projections. Report published by the University of New Hampshire, Durham, NH.

This Report is brought to you for free and open access by the Institute for the Study of Earth, Oceans, and Space (EOS) at University of New Hampshire Scholars' Repository. It has been accepted for inclusion in Earth Systems Research Center by an authorized administrator of University of New Hampshire Scholars' Repository. For more information, please contact Scholarly.Communication@unh.edu. 
Ki l.
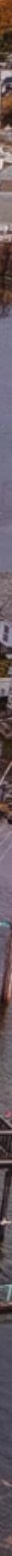

Prepared in partnership with the New Hampshire Coastal Flood Risk Science and Technical Advisory Panel, the University of New Hampshire, and the New Hampshire Department of Environmental Services 


\section{SUGGESTED CITATION}

NH Coastal Flood Risk Science and Technical Advisory Panel (2020).

New Hampshire Coastal Flood Risk Summary, Part II: Guidance for

Using Scientific Projections. Report published by the University of

New Hampshire, Durham, NH. https://scholars.unh.edu/ersc/211/

\section{FUNDING AND ACKNOWLEDGMENTS}

This document was funded, in part, by the National Oceanic and Atmospheric Administration Office for Coastal Management under the Coastal Zone Management Act in conjunction with the NHDES Coastal Program. All icons used in this resource were designed by www.freepik.com.
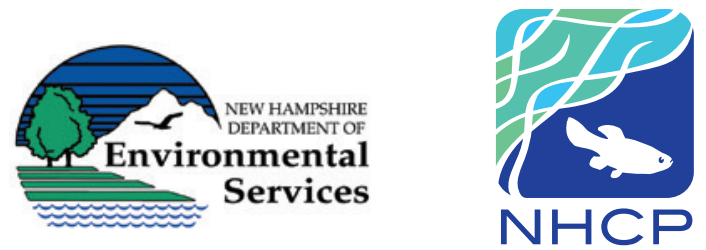

\section{nOAh} 量 


\section{ABOUT THIS DOCUMENT}

This document was prepared in fulfillment of RSA 483-B:22.

Beginning in November 2018, the New Hampshire Department of Environmental Services (NHDES) convened a Science and Technical Advisory Panel (STAP) comprised of representatives from the New Hampshire Department of Transportation (NHDOT), New Hampshire Homeland Security and Emergency Management (HSEM), New Hampshire Office of Strategic Initiatives (OSI), New Hampshire Department of Administrative Services (DAS), New Hampshire Fish and Game Department (NHFG), New Hampshire Department of Natural and Cultural Resources (DNCR), Rockingham Planning Commission (RPC), Strafford Regional Planning Commission (SRPC), University of New Hampshire (UNH), coastal municiaplities, and the New Hampshire Coastal Adaptation Workgroup to oversee and contribute to the development of the 2019-2020 New Hampshire Coastal Flood Risk Summary. The 2019-2020 New Hampshire Coastal Flood Risk Summary is comprised of two parts - Part I: Science ${ }^{1}$ and Part II: Guidance for Using Scientific Projections. This document constitutes Part II: Guidance for Using Scientific Projections.

Part I: Science ${ }^{1}$ provides a synthesis of the state of the science relevant to coastal flood risks in New Hampshire and includes updated projections of relative sea-level rise, coastal storms, groundwater rise, precipitation and freshwater flooding. Part I: Science ${ }^{1}$ was developed by a team of scientific advisors from UNH and was reviewed by the STAP and an external panel of regional experts. The final document was accepted by the Steering Committee on June 28, 2019.

Part II: Guidance for Using Scientific Projections provides sciencebased and user-informed guiding principles and a step-bystep approach for incorporating the updated coastal flood risk projections from Part I: Science ${ }^{1}$ into private, local, state, and federal projects, including planning, regulatory, and site-specific efforts. Part Il: Guidance for Using Scientific Projections was prepared in partnership with the STAP, UNH, and NHDES. The scope and content of Part II: Guidance for Using Scientific Projections was informed by STAP members and underwent public review throughout September 2019. The final document was accepted by the Steering Committee on November 1, 2019.

\section{RSA 483-B:22}

\section{COASTAL AND GREAT BAY REPORTS}

"The commissioner of the department of environmental services shall convene representatives of the department of transportation, the division of homeland security and emergency management, the office of strategic initiatives, and other agencies as he or she deems appropriate, at least every five years, commencing July 1, 2019 to supervise an updating of storm surge, sea-level rise, precipitation, and other relevant projections recommended in the coastal risks and hazards commission 2014 report "Sea-Level Rise, Storm Surges, and Extreme Precipitation in Coastal New Hampshire: Analysis of Past and Projected Trends."This report shall be distributed to all state agencies, municipalities in the coastal and Great Bay region, the governor, the speaker of the house of representatives, the president of the senate and the chairs of the house and senate committees with jurisdiction over issues related to such projections."

\section{RESOURCES TO REFERENCE IN ABOUT THIS DOCUMENT}

1 New Hampshire Coastal Flood Risk Summary Part I: Science. (2019). Prepared for the New Hampshire Coastal Flood Risk Science and Technical Advisory Panel by Wake et al. Published by the University of New Hampshire, Durham, NH. https://scholars.unh.edu/ersc/210. 


\section{SCIENCE AND TECHNICAL ADVISORY PANEL}

\section{PROJECT COORDINATORS}

Kirsten Howard, NH Department of Environmental Services

Nathalie Morison, NH Department of Environmental Services

\section{STEERING COMMITTEE}

Steve Couture, NH Department of Environmental Services

Jennifer Gilbert, NH Office of Strategic Initiatives

Sherry Godlewski, NH Department of Environmental Services

Jennifer Harper, NH Division of Homeland Security and Emergency Management

Ted Kupper, NH Department of Administrative Services Julie LaBranche, Rockingham Planning Commission

Kyle Pimental, Strafford Regional Planning Commission

Cory Riley, NH Department of Fish and Game, Great Bay National Estuarine Research Reserve

Ann Scholz, NH Department of Transportation

Cameron Wake, University of New Hampshire

Gail Wolek, NH Department of Natural and Cultural Resources

\section{CONTRIBUTORS}

University of New Hampshire Science Advisors, members of the New Hampshire Coastal Adaptation Workgroup (NHCAW), and members of the State Environmental Resilience Group (SERG) contributed valuable technical expertise and content throughout the Guidance development process. Key contributors are listed:

Ellie Baker, Horsley Witten Group, Inc.

Tom Ballestero, University of New Hampshire

Jay Diener, Seabrook Hamptons Estuary Alliance

Elizabeth Durfee, EF Design \& Planning LLC

Stefanie Giallongo, NH Department of Environmental Services

Brianna Group, The Nature Conservancy

Adrianne Harrison, National Oceanic and Atmospheric Administration on contract with Lynker Technologies

Jennifer Jacobs, University of New Hampshire

Kevin Knuuti, Independent Consultant

Jayne Knott, JFK Environmental Services LLC

Amy Lamb, NH Department of Natural and Cultural Resources

Thomas Lippmann, University of New Hampshire

Abigail Lyon, Piscataqua Region Estuaries Partnership

Trevor Mattera, Piscataqua Region Estuaries Partnership

Steve Miller, NH Department of Fish and Game, Great Bay National Estuarine Research Reserve

Tom Morgan, Town of Seabrook

David Price, NH Department of Environmental Services

Todd Selig, Town of Durham

Mary Stampone, University of New Hampshire

Sabrina Stanwood, NH Department of Natural and Cultural Resources

Pete Steckler, The Nature Conservancy

Amanda Stone, UNH Cooperative Extension

David Trubey, NH Department of Natural and Cultural Resources

Lisa Wise, UNH Cooperative Extension and NH Sea Grant 


\section{CONTENTS}

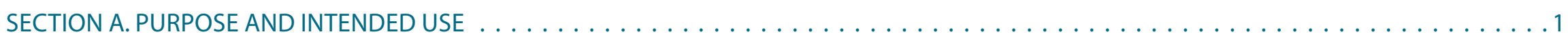

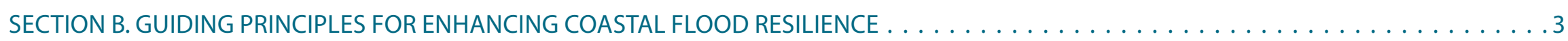

SECTION C. STEP-BY-STEP APPROACH FOR SELECTING AND INCORPORATING COASTAL FLOOD RISK PROJECTIONS . . . . . . . . . . .6

Step 1. Define Project Goal, Type, Location, and Timeframes. . . . . . . . . . . . . . . . . . . . . . 8

Step 2. Determine Tolerance for Flood Risk . . . . . . . . . . . . . . . . . . . . . . . . . . . 12

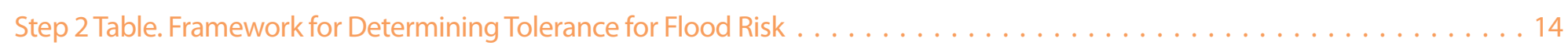

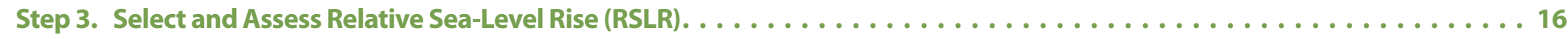

Step 3 Table A. Recommended Decadal RSLR Estimates (in feet above 2000 levels) Based on RCP 4.5,

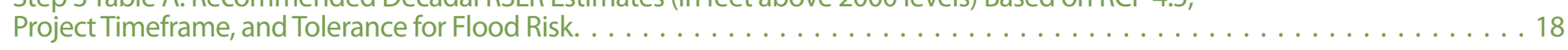

Site-Specific Project Case Study: Lubberland Creek Culvert Replacement Design . . . . . . . . . . . . . . . . . 20

Step 3 Table B. Alternate Decadal RSLR Estimates (in feet above 2000 levels) Based on RCP 8.5, Project Timeframe,

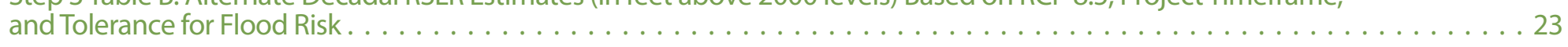

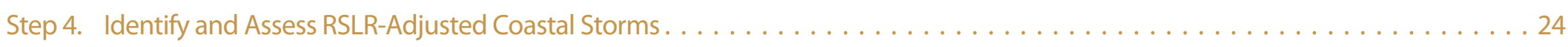

Step 4 Table. RSLR-Adjusted Design Flood Elevations (DFE) Based on Tolerance for Flood Risk . . . . . . . . . . . . . 26

Regulatory Project Case Study: Durham Advisory Climate Change Risk Areas . . . . . . . . . . . . . . . . . 27

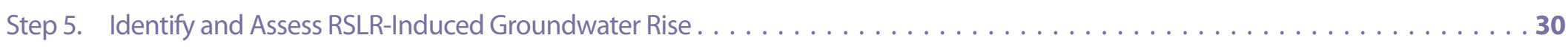

Planning Project Case Study: Mapping Changing Wetlands in Portsmouth $\ldots \ldots \ldots \ldots \ldots \ldots$

Step 5 Table. Approaches for Calculating Depth to RSLR-Adjusted Groundwater. . . . . . . . . . . . . . 33

Step 6. Identify and Assess Extreme Precipitation Estimates. . . . . . . . . . . . . . . . . . . . . 34

Step 6 Table. Approach for Calculating Extreme Precipitation Estimates Based on Tolerance for Flood Risk . . . . . . . . . . 36

Regulatory Project Case Study: Hypothetical Alteration of Terrain Permit Application . . . . . . . . . . . . 37

Planning Project Case Study: Inundation Mapping for Lee, New Hampshire . . . . . . . . . . . . . . . . 38

Step 7. Assess Cumulative Risk and Evaluate Adaptation Options . . . . . . . . . . . . . . . . . . . . 40

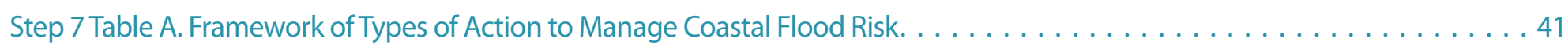

Step 7 Table B. Examples of Types of Actions to Manage Coastal Flood Risk . . . . . . . . . . . . . . . . 42

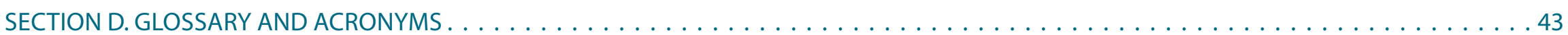

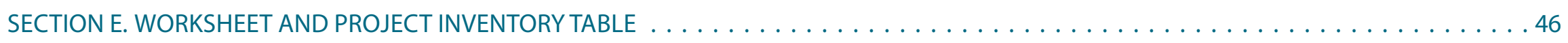




\section{SECTION A. PURPOSE AND INTENDED USE}

Coastal flood risks in New Hampshire, including relative sea-level rise (RSLR), coastal storms, RSLR-induced groundwater rise, extreme precipitation, and freshwater flooding pose an immediate and increasing threat to New Hampshire's public health and safety, public and private structures and facilities, livelihoods and economies, and natural, historic, and cultural resources. Proactive planning for these coastal flood risks is essential to save lives and money, sustain quality of life, mitigate crises and conflict, and avoid the otherwise likely and painful degradation of New Hampshire's most vulnerable coastal areas. The primary purpose of the New Hampshire Coastal Flood Risk Summary, Part II: Guidance for Using Scientific Projections (Guidance), is to enhance understanding and application of the science summarized in the New Hampshire Coastal Flood Risk Summary, Part l: Science (Part l: Science). ${ }^{2}$ This science-based and userinformed Guidance is intended to be flexible and is designed to help decision makers select and incorporate updated coastal flood risk projections into multiple private, local, state, and federal projects, including planning, regulatory, or site-specific efforts.

In particular, this Guidance provides:

- Guiding principles for enhancing coastal flood resilience;

- A step-by-step approach and companion worksheet for selecting and incorporating updated coastal flood risk projections into private, local, state, and federal projects, including planning, regulatory, or site-specific efforts; and

- Local case study examples of how coastal flood risk information has been applied to date.

Primary intended users of the Guidance include decision makers involved in developing, providing inputon, and implementing private, local, state, and federal projects, including planning, regulatory, or site-specific efforts in coastal New Hampshire. "Decision makers" may include, but are not limited to, government officials, employees, and volunteer board and commission members; professional consultants; technical assistance providers; private property owners; businesses; and affected stakeholders.

\section{PROJECT}

For the purposes of this Guidance, the term "project" refers broadly to any private, local, state, and federal planning, regulatory, or sitespecific efforts that should consider and incorporate coastal flood risk projections. Examples of applicable private, local, state, or federal projects include, but are not limited to:

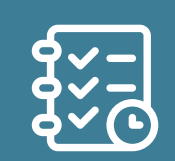

Planning projects: master plans; hazard mitigation plans; post-disaster redevelopment/relocation/ recovery plans; emergency operations and evacuation plans; capital improvement plans; transportation improvement plans; economic development plans; open space plans; etc.

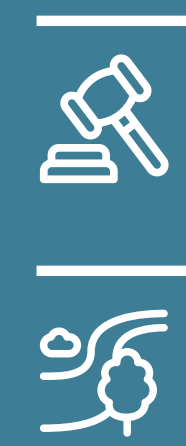

Regulatory projects: zoning ordinances; site plan and subdivision regulations; wetlands and shoreland regulations; alteration of terrain regulations; waste management regulations; etc.

Site-specific projects: new construction and redevelopment or relocation of buildings and structures; road, bridge, culvert construction, maintenance, or relocation; shoreline stabilization projects; wetland restoration; land conservation; etc. 
For planning projects, decision makers may use the Guidance to identify and prioritize action in vulnerable and non-vulnerable areas. For regulatory projects, decision makers may follow the Guidance to determine regulatory standards (e.g., setbacks, Design Flood Elevation, separation distances, etc.) or require use of the Guidance, in full or in part, by regulated parties. For site-specific projects, decision makers may use the Guidance to inform project design and construction.

The Guidance is intended to be integrated within existing planning, regulatory, and site-specific decision-making processes. The specific decision makers involved in a given project will vary depending on the context and it is incumbent upon those decision makers to ensure that all relevant stakeholders, including socially vulnerable populations, are adequately and equitably involved in the decisionmaking process.

The Guidance is advisory, and decision makers may choose to apply it in its entirety or only use parts that are useful for and/or applicable to their specific context. The Guidance should not be construed as superseding existing regulations and design and construction standards. The Guidance shall only become regulatory, mandated, or required if and when incorporated into statutes and/or regulations. Establishing mandatory use of the Guidance is the responsibility of appropriate decision-making authorities in accordance with formal law- and rule-making processes. The Guidance is dynamic and will be updated at least every five years in conjunction with updates to Part I: Science. ${ }^{2}$ As part of the update process, use of the Guidance will be evaluated to determine its effectiveness and identify adjustments that will improve and expand its use. Updates to the Guidance are expected to address best available science, information, approaches, and legal precedent. Guidance updates and/or addenda may be tailored for specific disciplines (e.g., planning, architecture, engineering, natural resources management, historic preservation).
RESOURCES TO REFERENCE IN PURPOSE AND INTENDED USE

2 New Hampshire Coastal Flood Risk Summary Part I: Science. (2019). Prepared for the New Hampshire Coastal Flood Risk Science and Technical Advisory Panel by Wake, C. et al. Published by the University of New Hampshire, Durham, NH. https://scholars.unh.edu/ersc/210.

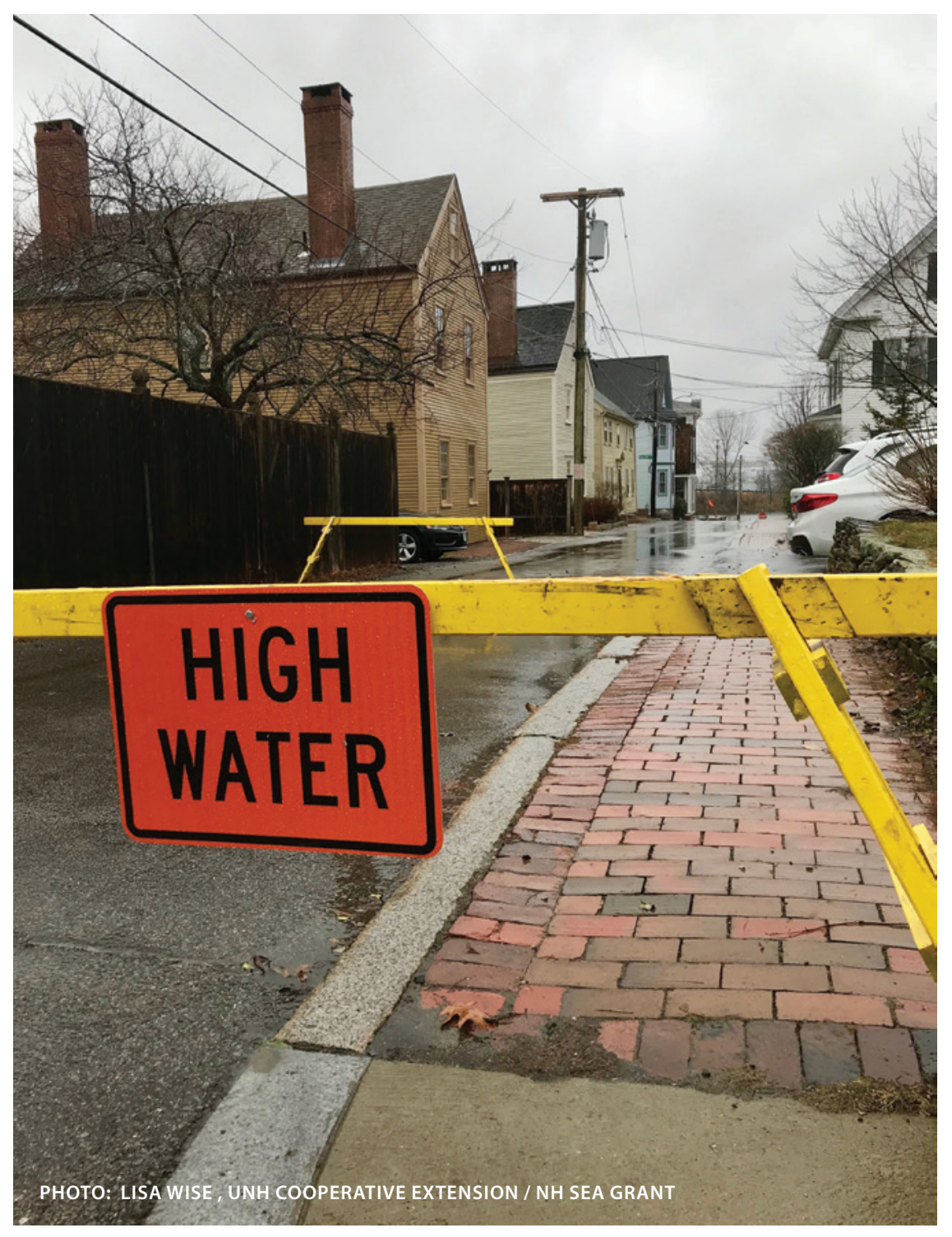

2 PURPOSE AND INTENDED USE | NH COASTAL FLOOD RISK SUMMARY PART II: GUIDANCE 


\section{SECTION B. GUIDING PRINCIPLES FOR ENHANCING COASTAL FLOOD RESILIENCE}

The following set of principles should guide projects that seek to incorporate future coastal flood risk projections and enhance coastal flood resilience. These principles build upon the guiding principles outlined in the 2016 New Hampshire Coastal Risk and Hazards Commission final report and recommendations ${ }^{3}$ with the goal of establishing a common framework that allows for flexibility, encourages creativity, integrates advances in scientific understanding, and prioritizes equity and justice in the approaches private, local, state, and federal entities employ to address future coastal flood risks in New Hampshire.

\section{Support greenhouse gas reduction policies that avoid} the worst coastal flood risks. The relative sea-level rise (RSLR) estimates recommended for use in Part I: Science ${ }^{4}$ and the Guidance are based on an assumption that global greenhouse gas emissions will peak around 2040 and decline to 2080 before stabilizing for the remainder of the century (Representative Concentration Pathway (RCP) 4.5; see Step 3: Science at a Glance for more information). Policies to reduce global greenhouse gas emissions are critical to avoid the most detrimental coastal flooding and other harmful climate change impacts around the world. Reducing greenhouse gas emissions should be an integral part of every strategy to minimize future coastal flood risk and consideration should be given to the greenhouse gas emissions implications in all adaptation-related decision-making in order to minimize "maladaptation" (i.e., actions that may help with adapting to coastal flood risks in the shortterm but inhibit long-term capacity or opportunities to adapt by contributing to more extreme, long-term climate change impacts).
Determine the tolerance for flood risk applicable to planning, regulatory, or site-specific projects. For the purposes of the Guidance, "tolerance for flood risk" refers to the decision makers' willingness to accept a higher or lower probability of flood impacts based on relevant project characteristics such as project value or replacement cost, capacity to adapt, importance for public function or safety, and sensitivity to inundation. Projects with Low to Very Low tolerance for flood risk, such as those that are critical to public safety or national security, may warrant the use of less likely but more damaging coastal flood risk projections and may justify the implementation of more intensive coastal flood risk protection or avoidance strategies.

Consideration of tolerance for flood risk on a project by project basis allows for important flexibility and practical cost efficiencies. However, tolerance for flood risk should not be applied to a project in a vacuum - the tolerance for flood risk of surrounding areas, access routes, and infrastructure that provide services and access to a project may be different than the tolerance for flood risk of the project itself.

Prioritize equity and justice of socially vulnerable populations in planning and decision-making. Communities of color as well as people with low incomes; elderly, young, and disabled people; and Indigenous peoples have historically been and continue to be marginalized from decision-making processes and are disproportionately vulnerable to and overburdened by environmental pollution, climate change, and flooding. Displacement, loss of historic and cultural resources, loss of access to support services, and loss of access to the coast are just a few of 
the impacts that will continue to disproportionately affect socially vulnerable populations as coastal flooding gets worse. All actions to prepare for future coastal flood risks must prioritize social equity and environmental justice for socially vulnerable populations by centering their perspectives, needs, and knowledge early in any decision-making process, and by evaluating the potential impacts of any decisions on these populations. Decision makers should 1) consider impacts of resilience-related planning, projects, and decisions on socially vulnerable, underserved populations ${ }^{5}$; 2) create roles for socially vulnerable populations in resilience-related planning and decision-making processes (i.e. "nothing about me without me"); and 3) explore ways to support socially vulnerable, underserved populations before, during, and after coastal flood events, especially in partnership with existing organizations and community groups that work on issues of social vulnerability. Decision makers should consult the Centers for Disease Control and Prevention's SocialVulnerability Index ${ }^{6}$ or other available data to identify characteristics that contribute to social vulnerability in their community. Additionally, decision makers should reference the Urban Sustainability Directors Network's Guide to Equitable, CommunityDriven Climate Preparedness Planning 5 for guidance on how to design and implement inclusive, equitable decision-making processes.

Protect natural, cultural and historic resources, and public access. Nature-based approaches (e.g., green, natural infrastructure) to mitigate coastal flooding will often be more effective, cost-efficient, and resilient in the long-term compared to hard, grey infrastructure strategies that attempt to keep water out. Impacts of increased coastal flooding on natural, cultural, and historic resources should be considered in planning and decision-making in order to help protect ecosystems and the services they provide, as well as preserve a sense of place within our coastal communities. One important naturebased strategy is to prioritize flood-resilient redevelopment and discourage new development that replaces existing open space and the important flood storage, storm protection, and erosion control benefits it provides. In some of the most vulnerable places, it will be necessary to relocate development, and those areas should be restored to open space. Maintaining existing and creating new public access to the coast, while also considering the vulnerability of these areas to coastal flooding, will be critical to preserving the cultural vibrancy and resilience of the New Hampshire coast.

\section{Create a bold vision, start immediately, and act incrementally} and opportunistically as projected coastal flood risks unfold. Significant lead times will likely be required to implement the institutional and infrastructural changes necessary to adequately address projected coastal flood risks. Efforts should begin immediately to envision these changes and identify the incremental actions and associated lead times required to achieve those changes.

\section{Consider the full suite of actions and the effectiveness and} consequences of those actions. Adaptation options will typically fall within a framework of five action categories: no action, avoid, accommodate, resist, and relocate (Step 7 Table A). A combination of actions spanning the five action categories may be necessary depending on the scope of the project. Robust actions will mitigate multiple coastal flood risks, perform as intended over a wide range of possible future conditions, and avoid exacerbating flood risk to existing assets, such as abutting structures and natural resources. Decision makers should strongly consider relocating priority assets or enabling migration out of harm's way and avoiding new development in high risk areas as these are the only actions that will significantly minimize or eliminate coastal flood risk. Decision makers should also weigh whether the level of investment required to implement an action is warranted, or if the project, as originally conceived, is no longer practicable and should be revised or called off given future coastal flood risk projections.

4 | GUIDING PRINCIPLES | NH COASTAL FLOOD RISK SUMMARY PART II: GUIDANCE 
Adopt a flexible adaptation approach and continuously monitor performance. Decision makers are encouraged to make creative adaptation decisions that are flexible and can be adjusted over time. Most importantly, decision makers should commit to monitoring the project and conditions, and adjust course as needed as new information becomes available, coastal flood risk conditions unfold, and opportunities arise to improve performance (e.g., new technology).

Coordinate and collaborate with private, local, state, and federal decision makers, and where feasible, use consistent coastal flood risk projections for cross-jurisdictional planning and regulatory decisions.

Consider the liability of not taking action. Case law is still in its infancy, however, decision makers who fail to act despite having science-based information about future coastal flood risks may face questions of liability. ${ }^{7}$ Conversely, the risk of municipal liability for adopting policies and regulations based on scientifically projected future conditions is generally low, so long as municipalities follow sound planning principles and provide a reasonable basis for enacting new ordinances (e.g., protecting the safety, health, and welfare of the community from flood hazards). ${ }^{8}$

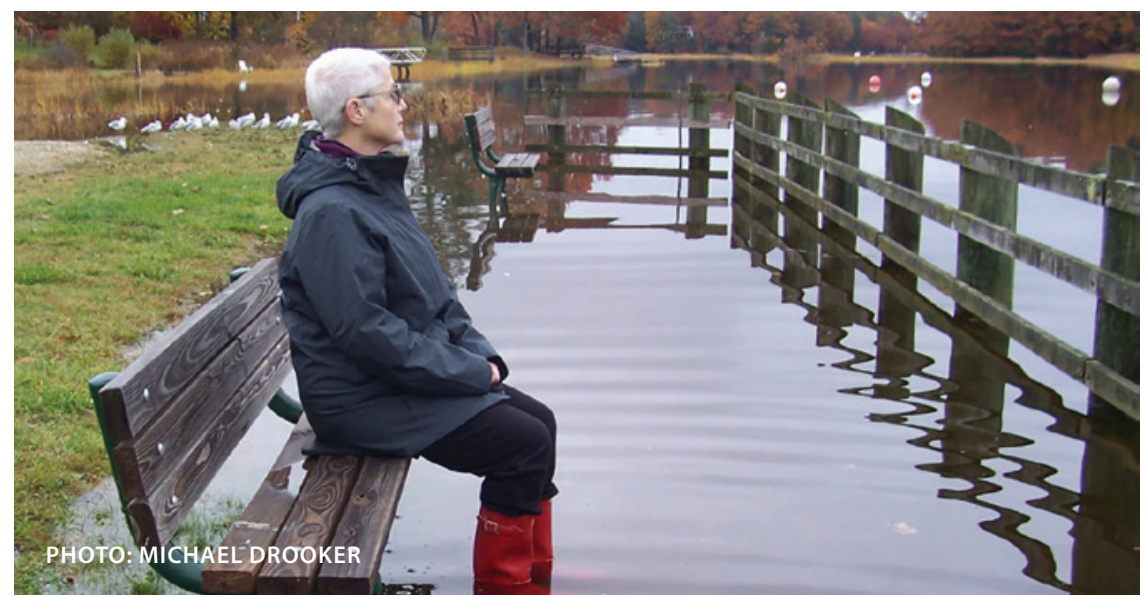

\section{RESOURCES TO REFERENCE IN GUIDING PRINCIPLES}

3 Preparing New Hampshire for Projected Storm Surge, Sea-Level Rise, and Extreme Precipitation. (2016). Published by the New Hampshire Coastal Risk and Hazards Commission. https://www.nhcrhc.org/wp-content/uploads/2016-CRHCfinal-report.pdf

4 New Hampshire Coastal Flood Risk Summary Part I: Science. (2019) Prepared for the New Hampshire Coastal Flood Risk Science and Technical Advisory Panel by Wake, C. et al. Published by the University of New Hampshire, Durham, $\mathrm{NH}$. https://scholars.unh.edu/ersc/210

5 Social Vulnerability Index (SVI). Center for Disease Control (webpage last updated September 12, 2018). https://svi.cdc.gov/index.html

6 Guide to Equitable, Community-Driven Climate Preparedness Planning. (2017). Published by the Urban Sustainability Directors Network. https://www.usdn.org/uploads/cms/documents/ usdn_guide_to_equitable_community-driven_climate_ preparedness-_high_res.pdf

7 Climate Adaptation and Liability: A legal primer and workshop summary report. (2018). Published by the Conservation Law Foundation. https://www.clf.org/wp-content/uploads/2018/01/ GRC_CLF_Report_R8.pdf

8 New Floodplain Maps for a Coastal New Hampshire Watershed and Questions of Legal Authority, Measures and Consequences. (2012). Published by the Vermont Law School Land Use Clinic. http://100yearfloods.org/resources/pdf/2012_ VermontLawSchool_LampreyRiver.pdf 


\section{SECTION C. STEP-BY-STEP APPROACH FOR SELECTING AND INCORPORATING COASTAL FLOOD RISK PROJECTIONS}

The step-by-step approach presented in the Guidance is recommended for private, local, state, and federal planning, regulatory, and site-specific projects affecting or taking place in New Hampshire's 17 coastal zone municipalities, including Dover, Durham, Exeter, Greenland, Hampton, Hampton Falls, Madbury, New Castle, Newfields, Newington, Newmarket, North Hampton, Portsmouth, Rollinsford, Rye, Seabrook, and Stratham. The seven steps provide a framework to guide decision makers as they select appropriate coastal flood risk projections, begin assessing the impacts of those projections, and consider flexible and incremental actions to increase project resilience. Project-specific guidance is provided for steps where Guidance application is likely to differ for planning, regulatory, and site-specific projects.

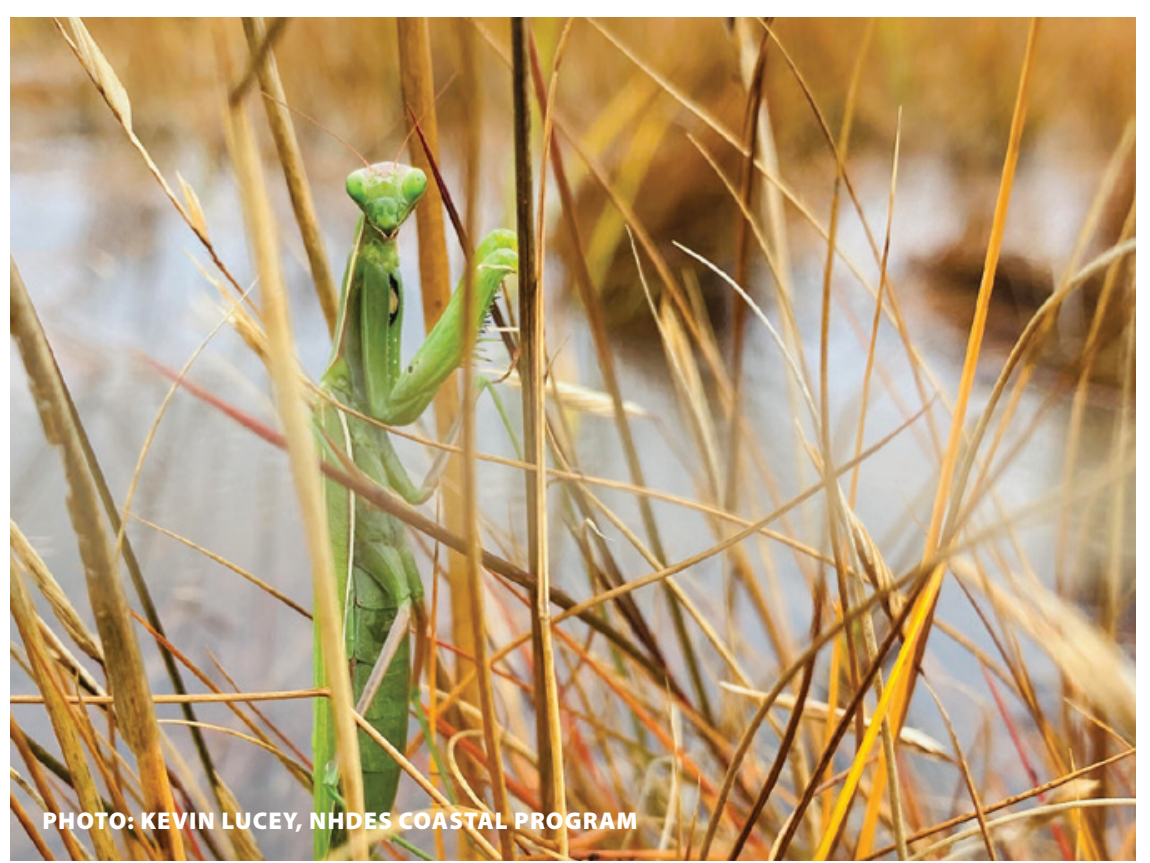

STEP 1. DEFINE PROJECT GOAL, TYPE, LOCATION, AND TIMEFRAME(S)

Step 1.1 | Define the project goal and project type

Step 1.2 | Define and inventory the project area

Step 1.3 | Define the timeframe(s) for the project

STEP 2. DETERIMINE TOLERANCE FOR FLOOD RISK

Step 2.1 | Identify project characteristics that influence tolerance for flood risk Step 2.2 | Determine tolerance for flood risk based on project characteristics

STEP 3. SELECT AND ASSESS RELATIVE SEA-LEVEL RISE (RSLR) Step 3.1 | Select RSLR estimate(s) for the project

Step 3.2 | Assess RSLR impacts to the project

STEP 4. IDENTIFY AND ASSESS RSLR-ADJUSTED COASTAL STORMS Step 4.1 | Identify RSLR-adjusted Design Flood Elevation (DFE)

Step 4.2 | Assess RSLR-adjusted coastal storm impacts to the project

STEP 5. IDENTIFY AND ASSESS RSLR-INDUCED GROUNDWATER RISE

Step 5.1 | Identify RSLR-induced groundwater rise for the project

Step 5.2 | Estimate depth to present-day and future groundwater

Step 5.3 | Assess RSLR-induced groundwater rise impacts to the project

STEP 6. IDENTIFY AND ASSESS PROJECTED EXTREME PRECIPITION Step 6.1 | Account for projected increases in extreme precipitation Step 6.2 | Assess projected extreme precipitation impacts to the project

STEP 7. ASSESS CUMULATIVE RISK AND EVALUATE ADAPTATION OPTIONS Step 7.1 | Assess cumulative coastal flood risk to the project

Step 7.2 | Identify and evaluate adaptation options to mitigate coastal flood risk Step 7.3 | Select and implement preferred option(s) or revisit previous steps

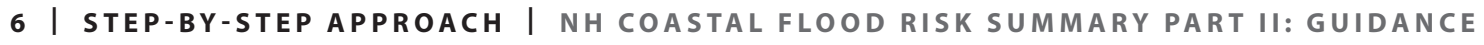




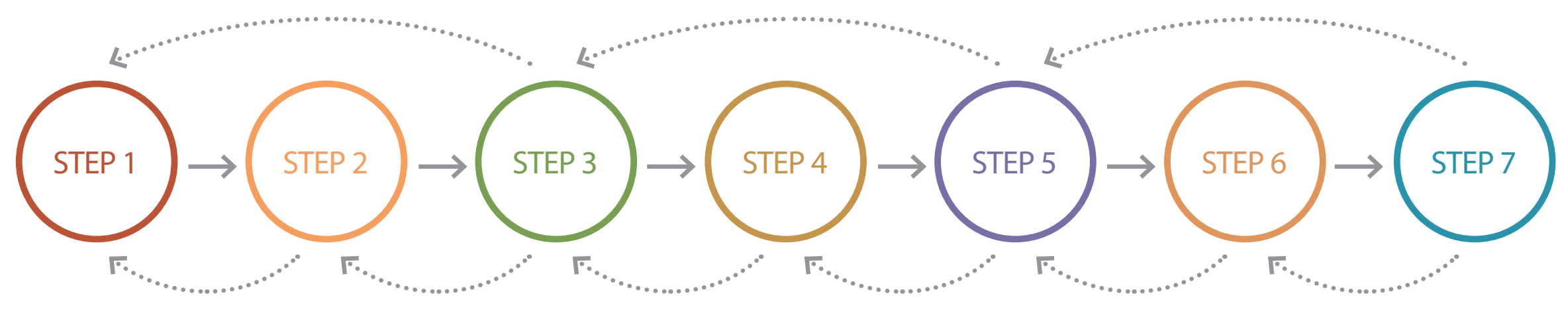

Figure 1. The seven step approach for selecting and incorporating updated coastal flood risk projections into projects is intended to be iterative.

Absent comparable guidance on expected changes to extreme precipitation statewide, projects in non-tidal New Hampshire communities may consider implementing steps 1, 2, 6, and 7 to evaluate future flood risk to projects associated with projected changes in extreme precipitation.

The primary advantage of this structured approach is to remind decision makers of important considerations that may otherwise be ignored or forgotten. Although the step-by-step approach outlined is presented in a linear fashion, selection and assessment of coastal flood risks will likely require revisiting and revising responses to previous steps and/or several iterations throughout the course of the project, depending on assessment results (Figure 1). It is also important to keep in mind that each step may not apply to all projects, and that discipline-specific methods may exist that are more appropriate for use in certain projects; in these cases, decision makers should use their best judgment to identify which steps are relevant for their project or adjust the proposed framework to best suit their needs.

A companion Worksheet to help decision makers work through the seven steps for incorporating coastal flood risk projections in decisions is provided in Section E. The Guidance provides principles, step-by-step instructions, and some of the key data sources needed to fill out the Worksheet. For some projects, decision makers may find that only part of the Worksheet is useful, that they need to adjust the Worksheet, or that they prefer to apply the Guidance to the project without using the Worksheet. Use of the Guidance and Worksheet is voluntary. Referenced resources that may be useful to complete the Worksheet appear at the end of each step in the Guidance. A Worksheet Project Inventory Table template is also provided in Section E for decision makers working on detailed projects that are broad in scale with multiple areas, facilities, structures, and/or resources to evaluate. 


\section{STEP 1: DEFINE PROJECT GOAL, TYPE, LOCATION, AND TIMEFRAME(S)}

\section{PROJECT}

For the purposes of this Guidance, the term "project"refers broadly to any private, local, state, and federal planning, regulatory, or sitespecific efforts that should consider and incorporate coastal flood risk projections. Examples of applicable private, local, state, or federal projects include, but are not limited to:

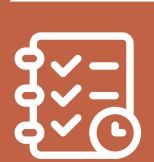

Planning projects: master plans; hazard mitigation plans; post-disaster redevelopment/relocation/ recovery plans; emergency operations and evacuation plans; capital improvement plans; transportation improvement plans; economic development plans; open space plans; etc.
}

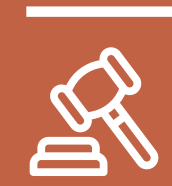

Regulatory projects: zoning ordinances; site plan and/or subdivision regulations; wetlands and shoreland regulations; alteration of terrain regulations; waste management regulations; etc.

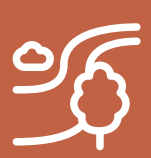

Site-specific projects: new construction and redevelopment or relocation of buildings and structures; road, bridge, culvert construction, maintenance, or relocation; shoreline stabilization projects; wetland restoration; land conservation; etc.

The first step to incorporate coastal flood risk projections into private, local, state, and federal projects is to define the project goal, type, location, and relevant timeframe. The term "project" refers broadly to any private, local, state, and federal planning, regulatory, and

8 STEP 1 | NH COASTAL FLOOD RISK SUMMARY PART II: GUIDANCE site-specific efforts that should consider and incorporate coastal flood risk projections. Recognize that project details may change as the decision-making process progresses and as new stakeholders are engaged.

\section{STEP 1.1 DEFINE THE PROJECT GOAL AND PROJECT TYPE.}

Identify the goal of the project, including any beneficiaries the project is intended to serve. For the purposes of this guidance, a "beneficiary" is defined as any individual, community, or wild life that benefits from a project. Determine whether the project is a planning, regulatory, or site-specific project.

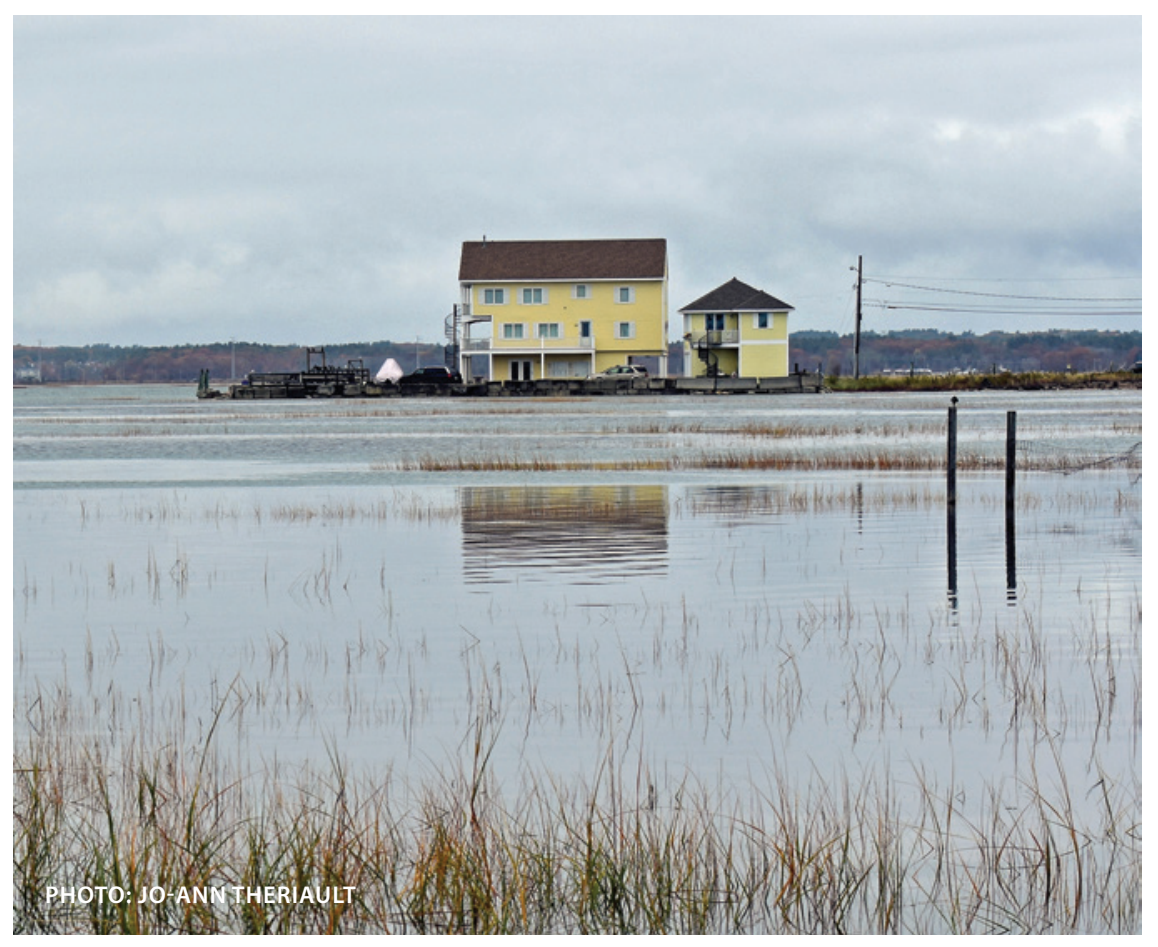




\section{STEP 1.2 DEFINE AND INVENTORY THE PROJECT AREA.}

Delineate the primary planning area, regulatory area, or site location relevant to the project. If helpful, divide the project area into smaller sub-areas based on unifying characteristics such as location; type of structures, facilities, and resources, or use. Consider conducting an inventory of existing structures, facilities, and/or resources within the project area that may have varying tolerances for flood risk and therefore may have different standards for preparedness (Step 2) and/or require different adaptation approaches (Step 7). Identify access and/or services the project provides to or depends on from surrounding areas.

\section{STEP 1.2: PROJECT-SPECIFIC CONSIDERATIONS / EXAMPLES}

There are multiple ways to define the project area for planning, regulatory, and site-specific projects. Approaches will vary based on project goals and decision maker preferences. The following considerations and hypothetical examples are intended to provide additional context and ideas for each project type, but may not apply to all projects.

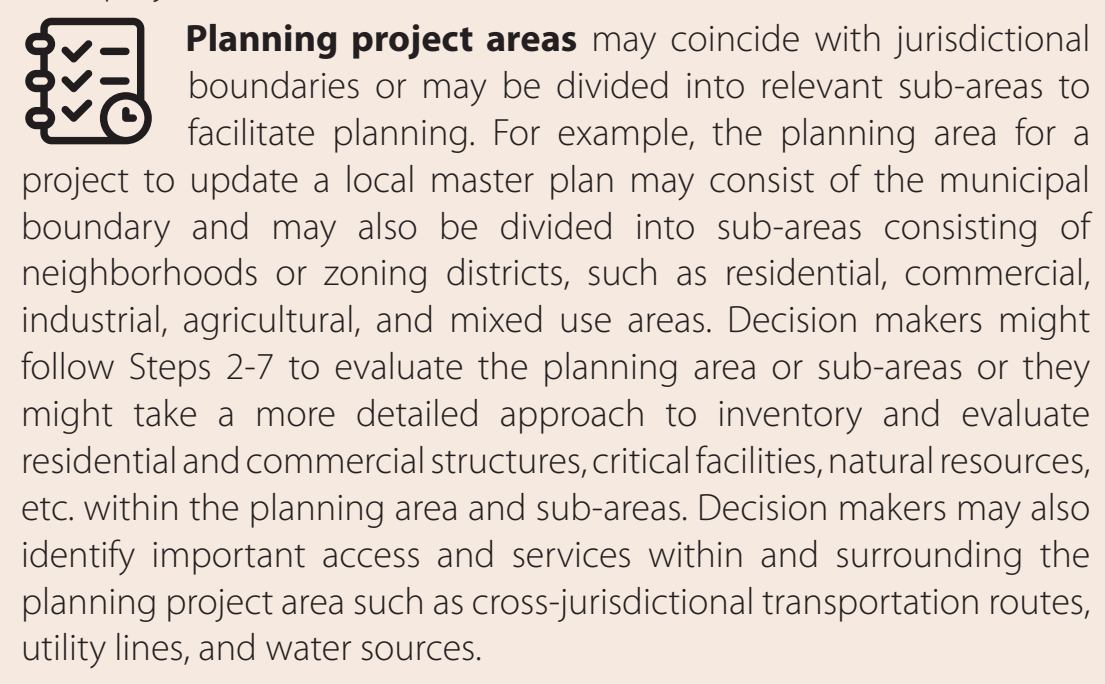

What is a local master plan? A master plan is a planning document that serves to guide the overall character, physical form, and development of a community in New Hampshire. It provides guidance to local officials making decisions on budgets, ordinances, capital improvements, zoning, subdivision matters, and other development-related issues (RSA 674:2). ${ }^{9}$

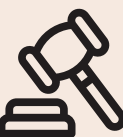

Regulatory project areas may coincide with jurisdictional boundaries or may be divided into relevant sub-areas to facilitate regulation design. For example, the regulatory area for a project to update a local floodplain ordinance may consist of the municipal boundary, current and possible future regulatory Special Flood Hazard Area (i.e., 1\% annual chance floodplain), and/or sub-areas consisting of FEMA Flood Zones (e.g., A Zones, V Zones, X Zones). Decision makers might follow Steps 2-7 to evaluate the regulatory area or sub-areas, or they might take a more detailed approach to inventory and evaluate residential, commercial, and other regulated structures and facilities under the existing floodplain ordinance as well as any additional development that might be regulated under the updated ordinance.

What is a localfloodplain ordinance? Municipalities that participate in the FEMA National Flood Insurance Program must regulate development in areas prone to flooding. The local floodplain ordinance or regulations, often incorporated as part of a municipal zoning ordinance, are intended to promote the public health, safety, and general welfare; to minimize hazards to persons and property from flooding; to protect watercourses from encroachment; and to maintain the capability of floodplains to retain and carry off floodwaters. ${ }^{10}$

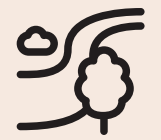

Site-specific project locations are likely to be relatively small and specific and may include address and tax lot identification number. For example, a site-specific project to construct a new hospital might identify the address(es), tax lot ID number(s) associated with the site, and detailed information provided on a design plan, including topography, building footprint, etc. Decision makers might follow Steps 2-7 to evaluate the project location as a whole, or might take a more detailed approach to inventory and evaluate the various buildings, accessory structures and facilities, open space, etc. associated with the site design. Decision makers may also identify the hospital's customers or service area, hospital access, utility lines, etc. 


\section{STEP 1.3 DEFINE THE TIMEFRAME(S) FOR THE PROJECT.}

In order for a project to be resilient throughout its duration, decision makers should plan for coastal flood risks that the project is expected to face at the end of a project's timeframe. In cases where a project has a long timeframe or it makes sense to divide the project timeframe into shorter segments, decision makers may identify incremental action points. Consider how future changes in project beneficiaries or project demand may affect project timeframe. For example, if demand for the project is likely to decline over time due to RSLR, consider abbreviating the project timeframe accordingly.

\section{STEP 1.3: PROJECT-SPECIFIC CONSIDERATIONS / EXAMPLES}

There are multiple ways to define the project timeframes for planning, regulatory, and site-specific projects. Approaches will vary based on project goals and decision maker preferences. The following considerations and hypothetical examples are intended to provide additional context and ideas for each project type, but may not apply to all projects.

\$- For planning projects, define the "planning horizon." For example, the planning horizon for a local master plan update 20 may depend on the timeframe associated with the community vision (e.g., 30 years, 50 years, etc.). In general, plan recommendations will fall within that planning horizon. Because a local master plan is recommended to be updated every five to ten years (RSA 674:3), ${ }^{11}$ the community may also plan for incremental adjustments to the vision and recommendations based on changes in priorities, technology, science, or other factors over the course of the planning horizon.

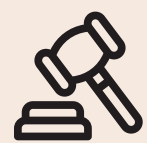

For regulatory projects, define the "regulatory period," or the timeframe relevant to the regulatory intent. For example, the regulatory period for a local floodplain ordinance update may be based on the "useful life" of the residential and commercial structures regulated by the ordinance (e.g., the average useful life of regulated structures in the floodplain may be 50-100 years). In this case, decision makers might pre-assign different "useful lives" to each type of regulated structure or, alternatively, require that regulated entities

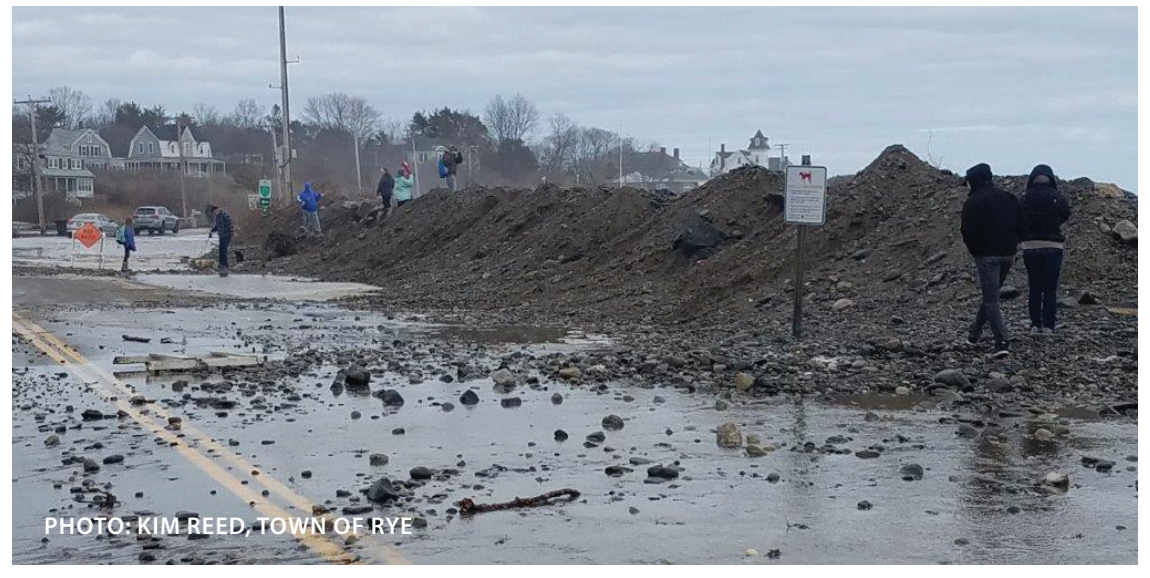

determine and justify the "useful life" relevant to their site-specific project (see site-specific project example for Step 1.3). In other cases, the regulatory intent may be to ensure safe development or to protect a resource for a very long time (or even in perpetuity), in which case decision makers may identify regular incremental action points appropriate for revisiting and incorporating updated coastal flood risk projections into the regulation. For example, if the average useful life of regulated structures in the floodplain is 100 years, but structures are expected to be substantially improved every 30 years, the regulation might ensure that structures are built to be safe from flooding for 30 year increments. Similarly, the incremental action point may be identified as the effective time limit of the regulation or the time period after which the regulation will no longer be valid (e.g., New Hampshire state agency certified administrative rules are valid for 10 years).

For site-specific projects, define the "useful life" of the 3 project, which refers to the extended service life of a project (assuming regular maintenance), as opposed to a project's "design life," which is defined as a project's life expectancy determined during project design. Useful life typically exceeds design life. For example, the useful life of a new hospital building might be 100+ years, assuming regular maintenance. Incremental action points might coincide with regular maintenance or upgrades of structural or service (e.g., electrical, plumbing, HVAC) components (e.g., every 15-30 years). 


\section{RESOURCES TO REFERENCE IN STEP 1}

${ }^{9}$ RSA 674:2. New Hampshire General Court. http://www.gencourt.state.nh.us/rsa/html//xiv/674/674-2.htm.

10 New Hampshire Model Floodplain Ordinances (2019). Published by New Hampshire Office of Strategic Initiatives. https://www. nh.gov/osi/planning/programs/fmp/regulations.htm

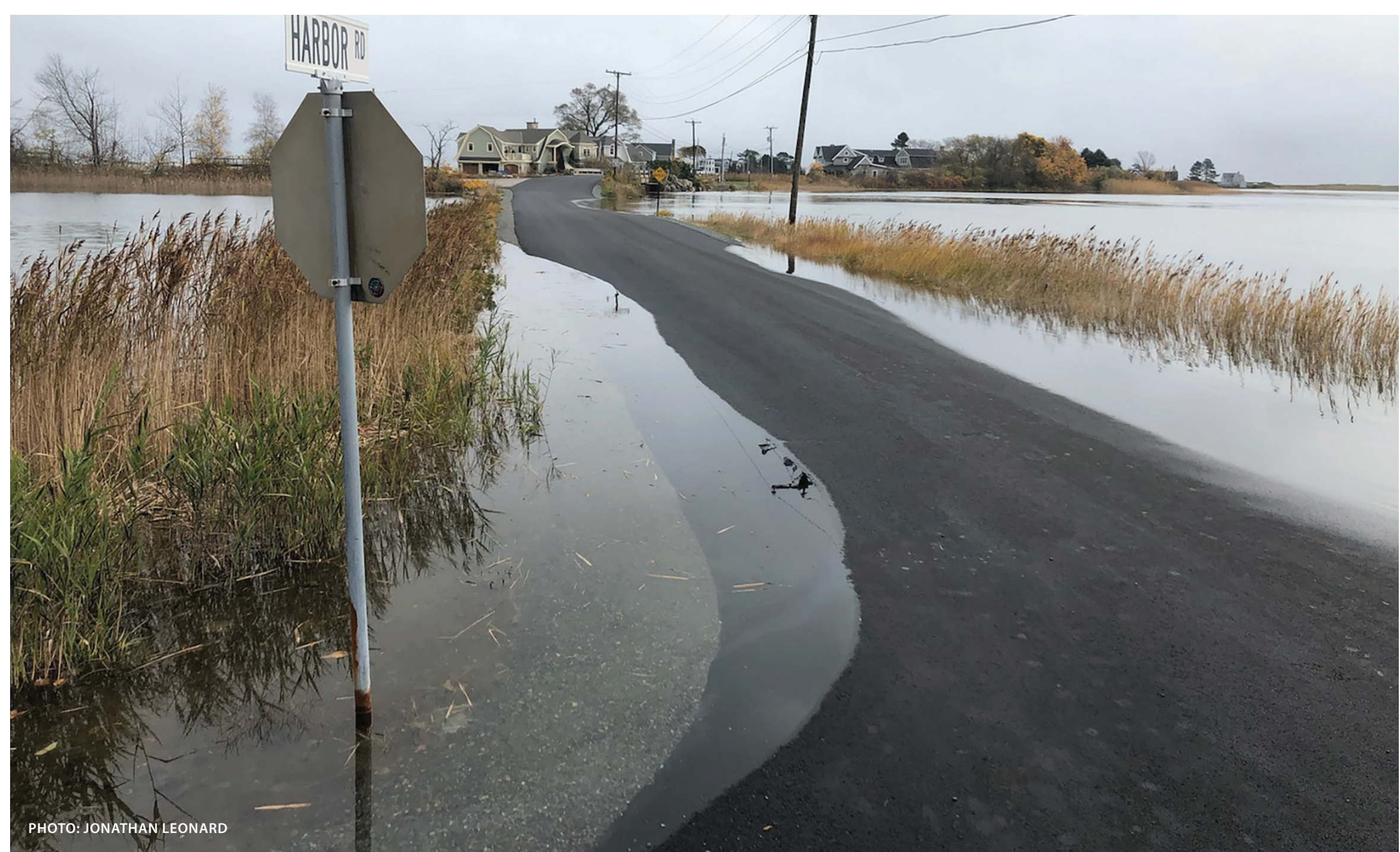

11 RSA 674:3. New Hampshire General Court.

http://www.gencourt.state.nh.us/rsa/html/LXIV/674/674-3.htm 
When preparing for future coastal flood risks, not all projects require the same standard of preparedness or adaptation. Determining tolerance for flood risk is an important step that will help decision makers select the most appropriate coastal flood risk projections as well as the most appropriate planning and design considerations for a project. For the purposes of the Guidance, tolerance for flood risk refers to the willingness of decision makers to accept a higher or lower probability of flood impacts, based on relevant project characteristics such as project value or replacement cost, capacity to adapt, importance for public function or safety, and sensitivity to inundation. ${ }^{12}$ Tolerance for flood risk is a subjective determination made by the decision makers and may change if the project is redefined (Step 1), as the project decision-making process progresses, and as new stakeholders are engaged.

Low tolerance for flood risk: Projects with Low tolerance for flood risk include those that have high value or high replacement costs, lack capacity to adapt or be adapted, are critical to public function or safety, and/or are highly sensitive to inundation. Facilities and assets with Low or Very Low tolerance for flood risk may include (but are not limited to) hospitals, water treatment facilities, power stations, emergency and response shelters, as well as irreplaceable or unique historic and cultural sites and essential ecosystems. Projects with Low tolerance for flood risk should plan for protective coastal flood risk projections that are less likely, but would cause devastating consequences if they were to occur. Management options should be protective for projects with Low tolerance for flood risk. ${ }^{13}$

High tolerance for flood risk: Projects with High tolerance for flood risk include those that have low value or low replacement costs, have capacity to adapt or be adapted, do not provide public function or safety, and/or are not sensitive to inundation. Facilities and assets with High tolerance for flood risk may include (but are not limited to) walking trails, sheds, and small docks. Projects with higher tolerance for flood risk have the option to plan for less protective coastal flood risk projections that are more likely to occur, but will cause less damage. In some cases, projects with High tolerance for flood risk may warrant a less protective coastal flood risk mitigation approach, recognizing that the likelihood of devastating damage to or loss of the project is lower.

\section{STEP 2.1 IDENTIFY PROJECT CHARACTERISTICS THAT INFLUENCE TOLERANCE FOR FLOOD RISK.}

Various project characteristics and the relative importance of those characteristics will inform the tolerance for flood risk category or categories selected for the project. Identify and rank project value or replacement cost, capacity to adapt, importance for public function or safety, sensitivity to inundation, and other relevant project characteristics.

\section{STEP 2.2 DETERMINE TOLERANCE FOR FLOOD RISK APPLICABLE TO THE PROJECT.}

Determining the tolerance for flood risk applicable to a project is a subjective exercise that should be undertaken by project decision makers. The Step 2 Table presents a framework for determining tolerance for flood risk for all project types based on project characteristics defined in Step 2.1. For consistency, the four categories of tolerance (High, Medium, Low, and Very Low) correspond in part with the Flood Design Class framework (Classes 1-4) presented in the American Society of Civil Engineers Flood Resistant Design and Construction standard (ASCE 24-14, 2015) ${ }^{14,15}$ referenced in International Codes, including the State of New Hampshire Building Code, effective September 15, 2019. ${ }^{16}$

12 | STEP 2 | NH COASTAL FLOOD RISK SUMMARY PART II: GUIDANCE 
Depending on a project's goal, scope, and scale, multiple categories of tolerance for flood risk may apply. If applicable, assign tolerances for flood risk to each of the sub-areas or types of inventoried structures, facilities, and resources identified in Step 1.2. Consider the tolerance for flood risk of important access and services identified in Step 1.2 and possible implications for the project. Keep in mind that the risk tolerance of surrounding access and services may be different than the tolerance for risk applicable to the project itself, which may result in the use of different coastal flood risk projections. Consider how the project goal and use of the project area may change over the course of the project timeframe and resulting changes in tolerance for flood risk.

\section{STEP 2.2: PROJECT-SPECIFIC CONSIDERATIONS / EXAMPLES}

There are multiple ways to determine the tolerance for flood risk for planning, regulatory, and site-specific projects. Approaches will vary based on project goals and decision maker preferences. The following considerations and hypothetical examples are intended to provide additional context and ideas for each project type, but may not apply to all projects.

For planning projects, decision makers might assign a tolerance for flood risk to the planning project area, or (1) different tolerances for flood risk to the sub-areas or to specific structures, facilities, and resources identified in Step 1.2. For example, when updating a local master plan, decision makers might assign a tolerance for flood risk of Very Low to the municipality overall, or different tolerances for flood risk ranging from High to Very Low to each of the municipal zoning districts. In some cases, decision makers may assign site-specific tolerances for flood risk to structures or sites of special importance to the municipality (e.g., wastewater treatment facility, evacuation road, public park, etc.). Consideration might also be given to the tolerance for flood risk of the transportation routes, utilities, and water sources, etc. in surrounding areas identified in Step 1.2.

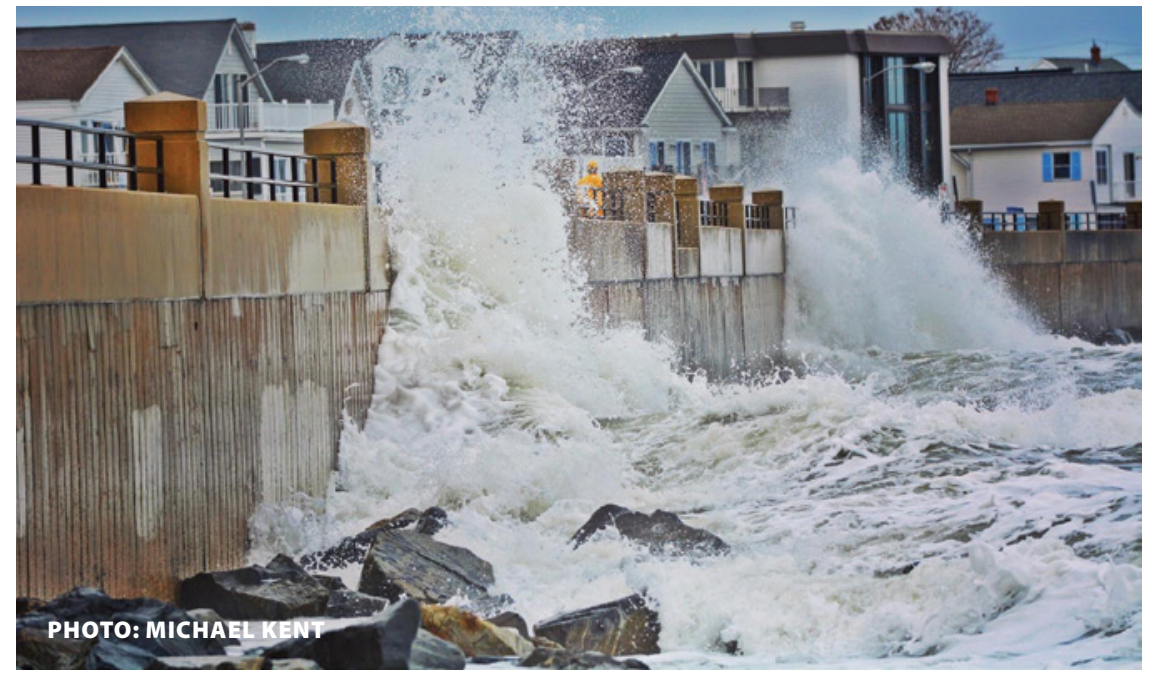

8

For regulatory projects, decision makers might pre-assign a tolerance for flood risk to the overall regulatory area, or different tolerances for flood risk to the sub-areas or regulated structures identified in Step 1.2. For example, when updating a local floodplain ordinance, decision makers may pre-assign a Medium tolerance for flood risk to all residential and commercial structures and a Low or Very Low tolerance for flood risk to critical facilities, based on the Step 2 Table. Alternatively, decision makers might require permit applicants to determine and justify their own tolerance for flood risk using the Step 2 Table or other relevant guidance. For example, the updated floodplain ordinance may require permit applicants subject to the floodplain regulations to assign a tolerance for flood risk to their own site-specific project based on the Step 2 Table.

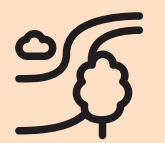

For site-specific projects, decision makers may assign a tolerance for flood risk to the overall project site, or different tolerances for flood risk to the different elements of the site design identified in Step 1.2. For example, when constructing a new hospital, decision makers might assign a Very Low tolerance for flood risk for the overall project based on the Step 2 Table. Assuming some of the main access routes to the hospital have Low and Medium tolerances for flood risk, decision makers may make note of possible issues accessing the hospital from those routes in a flood event. 
STEP 2 TABLE. FRAMEWORK FOR DETERMINING PROJECT TOLERANCE FOR FLOOD RISK.

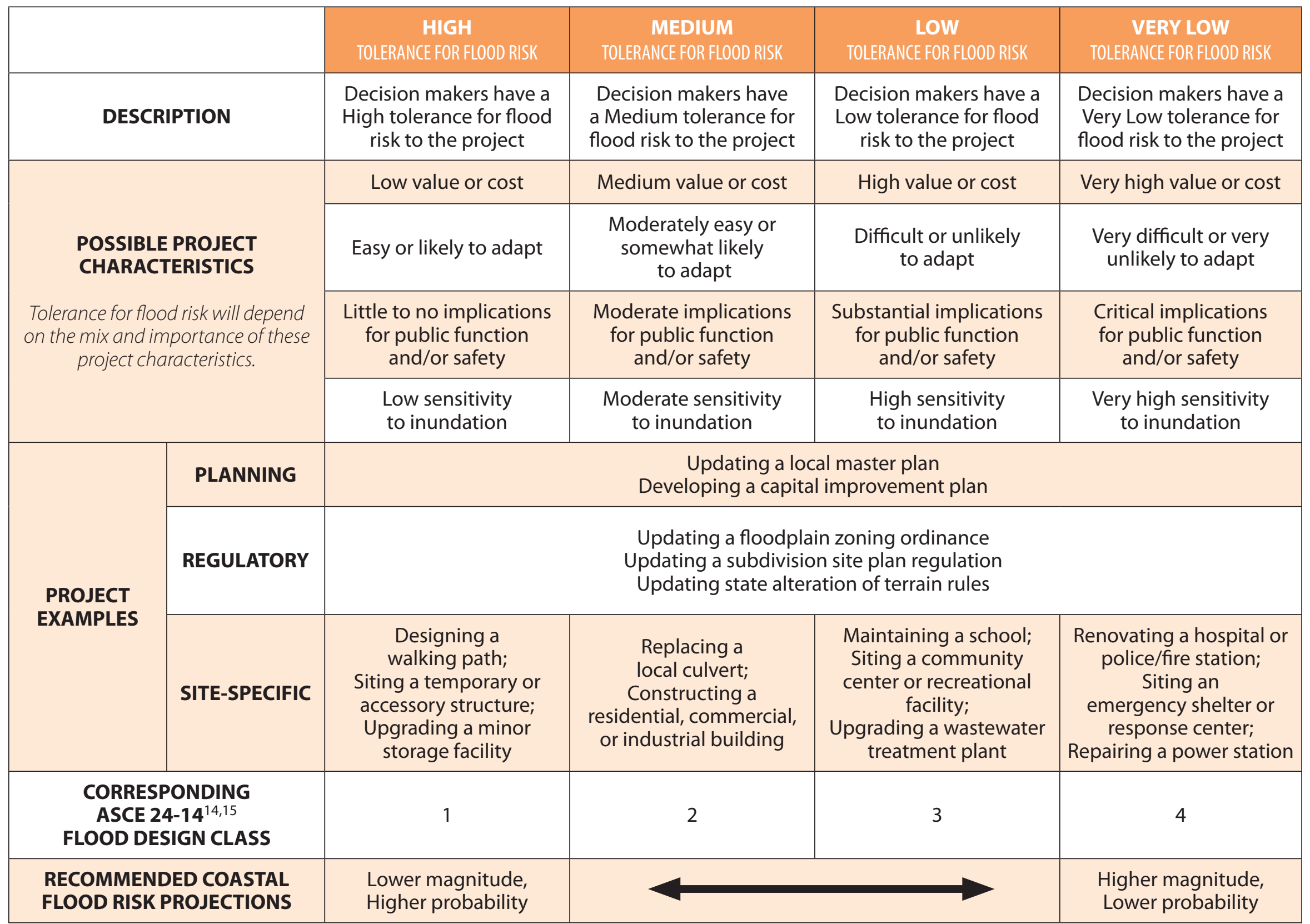




\section{RESOURCES TO REFERENCE IN STEP 2}

${ }^{12}$ State of California Sea-Level Rise Guidance - 2018 Update. (2018). Published by the Ocean Protection Council (OPC). http://www. opc.ca.gov/webmaster/ftp/pdf/agenda_items/20180314/ Item3_Exhibit-A_OPC_SLR_Guidance-rd3.pdf

13 Preparing New Hampshire for Projected Storm Surge, Sea-Level Rise, and Extreme Precipitation. (2016). Published by the New Hampshire Coastal Risk and Hazards Commission. https://www. nhcrhc.org/wp-content/uploads/2016-CRHC-final-report.pdf

${ }^{14}$ Flood Resistant Design and Construction 24-14. (2015). Published by the American Society of Civil Engineers. (ASCE).

https://ascelibrary.org/doi/book/10.1061/asce24

15 Highlights of ASCE 24-14 Flood Resistant Design and Construction. (2015). Published by the Federal Emergency Management Agency (FEMA). https://www.fema.gov/medialibrary/assets/documents/14983

${ }^{16}$ New Hampshire State Building Code. (2019). Released by the State Building Code Review Board. https://www.nh.gov/safety/ boardsandcommissions/bldgcode/nhstatebldgcode.html

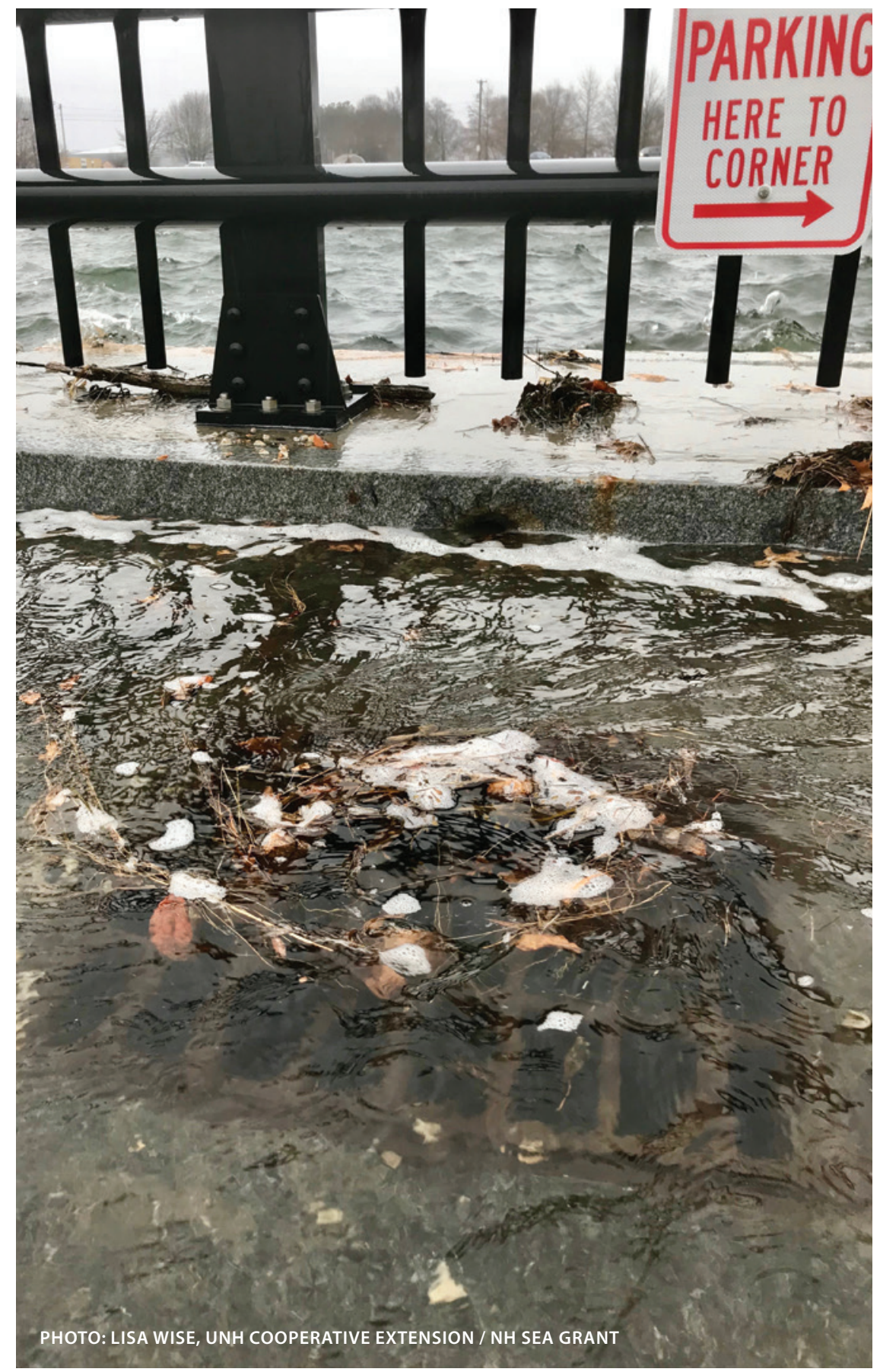

NH COASTAL FLOOD RISK SUMMARY PART II: GUIDANCE I STEP 2 | 15 


\section{STEP 3. SELECT AND ASSESS RELATIVE SEA-LEVEL RISE (RSLR)}

Before determining the appropriate RSLR for the project, decision makers must identify their tolerance for flood risk in Step 2. Return to Step 2 if not yet completed. If needed, revisit Step 1 to redefine the project.

\section{STEP 3 SCIENCE AT A GLANCE: RSLR PROJECTIONS FOR NEW HAMPSHIRE}

Relative sea-level in coastal New Hampshire is rising and is projected to rise for centuries into the future. High tide flooding and flood/ ebb tidal currents are expected to increase with RSLR. The RSLR projections for coastal New Hampshire presented in Part I: Science ${ }^{17}$ were developed based on four different global greenhouse gas concentration scenarios, called Representative Concentration Pathways (RCPs). The RCPs represent a broad range of climate outcomes, consistent with a range of different socioeconomic and policy futures, including an ambitious mitigation scenario (RCP 2.6), two intermediate stabilization scenarios (RCP 4.5 and RCP 6.0), and a growing greenhouse gas concentration scenario (RCP 8.5). For more information about the RCPs, see Section 4.5 in Part I: Science. ${ }^{17}$ Note: There is little difference between RSLR projections from 2000 to 2050 for RCP 2.6, RCP 4.5, RCP 6.0, and RCP 8.5 (see Figure 4.6 in Part I: Science ${ }^{17}$ ), therefore selection of an RCP is most relevant for projects with useful life after 2050 . Although the Guidance recommends use of RCP 4.5 RSLR estimates, it is important to note that this is strictly a recommendation, and project proponents may be justified in using RSLR estimates for alternative RCPS.

\section{Justification for Recommending Use of the RSLR Estimates for RCP 4.5}

Part I: Science 17 recommends use of RSLR estimates for RCP 4.5 for the following reasons:

- RCP 4.5 is an intermediate stabilization pathway and represents a somewhat optimistic perspective whereby global greenhouse gas emissions peak at 2040 and decline to 2080 before stabilizing throughout the remainder of the century.

- RSLR estimates for RCP 6.0 are only provided to 2100 as only a few of the global climate model runs using RCP 6.0 extend beyond 2100. Given the limited projections available for RCP 6.0, it is not a preferred scenario at this time.

- RCP 2.6 represents a very optimistic scenario that requires immediate reduction in global greenhouse gas emissions. RCP 8.5 represents a high emissions scenario and there is ongoing scientific debate about whether it is a possible future given some assumptions regarding reservoirs of accessible fossil fuels (see Section 4.5 in Part I: Science ${ }^{17}$ ).

16 | STEP 3 | NH COASTAL FLOOD RISK SUMMARY PART II: GUIDANCE 
STEP 3 SCIENCE AT A GLANCE: RSLR PROJECTIONS FOR NEW HAMPSHIRE, CONT.

\section{Recommended RSLR Estimates for Coastal New Hampshire}

Under the stabilized greenhouse gas concentration scenario (RCP 4.5), if all model assumptions hold true, and using 2000 sea levels as the baseline:

- Coastal New Hampshire is likely (67\% probability) to experience RSLR of 0.5 to 1.3 feet between 2000 and 2050 . There is a 1-in-20 chance that RSLR will exceed 1.6 feet, a 1-in-100 chance that RSLR will exceed 2.0 feet, a 1-in-200 chance that RSLR will exceed 2.3 feet, and a 1-in-1000 chance that RSLR will exceed 2.9 feet by 2050.

- Coastal New Hampshire is likely (67\% probability) to experience RSLR of 1.0 to 2.9 feet between 2000 and 2100 . There is a 1-in-20 chance that RSLR will exceed 3.8 feet, a 1-in-100 chance that RSLR will exceed 5.3 feet, a 1-in-200 chance that RSLR will exceed 6.2 feet, and a 1-in-1000 chance that RSLR will exceed 8.7 feet by 2100.

- Coastal New Hampshire is likely (67\% probability) to experience RSLR of 1.2 to 4.6 feet between 2000 and 2150 . There is a 1-in-20 chance that RSLR will exceed 6.4 feet, a 1-in-100 chance that RSLR will exceed 9.9 feet, a 1-in-200 chance that RSLR will exceed 11.7 feet, and a 1-in-1000 chance that RSLR will exceed 18.1 feet by 2150.

Figure 2. (see also Figure 4.5 in Part I: Science ${ }^{17}$ ). Observed and relative sea-level rise for the Seavey Island, ME, tide gauge based on Kopp et al. $2014^{18}$ (K14) and the stabilized greenhouse gas concentration scenario (RCP 4.5).

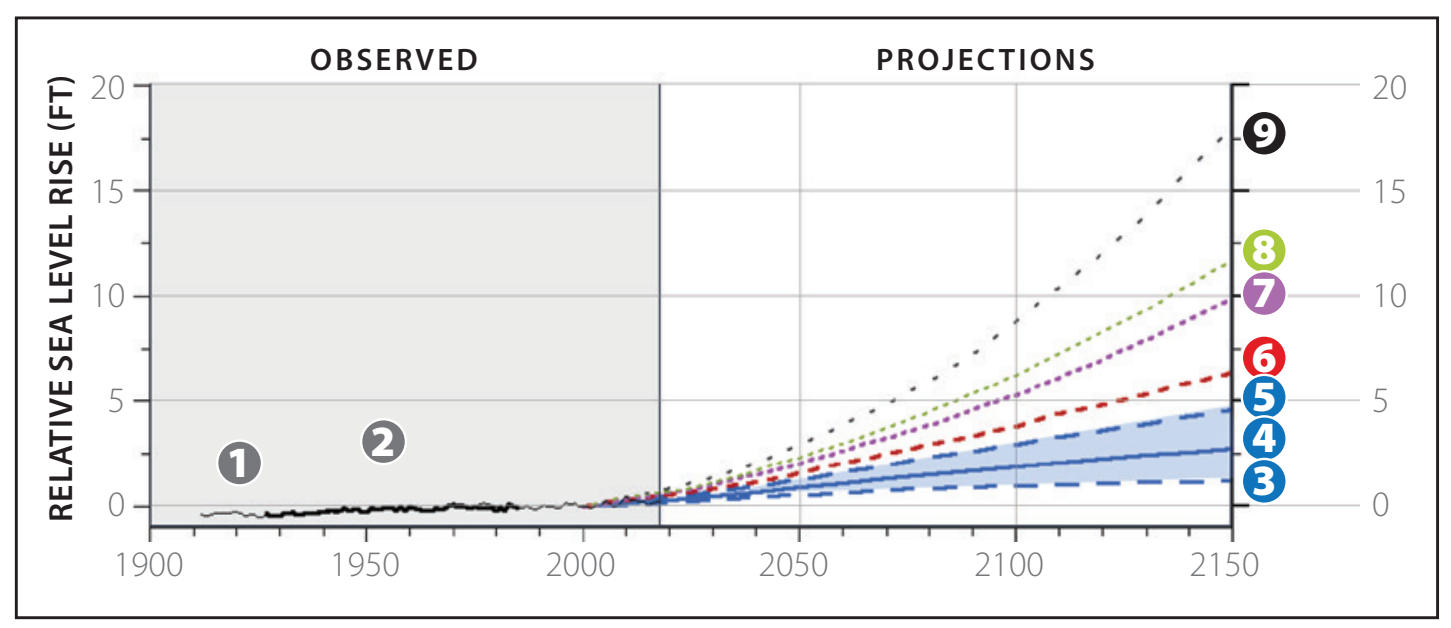

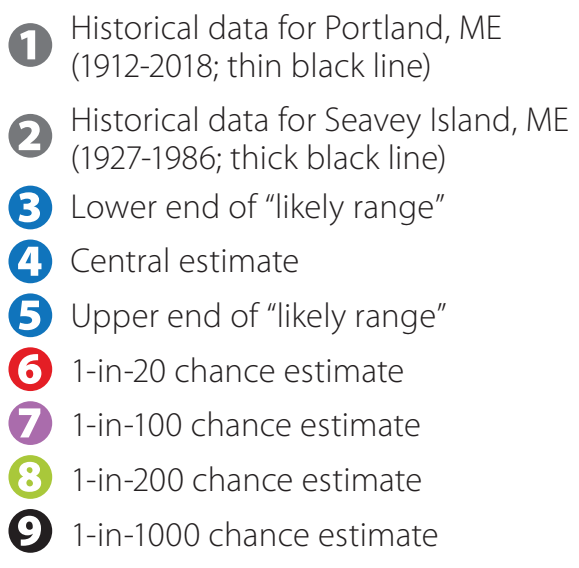

For decision makers who would prefer to plan for the more extreme greenhouse gas concentration scenario, decadal RSLR estimates for RCP 8.5 are provided in Step 3 Table B. For more information on RSLR in coastal New Hampshire, see Section 4 in Part I: Science. ${ }^{17}$ 
STEP 3 TABLE A. RECOMMENDED DECADAL RSLR ESTIMATES (IN FEET ABOVE 2000 LEVELS) BASED ON RCP 4.5, PROJECT TIMEFRAME, AND TOLERANCE FOR FLOOD RISK.

\begin{tabular}{|c|c|c|c|c|}
\hline \multirow[b]{2}{*}{ TIMEFRAME } & $\begin{array}{c}\text { HIGH } \\
\text { TOLERANCE FOR FLOOD RISK }\end{array}$ & $\begin{array}{c}\text { MEDIUM } \\
\text { TOLERANCE FOR FLOOD RISK }\end{array}$ & $\begin{array}{l}\text { LOW } \\
\text { TOLERANCE FOR FLOOD RISK }\end{array}$ & $\begin{array}{l}\text { VERY LOW } \\
\text { TOLERANCE FOR FLOOD RISK }\end{array}$ \\
\hline & \multicolumn{4}{|c|}{$\begin{array}{l}\text { Plan for the following RSLR estimate }(\mathrm{ft})^{*} \\
\text { compared to sea level in the year } 2000\end{array}$} \\
\hline 2030 & 0.7 & 0.9 & 1.0 & 1.1 \\
\hline 2050 & 1.3 & 1.6 & 2.0 & 2.3 \\
\hline 2060 & 1.6 & 2.1 & 2.6 & 3.0 \\
\hline 2070 & 2.0 & 2.5 & 3.3 & 3.7 \\
\hline 2080 & 2.3 & 3.0 & 3.9 & 4.5 \\
\hline 2110 & 3.3 & 4.4 & 6.1 & 7.3 \\
\hline 2120 & 3.6 & 4.9 & 7.0 & 8.3 \\
\hline 2130 & 3.9 & 5.4 & 7.9 & 9.3 \\
\hline 2140 & 4.3 & 5.9 & 8.9 & 10.5 \\
\hline 2150 & 4.6 & 6.4 & 9.9 & 11.7 \\
\hline
\end{tabular}

*The colors (blue, red, purple, green) in Step 3 Table A correspond with the colors of the graph depicted in Figure 2 (see also Figure 4.5 in Part l: Science ${ }^{17}$ ). The RSLR estimates for High tolerance for flood risk projects correspond with K14, upper end of "likely" estimates for RCP4.5 (83\% chance RSLR will not exceed this value). The RSLR estimates for Medium tolerance for flood risk projects correspond with K14, 1-in-20 chance estimates for RCP 4.5 . The RSLR estimates for Low tolerance for flood risk projects correspond with K14, 1-in-100 chance estimates for RCP 4.5. The RSLR estimates for Very Low tolerance for flood risk projects correspond with K14, 1-in-200 chance estimates for RCP4.5. For K14, 1-in-1000 chance estimates, see Table 4.2 in Part I: Science. ${ }^{17}$ Note that while the Bayesian probabilities associated with RSLR projections are useful, they have some limitations as described in Box 4.3 in Part l: Science. ${ }^{17}$

18 | STEP 3 | NH COASTAL FLOOD RISK SUMMARY PART II: GUIDANCE 


\section{MAPPING SEA-LEVEL RISE}

There are many publicly available datasets and visualization tools that can help visualize possible sea-level rise and other coastal flood impacts. The New Hampshire Sea-Level Rise, Storm Surge, and Groundwater Rise Mapper (Sea-Level Rise Mapper) is intended to provide easy access to future coastal inundation scenarios. The Mapper is a screening tool for planning purposes, and sites of interest should be further evaluated with a site-based survey. Data on the Mapper are provided by New Hampshire GRANIT.

ACCESS THE MAPPER: www.tinyurl.com/slrmapper

\section{STEP 3.1 | SELECT THE RSLR ESTIMATE(S) FOR THE PROJECT.}

Use Step 3 Table A to help select the appropriate RCP 4.5 (stabilized greenhouse gas concentration scenario) RSLR estimate(s) for the project ("Project RSLR") based on the project timeframe identified in Step 1.3 and on the tolerance for flood risk identified in Step 2.2. If the relevant timeframe for the project extends beyond 2150, use the projections for 2150 with recognition that RSLR is expected to continue rising beyond 2150 and implementation of additional adaptation strategies will likely be required. To consider more extreme RSLR estimates under RCP 8.5 (high emissions scenario), use Step 3 Table B provided in the "Resources to Reference" at the end of Step 3. Note that Step 3 Table A presents intermediate RSLR estimates for RCP 4.5 as recommended for use in Part I: Science, ${ }^{17}$ whereas Step 3 Table B presents more extreme RSLR estimates for RCP 8.5.

If the project is broad in scope and scale with multiple timeframes and/or multiple categories of tolerance for flood risk that apply to different aspects of the project, several approaches could be taken to select the Project RSLR. Decision makers may select a range of RSLR estimates that corresponds to the different timeframes and/ or categories of tolerance for flood risk. Alternatively, one protective RSLR estimate may be selected that encompasses the different timeframes and/or categories of tolerance for flood risk associated with the project.

\section{STEP 3.1: PROJECT-SPECIFIC CONSIDERATIONS / EXAMPLES}

There are multiple ways to select the RSLR estimates for planning, regulatory, and site-specific projects. Approaches will vary based on project goals and decision maker preferences. The following considerations and hypothetical examples are intended to provide additional context and ideas for each project type, but may not apply to all projects.

\$- For a planning project to update a local master plan with a hypothetical 30-year planning horizon (2050) and (6) tolerance for flood risk assigned to the municipal zoning districts in Step 2 ranging from High to Very Low, decision makers may plan for RSLR estimates ranging from 1.3 to 2.3 feet, based on Step 3 Table A. Alternatively, decision makers might select the upper end of the range of RSLR (2.3 feet) to simplify planning using a lower probability, more protective estimate.

For a regulatory project to update a local floodplain D. ordinance with a hypothetical incremental action point of 230 years (2050) and tolerance for flood risk assigned to the regulated structures in Step 2 ranging from Medium to Very Low, decision makers may regulate for RSLR estimates ranging from 1.6 to 2.3 feet, based on Step 3 Table A. To simplify regulatory decisions using a more protective RSLR, decision makers might select the upper end of the RSLR range (2.3 feet). Alternatively, decision makers might require permit applicants to determine and justify their own tolerance for flood risk using the Step 2 Table or other relevant guidance and select RSLR accordingly (e.g., 1.6 feet for a residential building, 2 feet for a school, and 2.3 feet for a hospital).

- For a site-specific project to build a new hospital with a 3 hypothetical useful life of 100 years (2120), and a Very Low tolerance for flood risk, decision makers may design for 8.3 feet of RSLR, based on Step 3 Table A. If incremental action points coincide with regular maintenance or upgrades of structural or service (e.g., electrical, plumbing, HVAC) components (e.g., every 15-30 years), decision makers might also determine RSLR estimates for those timeframes. For example, if decision makers anticipate that the hospital building will receive a major structural upgrade in 2070, they may choose to design the building for 3.7 feet of RSLR by 2070 and plan to reevaluate and adapt the building as part of the structural upgrade (i.e., incremental action point). 
For planning, regulatory, and site-specific projects, visualize RSLRadjusted water levels in the project area using available tools, including the New Hampshire Sea-level Rise, Storm Surge, and Groundwater Rise Mapper (Sea-Level Rise Mapper) ${ }^{19}$ and, for sitespecific projects, surveyed site plans. For projects with a range of RLSR estimates identified in Step 3.1, evaluate impacts across the range of scenarios selected.

Consider how depth and extent of the water vary based on project area and surrounding topography. When evaluating RSLR impacts to planning, regulatory, or site-specific projects, note that risks increase in multiple ways as water depths (or elevations) increase. Be aware that surface water levels, groundwater levels (evaluated in Step 5), waves, and current velocities will increase and sediment erosion and deposition will change in conjunction with RSLR-adjusted water levels. For example, wind over deeper water results in bigger waves, exacerbating flood risk. Consider how surrounding infrastructure that restricts tidal flow, such as undersized culverts and bridges, may affect flood risk in the project area now and in the future. Consider how future land use change may affect RSLR impacts to the project area. Assess RSLR impacts to the project, including but not limited to associated assets, natural resources, cultural and historic resources, public access, and socially vulnerable populations.

Note about vertical datums and reference lines: Remember to use a consistent vertical datum to compare baseline and other tidebased water levels relevant to the project. Datum comparison information for the Fort Point $\mathrm{NH}$ tide gauge is provided by NOAA Tides \& Currents. ${ }^{20} \mathrm{As}$ of publication of this document, the sea-level rise, storm surge, and groundwater rise map layers available on the Sea-Level Rise Mapper ${ }^{19}$ are referenced to Mean Higher High Water (MHHW). Elevations (NAVD88) used to generate MHHW in these data layers are as follows: 3.6 feet NAVD88 in the Great Bay area, 4.2 feet NAVD88 in the Piscataqua River area, and 4.4 feet NAVD88 in embayments throughout the Hampton-Seabrook Estuary and the open Atlantic coast. ${ }^{21}$

\section{SITE-SPECIFIC PROJECT CASE STUDY: LUBBERLAND CREEK CULVERT REPLACEMENT DESIGN 22,23,24}

The goal of this site-specific project was to replace an undersized culvert to reduce flood risk to a road and improve habitat.

The Town of Newmarket, NH, replaced an undersized and perched culvert where Bay Road crosses Lubberland Creek. The undersized culvert was a corrugated metal pipe arch, 36 inches wide and 30 inches tall, that presented public safety, emergency access, and evacuation concerns for the town. The road crossing, which was identified as a flood hazard in the Town's Federal Emergency Management Agency (FEMA) Hazard Mitigation Plan, flooded in a 5 -year precipitation event; Bay Road flooded at least three times in 2018 alone. The culvert site is tidally influenced on the downstream side, but the undersized and perched configuration of the culvert restricted natural hydrology and was a barrier to aquatic organisms like the American eel. Downstream of the culvert site is a parcel of conservation land that includes a 55-acre salt marsh, and when natural hydrology is restored, the salt marsh is expected to migrate upstream over time with sea-level rise. In partnership with The Nature Conservancy and the NHDES Coastal Program, the town redesigned the culvert to reduce flood risk, improve aquatic organism passage, and allow for future migration of salt marsh. The replacement culvert design life was determined to be 75 years. Using best available science at the time, the project team selected intermediate sea-level rise values of 1.3 feet for 2065 and 3.7 feet for 2115. Current (2015) tide elevations at the culvert site were measured using an electronic data logger adjusted to represent King Tide elevations based on the 


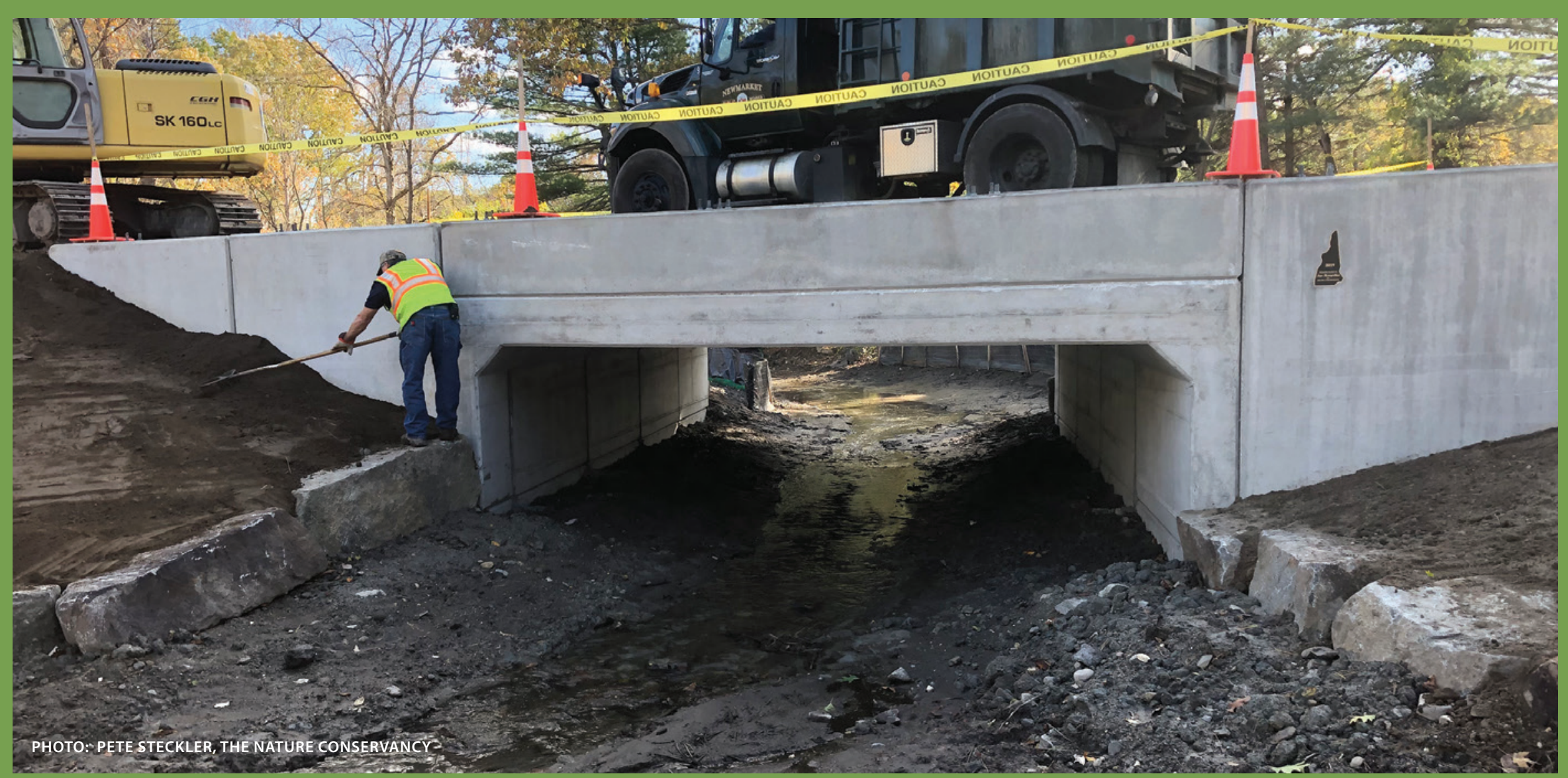

Bay Road at Lubberland Creek in Newmarket, NH; culvert replacement during construction, October 2019.

closest tide gauge values farther downstream at the Fort Point, NH, tide gauge station. The two sea-level rise scenarios were added to the adjusted 2015 tide level to create three tide scenarios for alternatives analysis_-2015, 2065, and 2115. Based on hydrologic and hydraulic model results prepared by a consultant, the project team evaluated alternative culvert design options under the three tide scenarios as well as scenarios for extreme flow precipitation events. The consultant determined bankfull width to be 10 to 12 feet and recommended that the stream channel reconstructed through the culvert meet state and federal standards of 1.2 times bankfull width, resulting in a recommended culvert width of 12 to 16 feet. The final design selected was a 16 -ft wide and 8.5 -ft tall concrete box culvert that will pass the $1 \%$ annual chance (100-year) precipitation event in 2065 and will be inundated by a few inches of water in the same extreme precipitation event in 2115 . The project erred on the side of caution by planning for coinciding King Tide conditions with the $1 \%$ annual chance precipitation event, which has an even lower probability of occurrence. The project also elevated 390 linear feet of Bay Road to allow one foot of freeboard between surface water elevation and the road in a 2115 storm event. Culvert replacement took place in October 2019 and was funded by the Town of Newmarket, The Nature Conservancy, the NHDES Aquatic Resource Mitigation Grant Program, NHDES Coastal Resilience Grant funding, and the National Oceanic and Atmospheric Administration Office for Coastal Management. 


\section{RESOURCES TO REFERENCE IN STEP 3}

17 New Hampshire Coastal Flood Risk Summary Part I: Science. (2019). Prepared for the New Hampshire Coastal Flood Risk Science and Technical Advisory Panel by Wake, C. et al. Published by the University of New Hampshire, Durham, $\mathrm{NH}$. https://scholars.unh.edu/ersc/210

18 Probabilistic 21st and 22nd Century Sea-Level Projections at a Global Network of Tide Gauge Sites. (2014). Published by Kopp, R.E., Horton, R.M., Little, C.M., Mitrovica, J.X., Oppenheimer, M., Rasmussen, D.J., Strauss, B.H., \&Tebaldi, C. in Earth's Future, 2, 287-306. doi: https://doi.org/10.1002/2014EF000239

${ }^{19}$ The New Hampshire Sea-Level Rise, Storm Surge, and Groundwater Rise Mapper (Sea-Level Rise Mapper) (2020). Managed by the New Hampshire Department of Environmental Services. http://www.tinyurl.com/slrmapper

20 Datums for Station 8423898, Fort Point NH. National Oceanic and Atmospheric Administration Center for Operational Oceanographic Products and Services https://tidesandcurrents.noaa.gov/datums.html?id=8423898.
21 Sea-Level Rise Mapping - New Hampshire Open Coast, Piscataqua River, and Great Bay. (2013). Prepared by AECOM for the University of New Hampshire. Report available upon request from the NH Geographically Referenced Analysis and Information Transfer System at granit@unh.edu.

22 Contract Drawings for Lubberland Creek Restoration, Newmarket, $\mathrm{NH}$. (2019). By The Nature Conservancy \& Wright-Pierce. Available upon request to the NHDES Coastal Program at coastal@des.nh.gov.

${ }^{23}$ New Hampshire Department of Environmental Services Water Division Wetlands Bureau Wetlands Permit Application for the Lubberland Creek Restoration/Culvert Replacement Project, Newmarket, NH. (2016). By the Town of Newmarket Department of Public Works and Wright-Pierce. Available upon request to the NHDES Coastal Program at coastal@des.nh.gov.

${ }^{24}$ Lubberland Creek Restoration Bay Road Culvert Assessment, Newmarket, NH. (2015). Prepared for The Nature Conservancy by Wright-Pierce. Available upon request to the NHDES Coastal Program at coastal@des.nh.gov.

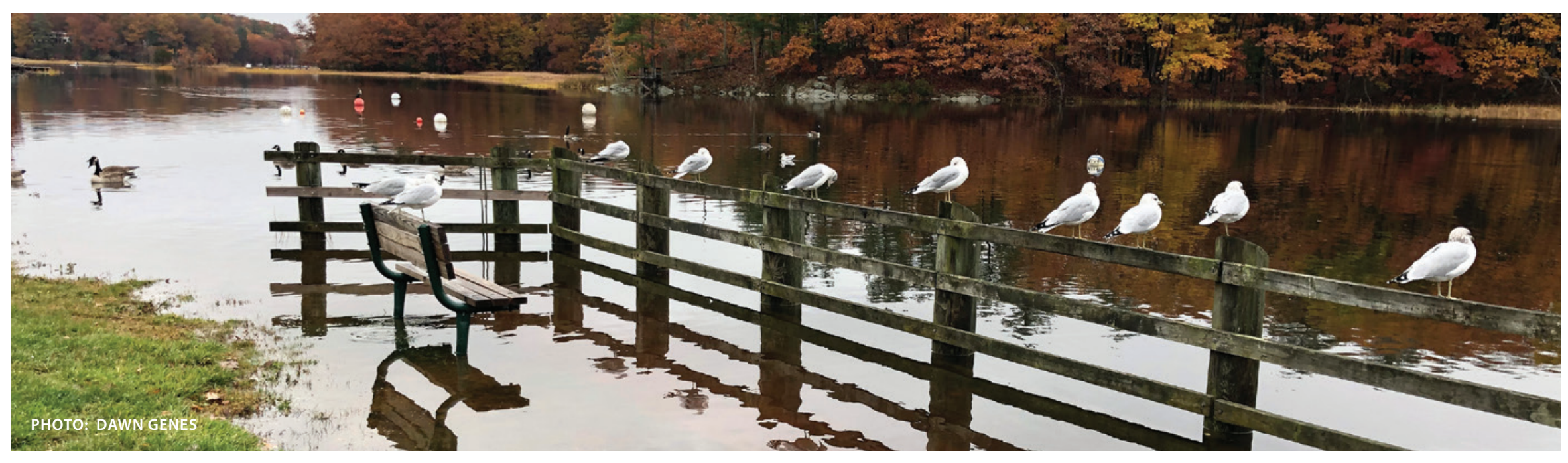

22 | STEP 3 | NH COASTAL FLOOD RISK SUMMARY PART II: GUIDANCE 
STEP 3 TABLE B. DECADAL RSLR ESTIMATES (IN FEET ABOVE 2000 LEVELS) BASED ON RCP 8.5, TIMEFRAME, AND TOLERANCE FOR FLOOD RISK.

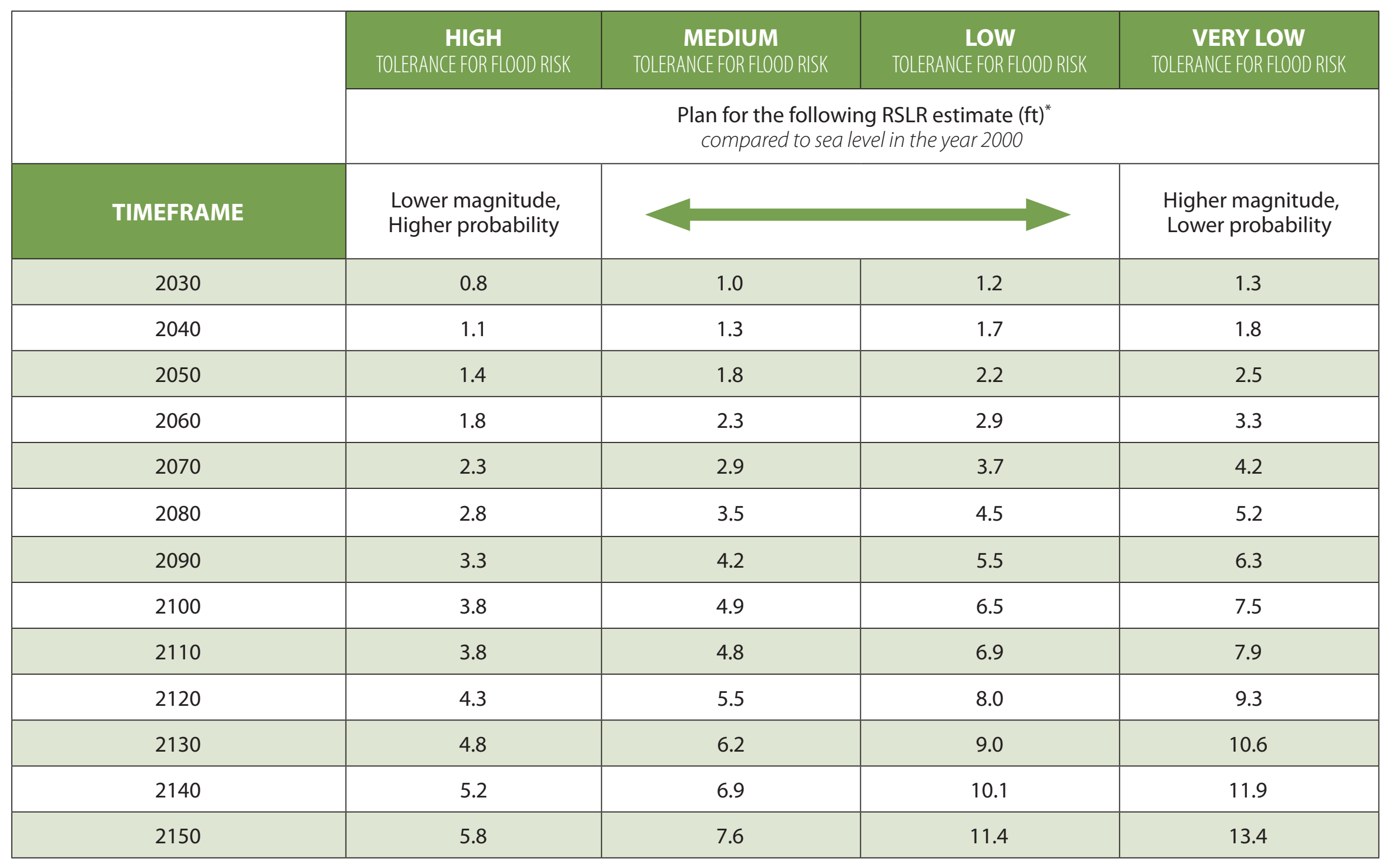

*Adapted from Appendix A in Part I: Science.17 RSLR estimates for High tolerance for flood risk projects correspond with K14 upper end of "likely" estimates for RCP 8.5. RSLR estimates for Medium tolerance for flood risk projects correspond with the K14 1-in-20 chance estimates for RCP 8.5. RSLR estimates for Low tolerance for flood risk projects correspond with the K14 1-in-100 chance estimates for RCP 8.5. RSLR estimates for Very Low tolerance for flood risk projects correspond with the K14 1-in-200 chance estimates for RCP 8.5. 


\section{STEP 4. IDENTIFY AND ASSESS RSLR-ADJUSTED COASTAL STORMS}

Before assessing coastal storm impacts to the project, decision makers must select a Project RSLR in Step 3. Return to Step 3 if not yet completed. If needed, revisit Step 1 to revise the project definition or Step 2 to revise tolerance for flood risk.

\section{STEP 4 SCIENCE AT A GLANCE: COASTAL STORM PROJECTIONS FOR NEW HAMPSHIRE}

- The number of intense hurricanes, extreme hurricane winds, and hurricane precipitation in the North Atlantic Basin are "more likely than not" to increase by the year $2080 .{ }^{25}$

- The change in the number and intensity of nor'easters in the North Atlantic Basin remains unknown. ${ }^{25}$

- Flood/ebb tidal current velocities will increase with storm surge and sea-level rise. ${ }^{26}$

For more information on coastal storms in New Hampshire, see Section 5 in Part I: Science. ${ }^{27}$

\section{FREEBOARD}

Freeboard is a factor of safety usually expressed in feet above a flood level for purposes of floodplain management.

\section{BASE FLOOD ELEVATION (BFE)}

The elevation to which floodwater is anticipated to rise during the base flood, equal to the $1 \%$ annual chance flood. Base Flood Elevations (BFEs) are shown on Flood Insurance Rate Maps (FIRMs) and on the flood profiles. .

\section{DESIGN FLOOD ELEVATION (DFE)}

The total flood elevation that a project is designed to protect for. DFE is typically at least BFE with freeboard, as required by building codes. RSLR-adjusted DFE is typically at least BFE with required freeboard and RSLR.

\section{STEP 4.1 IDENTIFY RSLR-ADJUSTED DESIGN FLOOD ELEVATION (DFE)。}

Use the Step 4 Table to help select the RSLR-adjusted DFE — the total flood elevation that a project is designed to protect against as sea levels rise-based on project tolerance for flood risk. To calculate RSLR-adjusted DFE, add Project RSLR selected in Step 3.1 to current flood protection standards established in the New Hampshire State Building Code and in local floodplain zoning regulations in order to account for larger future floods caused by storms occurring on top of higher sea levels. ${ }^{28,29,30,31}$ Decision makers may either add Project RSLR to current Base Flood Elevation (BFE) and regulatory freeboard (at minimum), or if greater and available, add Project RSLR to the 0.2\% annual chance flood elevation.

Sources of coastal floodplain management information include but are not limited to local effective Flood Insurance Rate Maps

24 | STEP 4 | NH COASTAL FLOOD RISK SUMMARY PART II: GUIDANCE 
(FIRMs) and associated Base Flood Elevations (BFE) for the 1\% annual chance flood event and, where available, the $0.2 \%$ annual chance flood event (find maps at the FEMA Flood Map Service Center ${ }^{32}$ ). Decision makers may reference the sea-level rise and storm surge maps on the Sea-Level Rise Mapper ${ }^{33}$ to help understand how RSLR may expand the extent and influence flood depths for the $1 \%$ annual chance floodplain. Decision makers should reference present-day coastal floodplain management and design standards for additional planning, regulatory, and site-specific project guidance, and factor RSLR into any guidance that recommends planning to a tidal reference line or considering hydrologic and hydraulic factors.

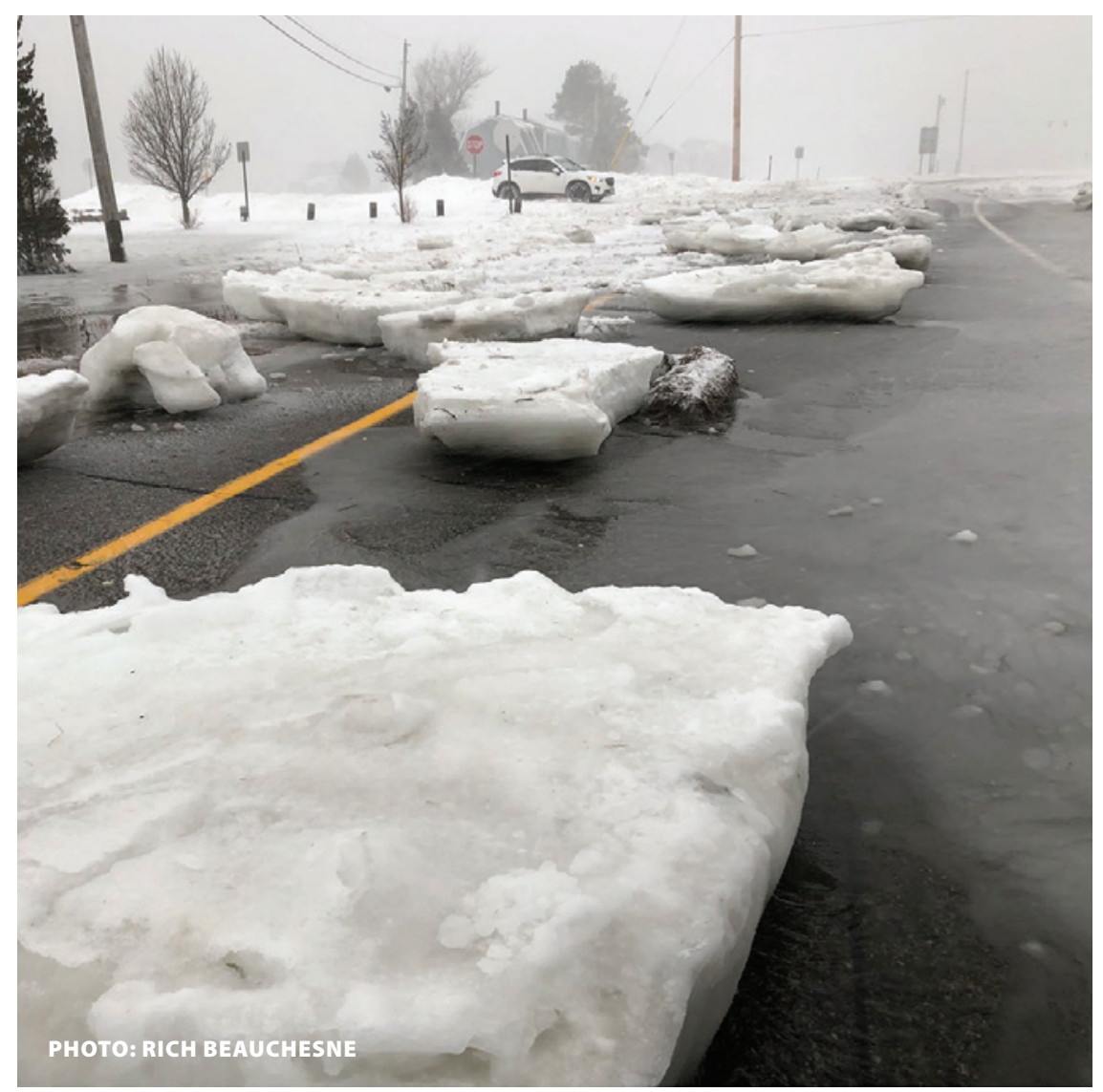

\section{STEP 4.1: PROJECT-SPECIFIC CONSIDERATIONS / EXAMPLES}

There are multiple ways to identify RSLR-adjusted DFE for planning, regulatory, and site-specific projects. Approaches will vary based on project goals and decision maker preferences. The following considerations and hypothetical examples are intended to provide additional context and ideas for each project type, but may not apply to all projects.

For a planning project to update a local master plan 20 and the upper end of RSLR selected in Step 3 (2.3 feet by 2050) and assuming the community has an AE Zone with BFE of 9 feet NGVD and VE Zone with BFE ranging from 11 to 20 feet NGVD, decision makers might plan for a RSLR-adjusted DFE of 13.3 feet NGVD in the AE Zone and a RSLR-adjusted DFE ranging from 15.3 to 24.3 feet NGVD in the VE Zone, based on the Step 4 Table.

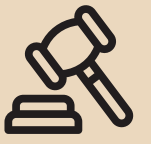

For a regulatory project to update a local floodplain ordinance using the range of RSLR estimates selected in Step 3 (1.6 to 2.3 feet by 2050) and assuming a BFE of 8 feet NAVD88 in AE Zones and a BFE of 18 feet NAVD88 in VE Zones, decision makers might require that regulated structures with Medium tolerance for flood risk be constructed to a DFE of 10.6 feet NAVD88 in AE Zones and 20.6 feet NAVD88 in VE Zones, based on the Step 4 Table. For regulated structures with Very Low tolerance for flood risk, the RSLR-adjusted DFE might be 12.3 feet NAVD88 in AE Zones and 22.3 feet NAVD88 in VE Zones.

- For a site-specific project to design a new hospital 3 with a 100-year useful life (2120) and a Very Low tolerance for flood risk (corresponding with 8.3 feet RSLR) at a site with BFE 8 feet NGVD29, decision makers would design for the higher of (1) a DFE of 18.3 feet NGVD29 or (2) the $0.2 \%$ chance elevation flood elevation added to 8.3 feet RLSR. The hospital might be designed for a lower DFE based on an incremental action point if decision makers plan for structural updates to accommodate higher RSLR in the future. 
STEP 4 TABLE. RSLR-ADJUSTED DESIGN FLOOD ELEVATIONS (DFE) BASED ON TOLERANCE FOR FLOOD RISK.

\begin{tabular}{|c|c|c|c|c|}
\hline & $\begin{array}{l}\text { HIGH } \\
\text { TOLERANCE FOR FLOOD RISK }\end{array}$ & $\begin{array}{c}\text { MEDIUM } \\
\text { TOLERANCE FOR FLOOD RISK }\end{array}$ & $\begin{array}{c}\text { LOW } \\
\text { TOLERANCE FOR FLOOD RISK }\end{array}$ & $\begin{array}{c}\text { VERY LOW } \\
\text { TOLERANCE FOR FLOOD RISK }\end{array}$ \\
\hline IF PROJECT AREA IS LOCATED IN: & \multicolumn{4}{|c|}{ RSLR-ADJUSTED DESIGN FLOOD ELEVATION (DFE) = } \\
\hline $\begin{array}{l}\text { A, AO, OR AE ZONE* } \\
\text { NOT IDENTIFIED AS } \\
\text { COASTAL A ZONE }^{* *}\end{array}$ & {$[B F E]+R S L R$} & $\begin{array}{c}{[B F E+(\text { required }} \\
\text { freeboard } \geq 1 \mathrm{ft})]+ \text { RSLR }\end{array}$ & $\begin{array}{c}{[B F E+(\text { required }} \\
\text { freeboard } \geq 1 \mathrm{ft})]+ \text { RSLR }\end{array}$ & $\begin{array}{c}\text { Whichever is greater: } \\
{[\mathrm{BFE}+(\text { required }} \\
\text { freeboard } \geq 2 \mathrm{ft})]+\mathrm{RSLR} \\
\text { OR } \\
0.2 \% \text { annual chance flood } \\
\text { elevation }+ \text { RSLR }\end{array}$ \\
\hline
\end{tabular}

Text depicted in [ ] represents Base Flood Elevation and freeboard requirements in the State of New Hampshire Building Code, ${ }^{29}$ at the time of Guidance publication. See additional guidance in ASCE 24-14 and add RSLR to any recommended present-day DFE based on historical and established freeboard standards.30,31

*A, AO, or AE Zone - An area inundated by $1 \%$ annual chance flooding according to FEMA FIRMs. A Zone areas do not have a BFE identified. AO Zone areas usually experience sheet flow on a slope and have average flood depth identified ranging from 1 to 3 feet. AE Zone areas have a BFE identified.

**Coastal A Zone - An area landward of a $V$ zone or landward of an open coast without a mapped $V$ Zone that is subject to flooding influenced by waves of heights between 1.5 and 3 feet according to FEMA FIRMs.

***VE Zone - An area along the coast inundated by $1 \%$ annual chance flooding with additional hazards associated with storm-induced waves, according to FEMA FIRMs.

\section{STEP 4.2 ASSESS RSLR-ADJUSTED COASTAL STORM IMPACTS TO THE PROJECT.}

For planning, regulatory, and site-specific projects, visualize RSLRadjusted coastal storm water levels in the project area using available tools, including the Sea-Level Rise Mapper ${ }^{33}$ and-for site-specific projects — surveyed site plans. For projects with a range of RLSR estimates identified in Step 3.1, evaluate impacts across the range of scenarios selected. See note about using consistent vertical datums in Step 3.2. Also note that some older FEMA Flood Insurance Rate Maps and associated BFEs are referenced to NGVD29 while others are referenced to NAVD88. Efforts are underway to update all Flood Insurance Rate Maps to reference NAVD88.

Consider how depth and extent of the water vary based on project area and surrounding topography. When evaluating impacts to the planning, regulatory, or site-specific project, note that risks increase in multiple ways as flood depths (or elevations) increase. Be aware that surface water levels, groundwater levels (evaluated in Step 5), waves, and current velocities will increase and sediment erosion and deposition will change in conjunction with RSLRadjusted storms. For example, wind over deeper water results in bigger waves, exacerbating flood risk. Consider how surrounding infrastructure that restricts tidal flow, such as undersized culverts and bridges, may affect flood risk in the project area now and in the future. Consider how future land use change may affect RSLRadjusted storm impacts in the project area. Evaluate RSLR-adjusted coastal storm impacts to the project, including but not limited to related assets, natural resources, cultural and historic resources, public access, and socially vulnerable populations.

26 | STEP 4 | NH COASTAL FLOOD RISK SUMMARY PART II: GUIDANCE 
The goal of this regulatory project was to amend the town's Flood Hazard Overlay District to improve flood safety by considering future relative sea-level rise.

In 2018, the Town of Durham, NH, worked with the Strafford Regional Planning Commission to amend the town's Flood Hazard Overlay District to: 1) require two feet of freeboard above the Base Flood Elevation (BFE); and 2) recommend (but not require) compliance with the standards of the overlay district for areas that are outside of the flood hazard area but within an advisory climate change risk area.

Freeboard Requirement - Prior to the 2018 amendments, the town's zoning ordinance ${ }^{34}$ required that new construction and substantial improvements within the $1 \%$ annual chance flood zone have the lowest floor of the building raised to the BFE. The 2018 amendments now require the lowest floor to be built two feet above BFE. The town justified this change based on the New Hampshire Coastal Risk and Hazards Commission final report ${ }^{35}$, which recommends that municipalities add an additional two feet to BFE for non-critical structures and facilities and an additional three feet to BFE for critical structures and facilities (see Recommendation BL2(c)).

Advisory Climate ChangeRiskAreas-The second amendment to the Town's Flood Hazard Overlay District recommends (but does not require) compliance with the overlay district standards in areas that are currently outside the flood hazard area, but that will be impacted by projected sea-level rise and storm surge.

To delineate the Advisory Climate Change Risk Areas, the town considered three sea-level rise scenarios: 1) low sea-level rise (1.7 feet by 2100$) ; 2)$ moderate sea-level rise (3.9 feet by 2100$)$; and 3 ) high sea-level rise ( 6.6 feet by 2100$)$. For all scenarios, the sea-level rise scenario was added to the $1 \%$ annual chance storm event based on the 2015 effective Digital Flood Insurance Rate Maps (DFIRM) for Strafford County. Ultimately, the town chose the moderate sea-level rise scenario (3.9 feet by 2100) to delineate the Advisory Climate Change Risk Areas, which affects a relatively small

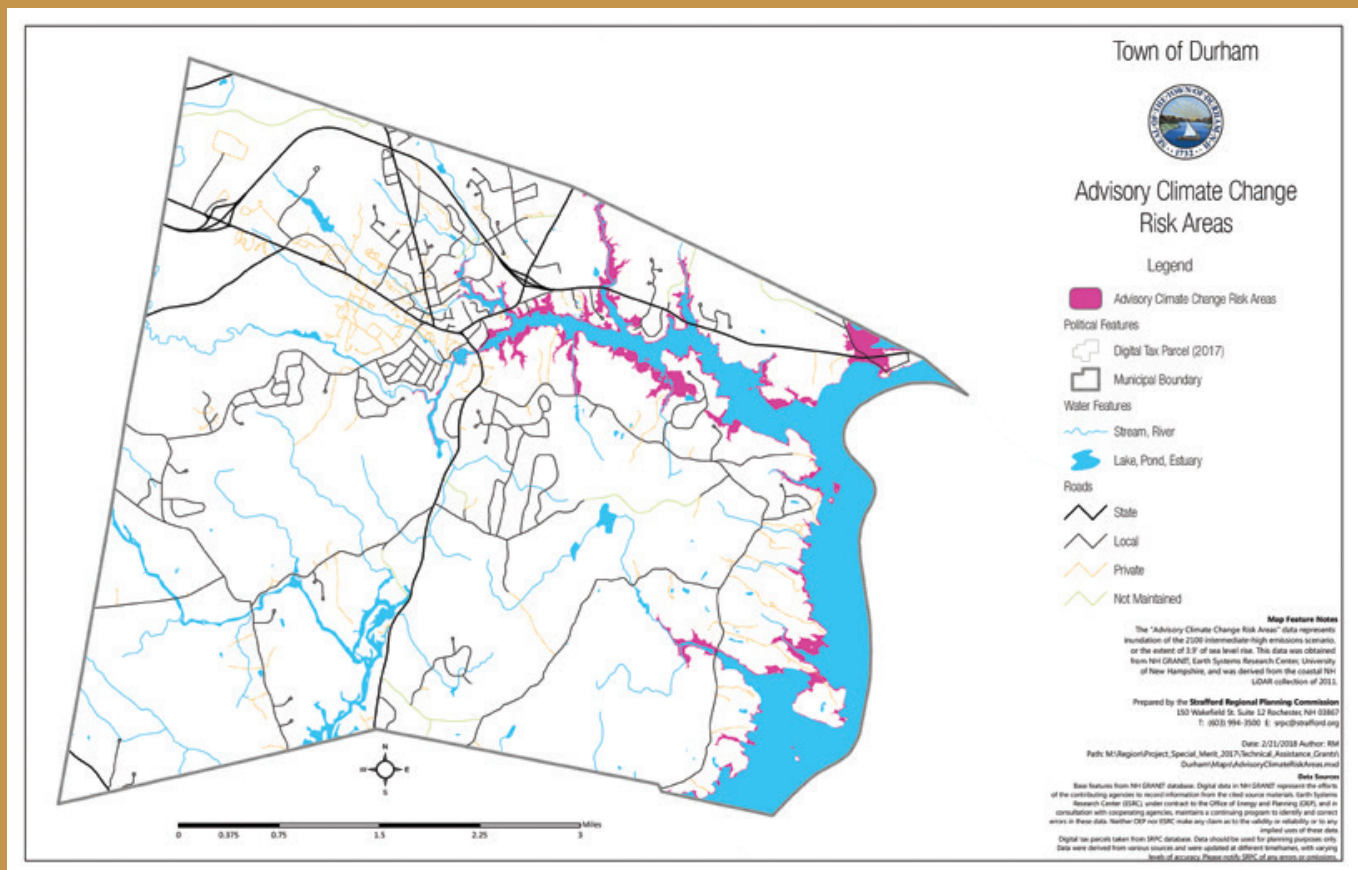

Figure 3. Advisory Climate Change Risk Areas approved by the Town of Durham, $\mathrm{NH}$, in 2018. Areas shaded in pink delineate areas vulnerable to 3.9 feet of sealevel rise plus a $1 \%$ annual chance flood event. New construction or substantial improvements located within the Advisory Climate Change Risk Area, but outside of the Special Flood Hazard Area, are encouraged (but not required) to adhere to the town's Flood Hazard Overlay District Standards. number of properties (Figure 3). The adoption of Advisory Climate Change Risk Areas provides the Town with an opportunity to educate landowners about potential future risks to their property and encourage new construction and substantial improvements in future vulnerable areas to adhere to more stringent building standards.

This project wasfunded, in part, by the NOAA Office for Coastal Management under the Coastal Zone Management Act in conjunction with the NHDES Coastal Program. 


\section{RESOURCES TO REFERENCE IN STEP 4}

${ }^{25}$ Mapping Sea-Level Change in Time, Space, and Probability. (2018). Published by Horton, B.P., Kopp, R.E., Garner, A.J., Hay, C.C., Khan, N.S., Roy, K., \& Shaw, T.A. in Annual Review of Environment and Resources, 43, 481-521. doi: https://doi.org/10.1146/annurevenviron-102017-025826

${ }^{26}$ Effects of Sea-Level Rise on Modeled Storm Surge and Current Speeds in New Hampshire Estuaries. (2019). Published by Lippmann, T.C., Simpson, A.E., Cook, S.E., \& Kirshen, P. in Journal of Waterway, Port, Coastal, and Ocean Engineering, sub judice.

${ }^{27}$ New Hampshire Coastal Flood Risk Summary Part I: Science. (2019). Prepared for the New Hampshire Coastal Flood Risk Science and Technical Advisory Panel by Wake, C. et al. Published by the University of New Hampshire, Durham, NH. https:// scholars.unh.edu/ersc/210

${ }^{28}$ Climate Resiliency Design Guidelines. (2019). Published by the New York City Mayor's Office of Recovery and Resiliency. https://www1.nyc.gov/assets/orr/pdf/NYC_Climate_ Resiliency_Design_Guidelines_v3-0.pdf

${ }^{29} \mathrm{NH}$ State Building Code. (2019). Released by the State Building Code Review Board. https://www.nh.gov/safety/ boardsandcommissions/bldgcode/nhstatebldgcode.html

${ }^{30}$ Flood Resistant Design and Construction 24-14. (2015). Published by ASCE. https://ascelibrary.org/doi/book/10.1061/asce24

${ }^{31}$ Highlights of ASCE 24-14 Flood Resistant Design and Construction. (2015). Published by FEMA. https://www.fema.gov/media-library/assets/documents/14983

${ }^{32}$ Flood Map Service Center. Maintained by FEMA. https://msc.fema.gov/portal/home

${ }^{33}$ The New Hampshire Sea-Level Rise, Storm Surge, and Groundwater Rise Mapper (Sea-Level Rise Mapper). (2020). Managed by the New Hampshire Department of Environmental Services. http://www.tinyurl.com/slrmapper
${ }^{34}$ Durham, New Hampshire, Zoning Ordinance art. XV, §175-77§175-83 (2018). https://www.ci.durham.nh.us/sites/default/ files/fileattachments/planning/page/21491/article_xv.pdf

35 Preparing New Hampshire for Projected Storm Surge, Sea-Level Rise, and Extreme Precipitation. (2016). Published by the New Hampshire Coastal Risk and Hazards Commission. https://www. nhcrhc.org/wp-content/uploads/2016-CRHC-final-report.pdf

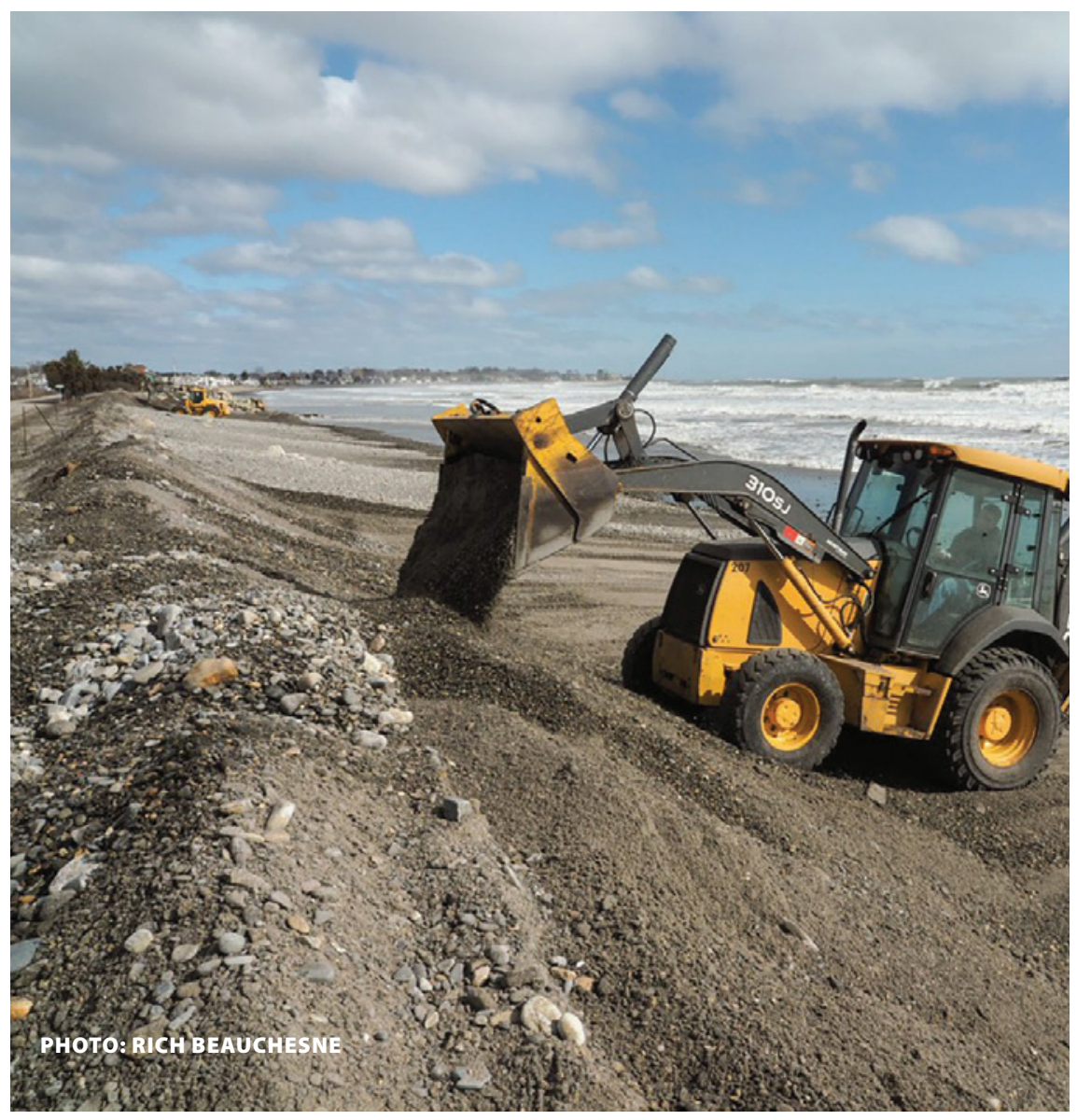

28 | STEP 4 | NH COASTAL FLOOD RISK SUMMARY PART II: GUIDANCE 


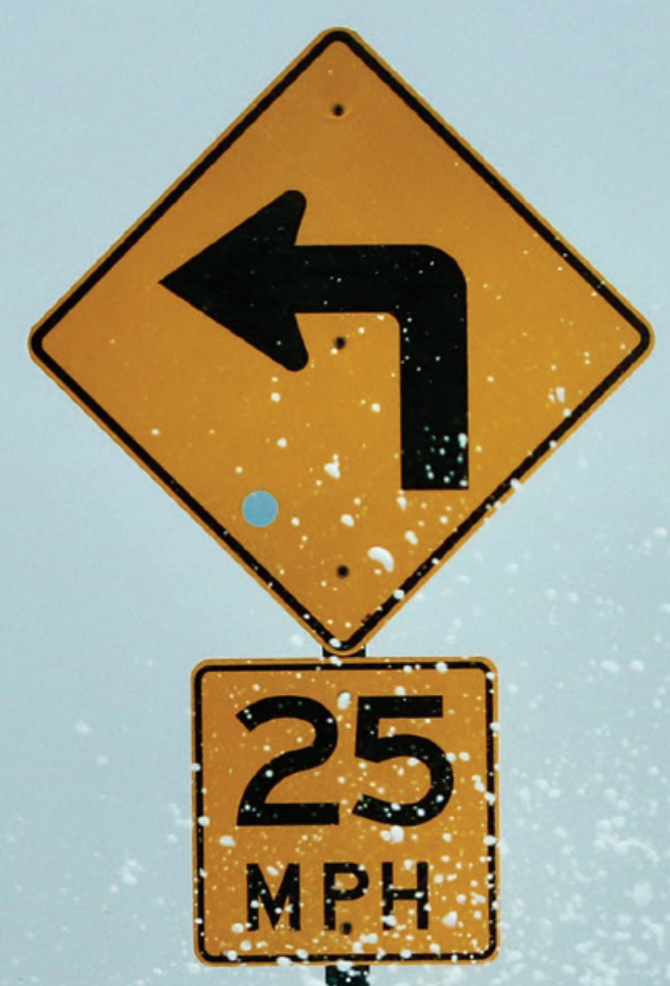

ט

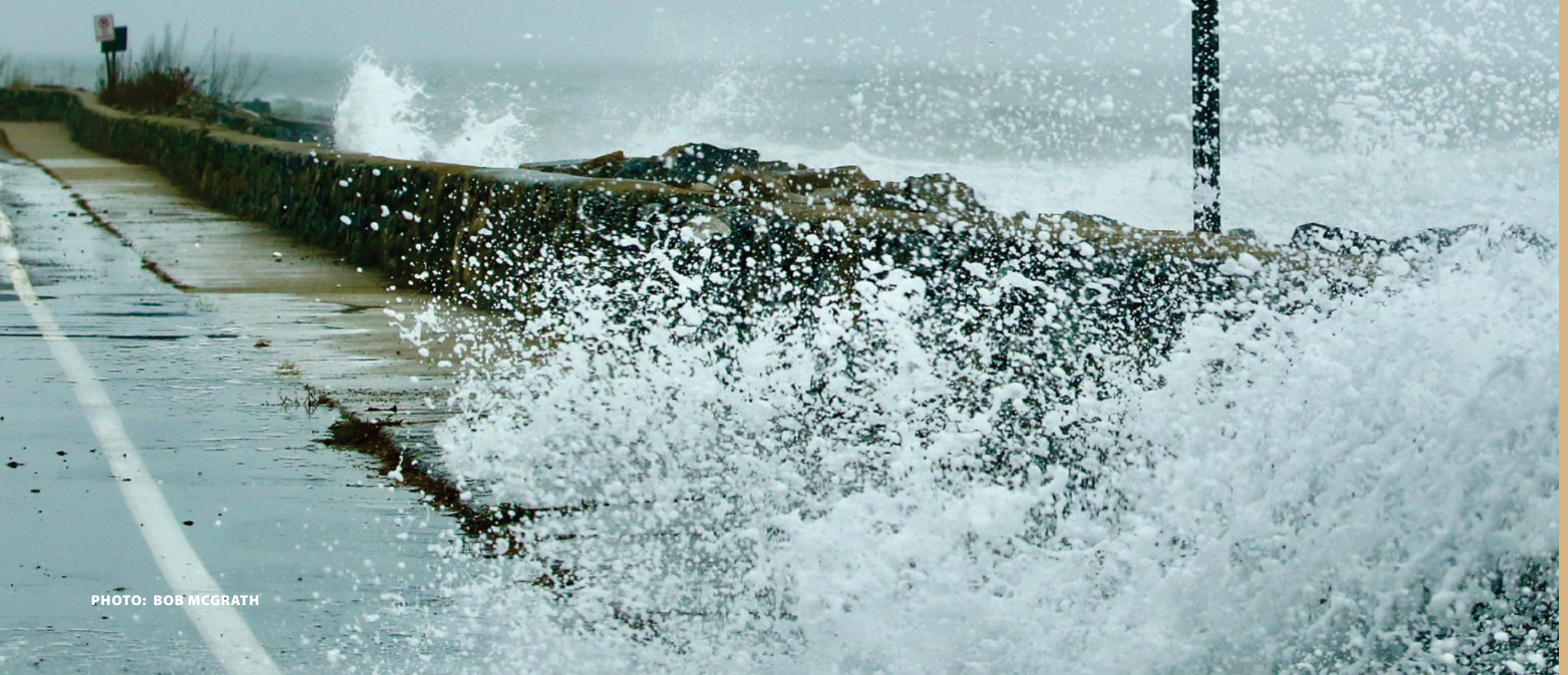




\section{STEP 5. IDENTIFY AND ASSESS RSLR-INDUCED GROUNDWATER RISE}

Before assessing RSLR-induced groundwater rise impacts to the project, decision makers must select a Project RSLR in Step 3. Return to Step 3 if not yet completed. If needed, revisit Steps 1-3 to revise project definition, tolerance for flood risk, and RSLR selection.

\section{STEP 5 SCIENCE AT A GLANCE:}

\section{RSLR-INDUCED GROUNDWATER RISE} PROJECTIONS FOR NEW HAMPSHIRE

- Mean groundwater rise is projected to be $66 \%$ of RSLR between 0-0.6 miles from the coast, 34\% between 0.61.2 miles from the coast, $18 \%$ between 1.2-1.9 miles from the coast, $7 \%$ between 1.9-2.5 miles from the coast, and $3 \%$ between 2.5-3.1 miles of the coast. ${ }^{36}$

For more information on RLSR-induced groundwater rise in New Hampshire, see Section 6 of Part I: Science. ${ }^{37}$

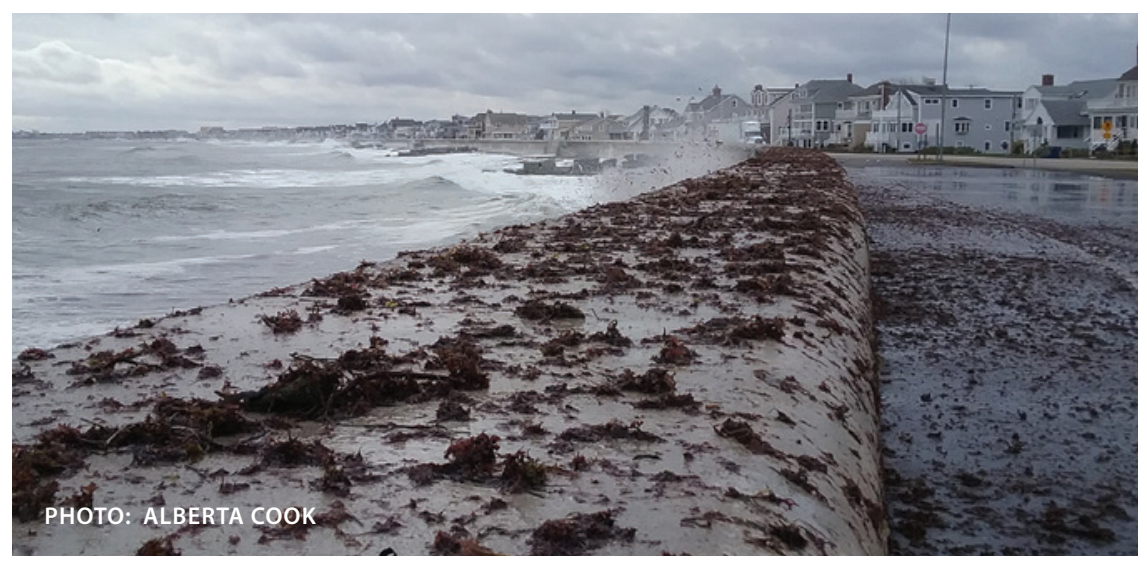

STEP 5.1 IDENTIFY RSLR-INDUCED GROUNDWATER RISE FOR THE PROJECT.

Consult the list of communities provided in this step to determine ifRSLRinduced groundwater rise has been mapped for the project location as of this Guidance publication. If the project is located in a mapped community, follow the instructions for the Preferred Approach. If the project is located in an unmapped community, follow the instructions for the Alternate Approach.

\section{Preferred Approach for Mapped Communities}

Exeter, Greenland, Hampton, Hampton Falls, Newington, North Hampton, Portsmouth, Rye, Seabrook, Stratham

Use the Sea-Level Rise Mapper ${ }^{38}$ to identify RSLR-induced groundwater rise for the project based on Project RSLR selected in Step 3.1. Note that RSLR-induced groundwater rise extends farther inland than RSLR land-surface inundation, so check the maps regardless of the project proximity to the coast.

\section{Alternate Approach for Unmapped Communities}

Dover, Durham, Madbury, New Castle, Newfields, Newmarket, Rollinsford It is recommended that unmapped communities map projected RSLR-induced groundwater rise. In the absence of maps, projects that occur within three miles of a tidal shoreline should commit to manage mean groundwater rise of at least 33\% of the RSLR estimate selected in Step 3, but be prepared to manage mean groundwater rise of up to $66 \%$ of the RSLR estimate selected in Step 3. In general, groundwater rise will be higher closer to the tidal shoreline.

For example: a planning, regulatory, or site-specific project planning for 2.9 feet of RSLR by 2100 should commit to manage 1.0 feet of RSLR-induced groundwater rise, but be prepared to manage 1.9 feet of RSLR-induced groundwater rise. 
STEP 5.2 ESTIMATE DEPTH TO PRESENT-DAY AND FUTURE GROUNDWATER FOR THE PROJECT AREA.

Determine the present-day depth(s) to the seasonal high water table (SHWT) at the location through on-site observation, survey, and test pits, or, if no on-site information is available, by extrapolating from existing nearby surficial aquifer or overburden well data. Resources that may be used to extrapolate this data include but are not limited to the NHDES Water Well Inventory available on NHDES OneStop ${ }^{39}$ or the GEOLOGs database available upon request from the New Hampshire Geological Survey. ${ }^{40}$ If referencing the NHDES Water Well Inventory, find a nearby well for which "static water level" data is available. This is the depth to groundwater from the land surface on the day the well was drilled. Overburden wells are the most accurate for determining depth to groundwater. Note that registration is currently required to view secure water supply data, including the Water Well Inventory, on the NHDES OneStop Data Mapper. ${ }^{41}$ For larger projects or projects with Low to Very Low tolerance for flood risk, consult a hydrogeologist to assist with the groundwater analysis. In order to determine future depth to projected groundwater, subtract the amount of RSLR-induced groundwater rise from the present-day depth(s) to SHWT (Step 5 Table). If the calculated result is negative, that would indicate that the future SHWT will rise above the ground surface, resulting in possible inundation.

\section{STEP 5.2: PROJECT-SPECIFIC CONSIDERATIONS / EXAMPLES}

There are multiple ways to estimate depth to present-day and future groundwater for planning, regulatory, and site-specific projects. Approaches will vary based on project goals and decision maker preferences. The following considerations and examples are intended to provide additional context and ideas for each project type, but will not apply to all projects.

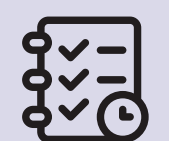

For a planning project to update a local master plan in an unmapped community within 3 miles of the tidal shoreline and using the upper end of the range of RSLR selected in Step 3 (2.3 feet by 2050), decision makers might commit to manage 0.8 feet and be prepared to manage 1.5 feet of RSLR-induced groundwater rise. Assuming that the average present-day depth to SHWT is 4 feet throughout the community, decision makers might commit to manage for a RSLR-adjusted depth to SHWT of 3.2 feet and be prepared to manage for a RSLR-adjusted depth to SHWT of 2.5 feet, based on the Step 5 Table.

$\$$

For a regulatory project to update a local floodplain ordinance, decision makers might require regulated entities to follow the preferred or alternative approach recommended in the Step 5 Table in order to determine the amount of RSLR-induced groundwater rise projected for their site-specific project. For example, decision makers might require a regulated residential structure located in a mapped community and planning for 1.6 feet of RSLR by 2050 to consult the Sea-Level Rise Mapper to determine the amount of RLSR-induced groundwater rise projected for its particular location. Assuming that the Mapper indicates that RSLR-induced groundwater rise is expected to be approximately 1 foot and presentday depth to SHWT is 3 feet, decision makers might require that the residential structure be constructed to withstand a RSLR-adjusted depth to SHWT of 2 feet, based on the Step 5 Table.

- For a site-specific project to build a new hospital within a mapped community, using the selected RSLR in Step 3 (8.3 feet by 2120), assume that the Sea-Level Rise Mapper indicates that RSLR-induced groundwater rise is expected to be 5 feet. Decision makers determine that the hospital site has a present-day depth to SHWT of 4 feet. To determine depth to projected groundwater, decision makers subtract 5 feet from 4 feet to get -1 foot. Decision makers should plan for a RSLR-adjusted depth to SHWT of -1 feet. A negative depth to SHWT means that the groundwater level will rise above ground, resulting in land surface inundation. 
The goal of this planning project was to understand the spatial distribution of future freshwater and tidal wetlands due to sea-level rise-induced groundwater rise in the City of Portsmouth.

Both RSLR and RSLR-induced groundwater rise will contribute to the expansion, migration, and transition of coastal and freshwater wetlands in New Hampshire. To better understand the potential implications of groundwater rise on wetlands, researchers evaluated possible wetland changes in the City of Portsmouth. ${ }^{36}$ According to baseline maps, $21 \%$ of Portsmouth's land area is occupied by freshwater wetlands and $9 \%$ of land area is occupied by tidal wetlands. ${ }^{42}$ Figure 4 shows projected tidal inundation from 6.6 feet of RSLR and groundwater inundation risk areas from RSLR-induced groundwater rise, where the depth to groundwater is less than 3.3 feet. Existing wetlands are most likely to expand into adjacent low-lying land due to groundwater inundation and RSLR. At high rates of sea-level rise (i.e., 6.6 feet by 2100 ), corresponding groundwater rise is projected to cause freshwater wetlands in Portsmouth to expand 3\% by 2030, $10 \%$ by 2050 , and 19 to $25 \%$ by 2100 . Wetland expansion has implications for local, state, and federal wetlands regulations as well as surface and groundwater quality, flood protection, wildlife habitat, and infrastructure and other project siting and repair. The United States Army Corps of Engineers, the New Hampshire Department of Environmental Services, and the City of Portsmouth protect wetlands for their important natural resource functions and values. Jurisdictional freshwater and tidal wetland areas are based on reference lines, including delineations determined by professional wetlands scientists as well as the highest observable tide line. As wetlands continue to expand and transition with RSLR and associated groundwater rise, jurisdictional wetland areas will change with implications for permitting agencies and permit applicants alike.

32 | STEP 5 | NH COASTAL FLOOD RISK SUMMARY PART II: GUIDANCE

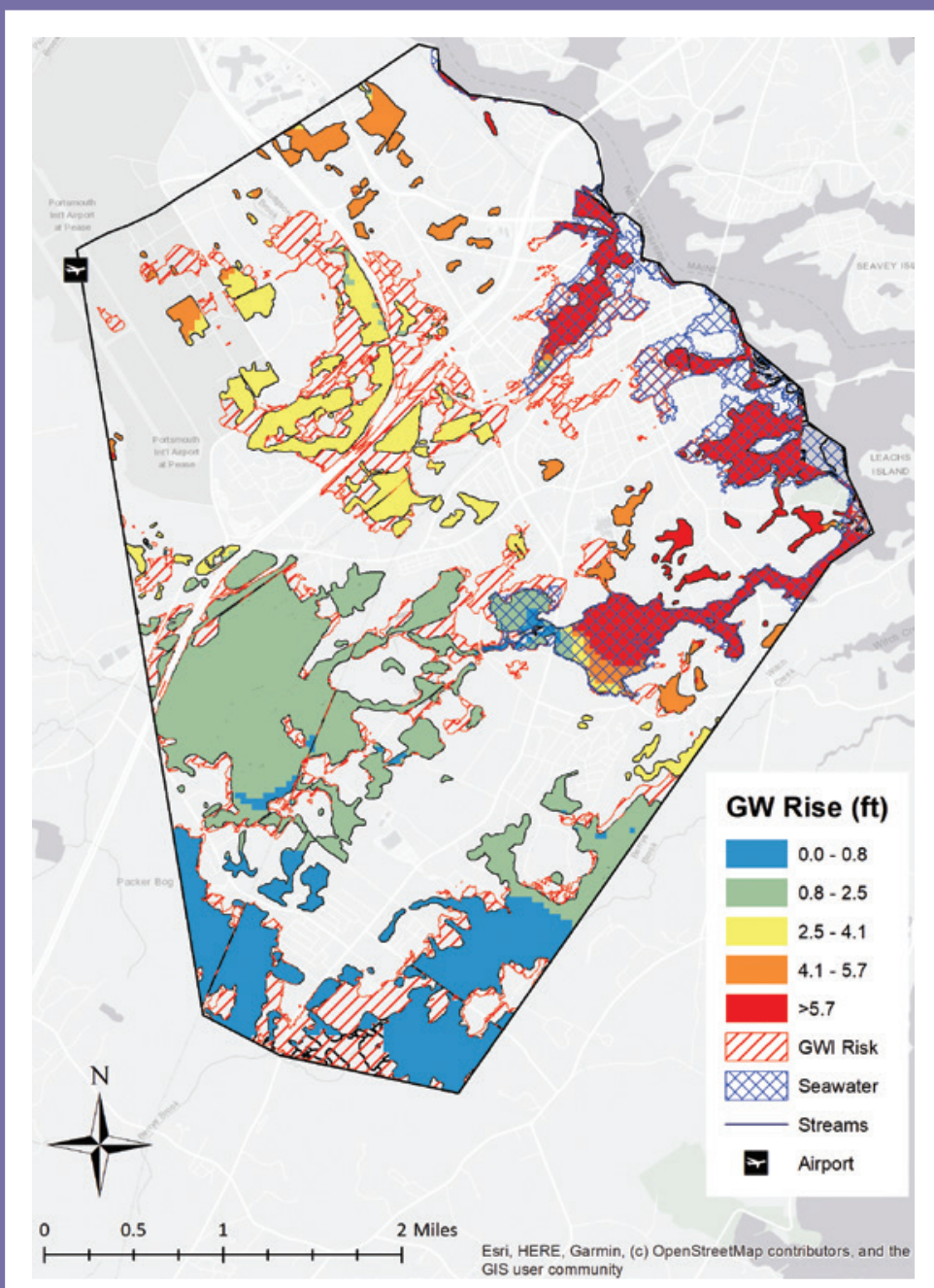

Figure 4. Simulated RSLR-induced groundwater rise in Portsmouth's tidal and freshwater wetlands with 6.6 feet of RSLR. ${ }^{36}$ The solid colors illustrate projected groundwater rise within existing wetland boundaries from the National Wetlands Inventory. ${ }^{42}$ Areas of groundwater inundation risk (groundwater table $<3.3$ feet deep) are shown with red diagonal lines and projected mean higher high water tidal inundation is delineated with blue crosshatch. 
STEP 5 TABLE. APPROACHES FOR CALCULATING DEPTH TO RSLR-ADJUSTED GROUNDWATER.

\begin{tabular}{|c|c|c|}
\hline & $\begin{array}{c}\text { PREFERRED APPROACH } \\
\text { (MAPPED COASTAL COMMUNIT) }\end{array}$ & $\begin{array}{c}\text { ALTERNATE APPROACH } \\
\text { (UNMAPPED COASTAL COMMUNIT) }\end{array}$ \\
\cline { 2 - 3 } & $\begin{array}{c}\text { IF PROJECT AREA IS LOCATED IN A MAPPED } \\
\text { COASTAL COMMUNITY: }\end{array}$ & $\begin{array}{c}\text { IF PROJECT AREA IS LOCATED WITHIN 3 MILES } \\
\text { OF TIDAL SHORELINE IN AN UNMAPPED } \\
\text { COASTAL COMMUNITY: }\end{array}$ \\
\hline $\begin{array}{c}\text { RSLR-INDUCED GROUNDWATER } \\
\text { RISE }=\end{array}$ & $\begin{array}{c}\text { Refer to Sea-Level Rise Mapper }{ }^{38} \text { to estimate } \\
\text { RSLR-induced groundwater rise }\end{array}$ & $\begin{array}{c}\text { Commit to manage }=(\mathrm{RSLR}) \times(0.33) \\
\text { Be prepared to manage }=(\mathrm{RSLR}) \times(0.66)\end{array}$ \\
\hline $\begin{array}{c}\text { DEPTH TO RSLR-ADJUSTED } \\
\text { GROUNDWATER }\end{array}$ & (Present-day depth to groundwater) - (RSLR-induced groundwater rise) \\
\hline
\end{tabular}

\section{STEP 5.3 | ASSESS RSLR-INDUCED GROUNDWATER RISE} IMPACTS TO THE PROJECT.

Assess RSLR-induced groundwater rise impacts to the project, including but not limited to related assets, natural resources, cultural and historic resources, public access, and socially vulnerable populations. Note that underground assets are most vulnerable to RSLR-induced groundwater rise.

\section{RESOURCES TO REFERENCE IN STEP 5}

36 Modeling Groundwater Rise Caused by Sea-Level Rise in Coastal New Hampshire. (2018). Published by Knott, J.F., Jacobs, J., Daniel, J.S., \& Kirshen, P. in Journal of Coastal Research, 35, 143-157. doi: https://doi.org/10.2112/JCOASTRES-D-17-00153.1

${ }^{37}$ New Hampshire Coastal Flood Risk Summary Part I: Science. (2019) Prepared for the New Hampshire Coastal Flood Risk Science and Technical Advisory Panel by Wake, C. et al. Published by the University of New Hampshire, Durham, $\mathrm{NH}$.

https://scholars.unh.edu/ersc/210
38 The New Hampshire Sea-Level Rise, Storm Surge, and Groundwater Rise Mapper (Sea-Level Rise Mapper) (2020). Managed by the New Hampshire Department of Environmental Services. http://www.tinyurl.com/slrmapper

39 OneStop. Managed by the New Hampshire Department of Environmental Services. http://www4.des.state.nh.us/ DESOnestop/BasicSearch.aspx

40 Contact the New Hampshire Geological Survey. https://www.des.nh.gov/organization/commissioner/gsu/ categories/contactus.htm

41 OneStop Data Mapper. Managed by the New Hampshire Department of Environmental Services. https://www4.des.state. nh.us/onestopdatamapper/onestopmapper.aspx

42 National Wetlands Inventory. (2001). Published by the U.S. Fish and Wildlife Service. https://www.fws.gov/wetlands/ 


\section{STEP 6. IDENTIFY AND ASSESS EXTREME PRECIPITATION ESTIMATES}

Decision makers should complete steps 1-5 before assessing extreme precipitation. Increases in extreme precipitation are expected throughout the State of New Hampshire, therefore, projects sited outside of the influence of $R S L R$, coastal storms, and RSLR-induced groundwater rise may skip to this step after completing steps 1 and 2 . If needed, revisit and revise work completed in previous steps.

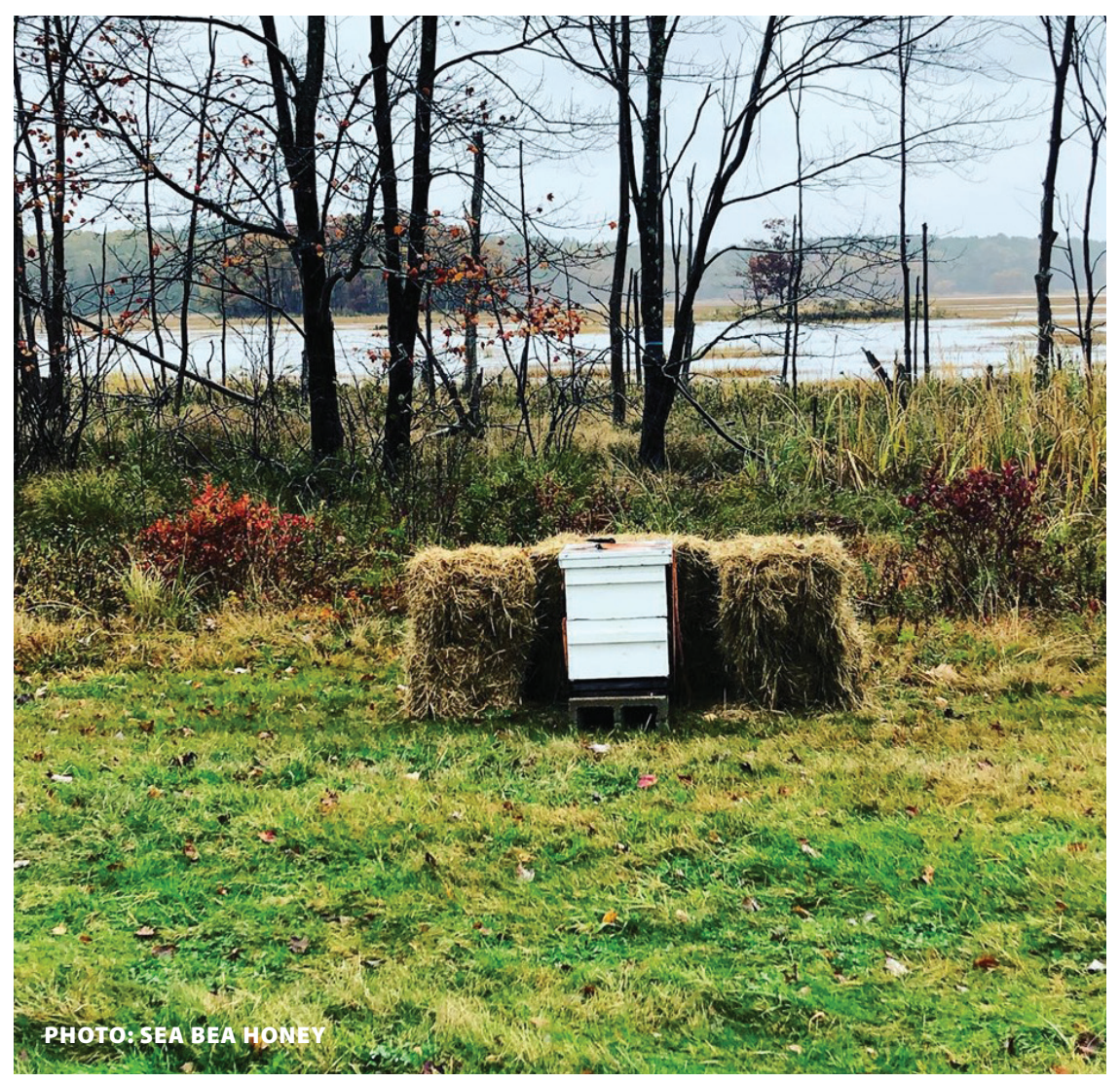

STEP 6 SCIENCE AT A GLANCE:

\section{EXTREME PRECIPITATION PROJECTIONS FOR} COASTAL NEW HAMPSHIRE

- By the end of the century, the amount of precipitation falling on the wettest day of the year is projected to increase by $8-15 \%$ under RCP 4.5 and $13-24 \%$ under RCP 8.5 compared to the historical 1980-2009 average.

- By the end of the century, the number of 24-hour events per year that produce 1 inch of precipitation is projected to increase 23-26\% under RCP 4.5 and 38-44\% under RCP 8.5 (with even greater increases in 2 inch precipitation events under both scenarios) compared to the historical 1980-2009 average.

- By the end of the century, the number of 48-hour storm events per decade that produce 4 inches or more of precipitation is projected to increase 64-77\% under RCP 4.5, and more than double (114-154\%) under RCP 8.5, compared to the historical 1980-2009 average.

For a more detailed synthesis of the state of the science related to extreme precipitation in coastal New Hampshire, see Section 6 in Part l: Science. ${ }^{43}$ 
STEP 6.1 ACCOUNT FOR PROJECTED INCREASES IN EXTREME PRECIPITATION.

Projects with High to Medium tolerance for flood risk should account for a 15\% increase in extreme precipitation estimates. Projects with Low to Very Low tolerance for flood risk should account for a greater than 15\% increase in extreme precipitation estimates. For projects involving detailed hydrologic and hydraulic modeling, increase best available present-day extreme precipitation estimates for relevant durations and recurrence intervals by $15 \%$ for High to Medium tolerance for flood risk and greater than 15\% for Low to Very Low tolerance for flood risk (Step 6 Table).

Best available extreme precipitation estimates can be found in the Northeast Regional Climate Center Extreme Precipitation in New York \& New England Atlas ${ }^{44}$ or NOAA Atlas 14, Volume 10 Version 3.0: Northeastern States. ${ }^{45}$ For projects involving detailed hydrologic and hydraulic modeling, projected extreme precipitation estimates can also be generated by downscaling output from a broad suite of Atmosphere-Ocean General Circulation Models (AOGCMs) and using the ensemble mean estimate. ${ }^{46,47,48}$

\section{STEP 6.1: PROJECT-SPECIFIC CONSIDERATIONS / EXAMPLES}

There are multiple ways to account for projected increases in extreme precipitation for planning, regulatory, and site-specific projects. Approaches will vary based on project goals and decision maker preferences. The following considerations and examples are intended to provide additional context and ideas for each project type, but will not apply to all projects.

For a planning project to update a local master plan with tolerance for flood risk ranging from High to Very Low, Q decision makers might acknowledge that future extreme precipitation events are likely to increase by at least $15 \%$ in volume. If relevant, decision makers might multiply present-day extreme precipitation estimates for storm durations and recurrence intervals of interest by 1.15 to determine the minimum projected extreme precipitation estimates for the community, based on the Step 6 Table.

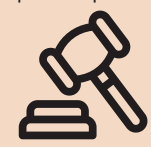

For a regulatory project to update a local floodplain ordinance with High to Very Low tolerance for flood risk, decision makers would determine the volume of the 24hour, $1 \%$ annual chance rain event and multiply it by at least 1.15 to determine the minimum projected extreme precipitation estimates. Decision makers may consider hydrologic modeling to inform an adjustment to the regulatory project area encompassing the spatial extent of the future freshwater floodplain based on the projected storm precipitation volume (see Planning Case Study: Inundation Mapping for Lee, New Hampshire).

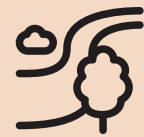

For a site-specific project to build a new hospital with a Very Low tolerance for flood risk and a present-day extreme precipitation estimate for the 24-hour, 10-year rainfall event of 4.9 inches, decision makers, using Step 6 Table, would multiply 4.9 inches by a number great than 1.15 to estimate projected extreme precipitation for the same rainfall event (i.e., 4.9 inches $\times 1.2$ $=5.9$ inches). 
STEP 6 TABLE. APPROACH FOR CALCULATING PROJECTED EXTREME PRECIPITATION ESTIMATES BASED ON TOLERANCE FOR FLOOD RISK.

\begin{tabular}{|c|c|c|c|c|}
\hline & HIGH & MEDIUM & LOW & VERY LOW \\
& TOLERANCE FOR FLOOD RISK & TOLERANCEFOR FLOOD RISK & TOLERANCE FOR FLOOD RISK & TOLERANCE FOR FLOOD RISK \\
\hline $\begin{array}{c}\text { PROJECTED EXTREME } \\
\text { PRECIPITATION ESTIMATE }=\end{array}$ & \multicolumn{2}{|c|}{ (Best available precipitation data) $\mathbf{x ( 1 . 1 5 )}$} & (Best available precipitation data) $\mathbf{x}$ (>1.15) \\
\hline
\end{tabular}

STEP 6.2 ASSESS PROJECTED EXTREME PRECIPITATION IMPACTS TO THE PROJECT.

Be aware that freshwater instream flow and floodplain extent are expected to increase with increasing precipitation and impervious cover. Higher relative sea levels may reduce seaward drainage capacity during and following precipitation events, which could cause additional flooding. Evaluate impacts of freshwater flooding on the project, including but not limited to related assets, natural resources, cultural and historic resources, public access, and socially vulnerable populations. Impacts evaluation may be qualitative or quantitative depending on whether the project involves hydrologic and hydraulic modeling.

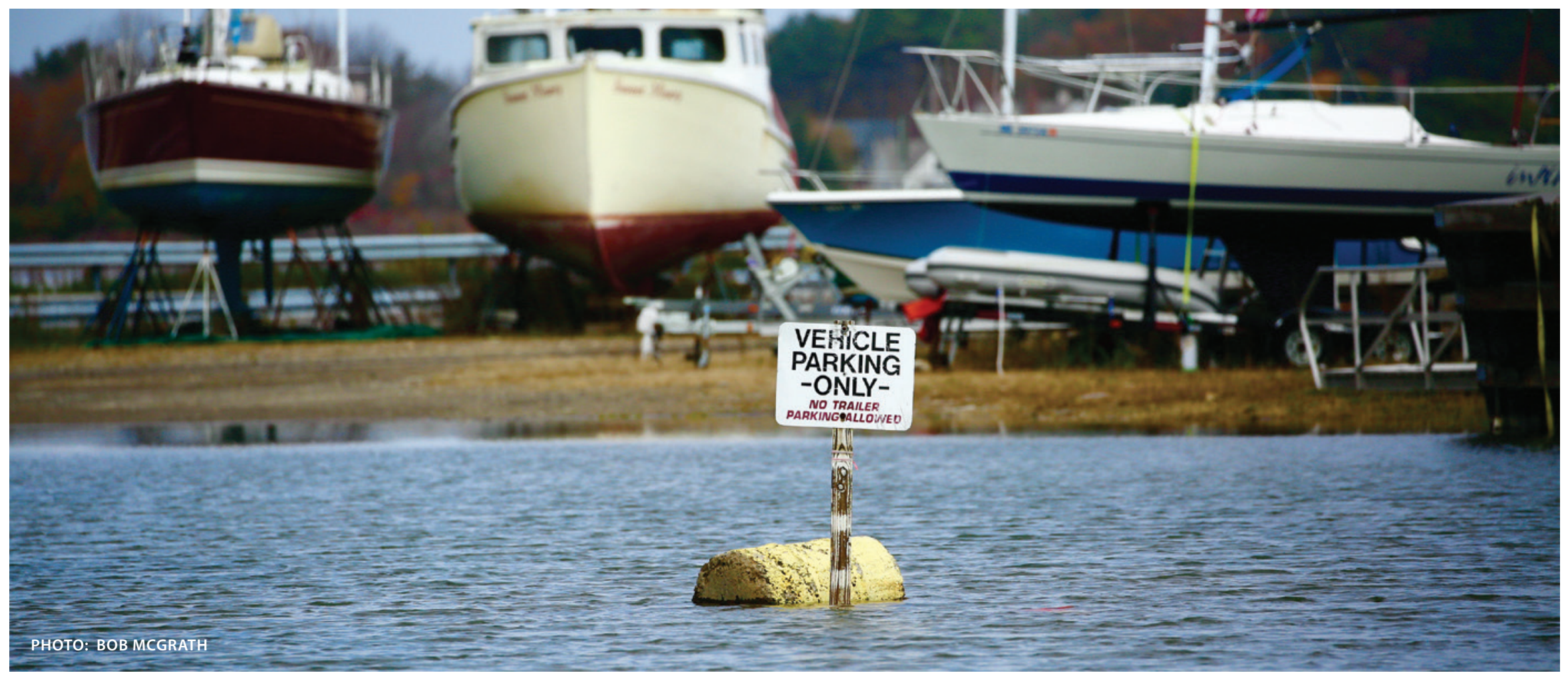

36 | STEP 6 | NH COASTAL FLOOD RISK SUMMARY PART II: GUIDANCE 
The goal of this regulatory project was to revise the New Hampshire Department of Environmental Services Alteration of Terrain rules to require consideration of increasing extreme precipitation in applicable stormwater management.

Effective August 15, 2017, the revised New Hampshire Department of Environmental Services Alteration of Terrain rules ${ }^{49}$ now require projects to use best available historic precipitation estimates from the Northeast Regional Climate Center ${ }^{44}$ or NOAA Atlas $14^{45}$ rather than outdated estimates from TP-40 referenced in the New Hampshire Stormwater Manual Volume 2. The rules also require projects in the Coastal or Great Bay Region to increase precipitation amounts by $15 \%$, as well as demonstrate through narrative that sea-level rise and coastal storms have been considered in the design process (Env-Wq 1503.08(I)). To comply with this new requirement, applicants must increase the depth of precipitation estimates for the 1-year, 2-year, 10-year, and 50-year, 24-hour storms obtained from the Northeast Regional Climate Center ${ }^{44}$ or NOAA Atlas $14^{45}$ by $15 \%$ before calculating pre- and post-construction stormwater drainage. In the example provided in Figure 5, a hypothetical Alteration of Terrain permit application for a project located in Portsmouth, $\mathrm{NH}$, would use the extreme precipitation estimates presented in for its stormwater drainage analysis.
Figure 5. Example of how extreme precipitation estimates obtained from the Northeast Regional Climate Center Extreme Precipitation in New York \& New England Atlas for Portsmouth, $\mathrm{NH}$, are increased by $15 \%$ for use in a stormwater drainage analysis for a hypothetical state Alteration of Terrain (AOT) permit application.

\section{Extreme Precipitation Tables}

\section{Northeast Regional Climate Center}

Data represents point estimates calculated from partial duration series. All precipitation amounts are displayed in inches.

\begin{tabular}{||cl|}
\hline \hline $\begin{array}{c}\text { Smoothing } \\
\text { State }\end{array}$ & Yes \\
Location & \\
Longitude & 70.763 degrees West \\
Latitude & 43.072 degrees North \\
Elevation & 0 feet \\
Date/Time & Wed, 04 Mar 2020 09:48:48 -0500 \\
\hline
\end{tabular}

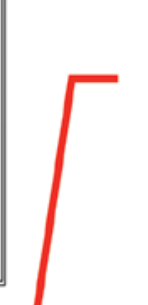

Extreme Precipitation Estimates

Increase extreme precipitation estimates by $15 \%$ :

1-yr, 24-hr: $2.66^{\prime \prime} \times 1.15=3.06^{\prime \prime}$ 2-yr, 24-hr: $3.21 " \times 1.15=3.69^{\prime \prime}$ 10-yr, 24-hr: $4.87^{\prime \prime} \times 1.15=5.60 "$ 50-yr, 24-hr: $7.39 " \times 1.15=8.50 "$

\begin{tabular}{|c|c|c|c|c|c|c|c|c|c|c|c|c|c|c|c|c|c|c|c|c|c|}
\hline & $5 \mathrm{~min}$ & $10 \mathrm{~min}$ & $15 \mathrm{~min}$ & 30min & $60 \mathrm{~min}$ & $120 \mathrm{~min}$ & & $1 \mathrm{hr}$ & $2 \mathrm{hr}$ & $3 \mathrm{hr}$ & $6 \mathrm{hr}$ & $\mid 12 \mathrm{hr}$ & $24 \mathrm{hr}$ & $48 \mathrm{hr}$ & & 1day & 2day & 4day & \begin{tabular}{|l|} 
7day \\
\end{tabular} & 10day & \\
\hline $1 \mathrm{yr}$ & 0.26 & \begin{tabular}{|l|}
0.40 \\
\end{tabular} & 0.50 & 0.65 & 0.81 & 1.04 & $1 \mathrm{yr}$ & 0.70 & 0.98 & 1.21 & 1.56 & \begin{tabular}{|l|}
2.03 \\
\end{tabular} & 2.66 & 2.92 & $1 \mathrm{yr}$ & \begin{tabular}{|l|}
2.35 \\
\end{tabular} & \begin{tabular}{|l|}
2.81 \\
\end{tabular} & \begin{tabular}{|l|}
3.22 \\
\end{tabular} & \begin{tabular}{|l|}
3.94 \\
\end{tabular} & 4.55 & $1 \mathrm{yr}$ \\
\hline $2 \mathrm{yr}$ & 0.32 & 0.50 & 0.62 & 0.81 & 1.02 & 1.30 & $2 \mathrm{yr}$ & 0.88 & 1.18 & 1.52 & 1.94 & \begin{tabular}{|l|}
2.49 \\
\end{tabular} & \begin{tabular}{|l|}
3.21 \\
\end{tabular} & 3.57 & $2 \mathrm{yr}$ & 2.84 & \begin{tabular}{|l|}
3.43 \\
\end{tabular} & \begin{tabular}{|l|}
3.94 \\
\end{tabular} & \begin{tabular}{|l|l|}
4.68 \\
\end{tabular} & 5.33 & $2 \mathrm{yr}$ \\
\hline $5 \mathrm{yr}$ & 0.37 & 0.58 & 0.73 & 0.98 & 1.25 & 1.61 & $5 \mathrm{yr}$ & 1.08 & 1.47 & 1.89 & 2.43 & \begin{tabular}{|l|}
3.14 \\
\end{tabular} & \begin{tabular}{|l|}
4.07 \\
\end{tabular} & 4.58 & $5 \mathrm{yr}$ & \begin{tabular}{l|l}
3.60 \\
\end{tabular} & \begin{tabular}{|l|}
4.40 \\
\end{tabular} & 5.04 & 5.94 & 6.70 & $5 \mathrm{yr}$ \\
\hline $10 \mathrm{yr}$ & 0.41 & 0.65 & 0.82 & 1.12 & 1.45 & 1.89 & $10 \mathrm{yr}$ & 1.25 & 1.73 & 2.23 & \begin{tabular}{|l|}
2.89 \\
\end{tabular} & \begin{tabular}{|l|}
3.75 \\
\end{tabular} & 4.87 & 5.53 & $10 \mathrm{yr}$ & \begin{tabular}{l|l|}
4.31 \\
\end{tabular} & \begin{tabular}{|l|l|}
5.32 \\
\end{tabular} & 6.09 & 7.11 & 7.98 & $10 \mathrm{yr}$ \\
\hline $25 \mathrm{yr}$ & 0.48 & 0.76 & 0.97 & 1.34 & 1.77 & 2.34 & $25 \mathrm{yr}$ & 1.53 & 2.14 & 2.78 & \begin{tabular}{|l|}
3.63 \\
\end{tabular} & \begin{tabular}{|l|}
4.74 \\
\end{tabular} & \begin{tabular}{|l|}
6.17 \\
\end{tabular} & 7.10 & $25 \mathrm{yr}$ & \begin{tabular}{l|l|}
5.46 \\
\end{tabular} & \begin{tabular}{|l|l|}
6.83 \\
\end{tabular} & 7.80 & \begin{tabular}{|l|}
9.03 \\
\end{tabular} & \begin{tabular}{|l|}
10.05 \\
\end{tabular} & $25 \mathrm{yr}$ \\
\hline $50 \mathrm{yr}$ & 0.54 & 0.86 & 1.10 & 1.54 & 2.07 & 2.76 & $50 \mathrm{yr}$ & 1.79 & 2.53 & 3.29 & \begin{tabular}{|l|}
4.32 \\
\end{tabular} & \begin{tabular}{|l|}
5.66 \\
\end{tabular} & \begin{tabular}{|l|}
7.39 \\
\end{tabular} & \begin{tabular}{|l|}
8.58 \\
\end{tabular} & $50 \mathrm{yr}$ & \begin{tabular}{|l|}
6.54 \\
\end{tabular} & 8.25 & \begin{tabular}{|l|}
9.42 \\
\end{tabular} & 10.81 & \begin{tabular}{|l|}
11.98 \\
\end{tabular} & $50 \mathrm{yr}$ \\
\hline $100 \mathrm{yr}$ & 0.60 & 0.97 & 1.25 & 1.77 & 2.42 & 3.26 & $100 \mathrm{yr}$ & \begin{tabular}{|l|}
2.09 \\
\end{tabular} & 2.98 & 3.90 & \begin{tabular}{|l|}
5.16 \\
\end{tabular} & 6.77 & \begin{tabular}{|l|l|}
8.85 & 1 \\
\end{tabular} & 10.38 & $100 \mathrm{yr}$ & \begin{tabular}{|l|}
7.83 \\
\end{tabular} & \begin{tabular}{|l|}
9.98 \\
\end{tabular} & 11.38 & 12.96 & \begin{tabular}{|l|l|}
14.27 \\
\end{tabular} & $100 \mathrm{yr}$ \\
\hline $200 \mathrm{yr}$ & 0.67 & 1.10 & 1.43 & 2.05 & 2.82 & 3.83 & $200 \mathrm{yr}$ & 2.44 & 3.52 & 4.62 & \begin{tabular}{|l|l|}
6.13 \\
\end{tabular} & 8.08 & \begin{tabular}{|l|l|l|}
10.61 & \\
\end{tabular} & 12.55 & $200 \mathrm{yr}$ & \begin{tabular}{|l|}
9.39 \\
\end{tabular} & 12.07 & 13.76 & 15.55 & 17.02 & $200 \mathrm{yr}$ \\
\hline $500 \mathrm{yr}$ & 0.80 & 1.31 & 1.71 & 2.48 & 3.48 & 4.76 & $500 \mathrm{yr}$ & \begin{tabular}{|l|}
3.00 \\
\end{tabular} & 4.38 & \begin{tabular}{|l|}
5.76 \\
\end{tabular} & 7.70 & 10.22 & \begin{tabular}{|l|l|}
13.48 \\
\end{tabular} & 16.14 & $500 \mathrm{yr}$ & 11.93 & 15.52 & 17.67 & 19.78 & 21.49 & $500 \mathrm{yl}$ \\
\hline
\end{tabular}


The goal of this planning project was to inform updates to the floodplain ordinance for the Town of Lee by understanding the spatial distribution of the future freshwater floodplain, based on estimated increases in extreme precipitation.

In 2018, the Strafford Regional Planning Commission (SRPC), in partnership with the University of New Hampshire and a consultant, prepared planninglevel potential flood inundation maps for the mainstem of the Lamprey, North, Little, and Oyster Rivers within the Town boundary.

The models and maps developed as part of this study were built upon previous technical work where a hydrologic (HEC-HMS) and hydraulic (HEC-RAS) model of the mainstem of the Lamprey River was initially developed, ${ }^{46,50}$ updated with future climate projections, ${ }^{51,52}$ and later used to generate potential inundation maps for an array of current and future flood scenarios. ${ }^{53}$ The modeling methodology utilized was consistent with the previous studies and involved: 1) collecting data; 2) updating the hydrologic model (HEC-HMS) and generating peak discharge estimates; 3 ) updating the hydraulic model (HEC-RAS) and generating peak water surface elevation estimates; and 4) generating inundation maps (RAS-Mapper). The model methodology used to develop water surface elevation estimates and predicted inundation areas was generally consistent with the methodology used by FEMA to develop FIRMS.

The final maps depict current and potential future flooding extent and depth associated with the $1 \%$-annual-chance (100-year) flood for the following conditions:

Present-day (2005) land use and 1\%-annual-chance, 24-hour rainfall depth of 8.5 inches

- Future (2050) projected build out and projected 1\%-annualchance, 24-hour rainfall depth of 11.5 inches

Present-day (2005) 1\%-annual-chance, 24-hour rainfall depth of 8.5 inches was obtained from the Northeast Regional Climate Center. ${ }^{44}$ Future (2050) 1\%-annual-chance, 24-hour rainfall depth was derived by downscaling outputs from four Atmosphere-Ocean General Circulation Model (AOGCM) simulations based on a high emissions scenario for two reliable long-term weather stations in the Great Bay watershed (Durham, NH and Lawrence, MA). The highest estimate of 24-hour rainfall depths (11.5 inches for Lawrence, MA) was selected to maximize the difference between present-day and future conditions. Based on this study and its assumptions, the difference between the present-day and future extreme precipitation estimates represents a 35\% increase (i.e., greater than $15 \%)$.

The Town of Lee is considering revising its floodplain ordinance to incorporate the new maps and other changes based on the updated model floodplain ordinance developed by the Office of Strategic Initiatives. ${ }^{54}$

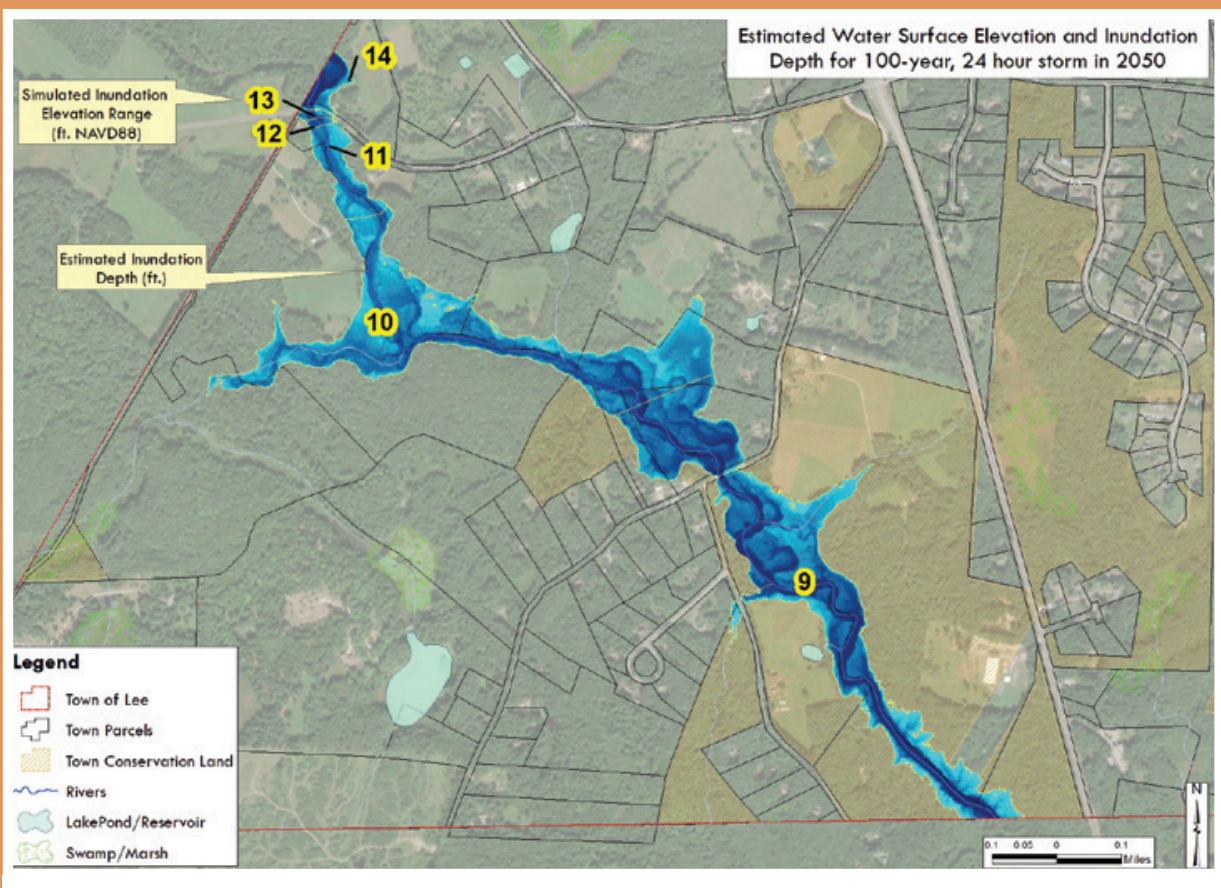

Figure 6. Example of the potential flood inundation maps for the projected (2050) 1\%-annual-chance (100-year) flood event developed for the North River in Lee, New Hampshire. 


\section{RESOURCES TO REFERENCE IN STEP 6}

43 New Hampshire Coastal Flood Risk Summary Part I: Science. (2019) Prepared for the New Hampshire Coastal Flood Risk Science and Technical Advisory Panel by Wake, C. et al. Published by the University of New Hampshire, Durham, $\mathrm{NH}$. https://scholars.unh.edu/ersc/210

44 Extreme Precipitation in New York \& New England, Version 1.12. Managed by the Northeast Regional Climate Center. http://precip.eas.cornell.edu/

45 Atlas 14 Volume 10, Precipitation-Frequency Atlas of the United States, Northeastern States. (2015, revised 2019). Published by NOAA. https://www.nws.noaa.gov/oh/hdsc/PF_documents/ Atlas14_Volume10.pdf

46 Review of Land Development (Build-Out) and Climate Scenarios. (2013). By Wake, C. et al. http://100yearfloods.org/resources/ pdf/2013_Lamprey_BuildoutMethodology.pdf

47 Global Climate Model Ensemble Approaches for Future Projections of Atmospheric Rivers. (2019). Published by Massoud, E.C. et al. in Earth's Future, 7(10), 1136-1151. https://doi.org/10.1029/2019EF001249

48 Skill and Independence Weighting for Multi-Model Assessment. (2017). Published by Sanderson, B.M. et al. in Geoscientific Model Development, 10, 2379-2395. https://doi.org/10.5194/gmd-102379-2017

49 New Hampshire Code of Administrative Rules, Chapter Env-Wq 1500, Alteration of Terrain (2017). https://www.des.nh.gov/organization/ commissioner/legal/rules/documents/env-wq1500.pdf
50 Assessing the Risk of the 100-year Freshwater Floods in the Lamprey River Watershed of New Hampshire Resulting from Changes in Climate and Land Use. (2013). By Wake, C. et al. http://100yearfloods.org/resources/pdf/2009_ LampreyRiver_100YearFloods_FINALReport.pdf

51 Climate and Land Use Consequences to 100-Year Flooding. M. Sc. Thesis, University of New Hampshire, Durham, NH. (2011). By Scholz, A. http://100yearfloods.org/resources/pdf/2011_Scholz_ MScThesis.pdf

52 Water Surface Elevation and Flood Flows at Flood Insurance (FIS) Cross Sections for Four Conditions. (2012). By Scholz, A., Roseen, R., Wake, C. http://100yearfloods.org/resources/pdf/2012_ LampreyRiver_CrossSections.pdf

53 Analysis of Flood Damage Cost Avoidance in the Lamprey River Watershed of New Hampshire. (2016). By Geosyntec Consultants, Inc. http://100yearfloods.org/resources/pdf/2016_Geosyntec_ LampreyHazus.pdf

54 NH Model Floodplain Ordinances. (2018). By the New Hampshire Office of Strategic Initiatives. https://www.nh.gov/osi/planning/ programs/fmp/regulations.htm 


\section{STEP 7: ASSESS CUMULATIVE RISK AND EVALUATE ADAPTATION OPTIONS}

Upon completing the previous six steps, Step 7 prompts decision makers to consider cumulative coastal flood risk to the project, identify and evaluate possible actions to minimize flood risk, and evaluate the possible consequences of those actions. If needed, revisit and revise work completed in previous steps.

\section{STEP 7.1 ASSESS CUMULATIVE COASTAL FLOOD RISK TO THE PROJECT.}

Consider possible compound impacts to the project as a result of coastal flood risk from RSLR, coastal storms, RSLR-induced groundwater rise, extreme precipitation, and/or freshwater flooding occurring together. Note that assessing cumulative flood risks is not necessarily quantitative and cannot be accomplished by adding up the individual projections and impacts identified in Steps 3-6. Methods and/or models for quantitatively assessing cumulative flood risks will likely evolve and become more accessible in the future. In the meantime, decision makers should attempt to qualitatively assess how these coastal flood risks interact to collectively impact the project. Note that for some projects, a particular coastal flood risk may clearly outweigh others in terms of magnitude and impact to the project, in which case it may be unnecessary to conduct a cumulative risk assessment and/or account for multiple coastal flood risks in the selection of adaptation options.

\section{STEP 7.2 IDENTIFY AND EVALUATE ADAPTATION OPTIONS TO MITIGATE COASTAL FLOOD RISK.}

Identify possible adaptation options to address or minimize the coastal flood risk impacts assessed in Steps 3-6. Adaptation options will typically fall within a framework of five action categories: no action, avoid, accommodate, resist, and relocate (Step 7 Table A for a basic framework and Step 7 Table B for hypothetical examples). A combination of options spanning the five action categories may be necessary depending on the scope of the project. Robust options will mitigate multiple coastal flood risks and perform as intended over a wide range of possible future conditions.

Decision makers should strongly consider relocating priority assets out of harm's way and avoiding new development with Medium to Very Low tolerance for flood risk in areas likely to be impacted by coastal flooding. Decision makers are also encouraged to entertain creative, unconventional, out-of-the-box options that are flexible and can be adjusted over time. Following a flexible, incremental adaptation approach, decision makers might implement options to reduce coastal flood risks to acceptable levels in the near term, conceptualize future actions that may be necessary, and implement a monitoring plan to continuously assess performance and adjust course as needed as new information becomes available, coastal flood risk conditions change, and/or opportunities (e.g., new technology) arise to improve performance.

When evaluating possible action alternatives, decision makers should follow the guiding principles, and at minimum, assess whether and the degree to which each of the possible action alternatives reduces vulnerability, is cost effective, and exacerbates or minimizes negative consequences, including maladaptation, disproportionate effects on socially vulnerable populations, and adverse impacts to natural, historic, and cultural resources and public access. Decision makers should weigh whether the level of investment required for action implementation is warranted, or if the project, as originally conceived, is no longer practicable and should be revised or called off given future coastal flood risk projections.

40 | STEP 7 | NH COASTAL FLOOD RISK SUMMARY PART II: GUIDANCE 
STEP 7 TABLE A. FRAMEWORK OF TYPES OF ACTION TO MANAGE COASTAL FLOOD RISK.

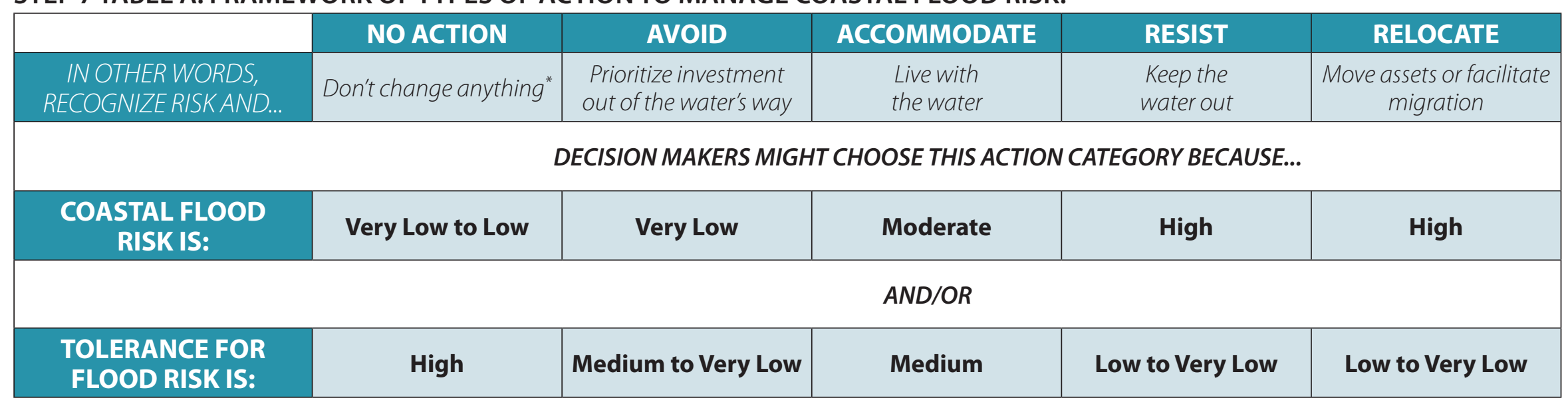

*Be sure to understand the potential liability associated with not taking action despite understanding risk information. Justification for no action should be based on risk assessment results. ${ }^{55}$

STEP 7.3 | SELECT PREFERRED OPTION(S) AND PROCEED WITH PROJECT OR REVISIT AND REVISE PREVIOUS STEPS.

Select preferred options based on the alternatives analysis in Step 7.2. If the evaluated alternatives will not be effective or feasible, decision makers may consider revisiting Steps 1-6 to revise project definition, tolerance for flood risk, RSLR projections, RSLR-adjusted coastal storm estimates, RSLR-induced groundwater rise, and precipitation and/or freshwater flooding. Transparency is critical for all projects. In particular, for site-specific projects where transfer of ownership is likely over time, project decision makers should publicly disclose assessed flood risk, implemented actions, and any future actions that may be necessary to further mitigate flood risk, particularly if a flexible adaptation approach is followed.

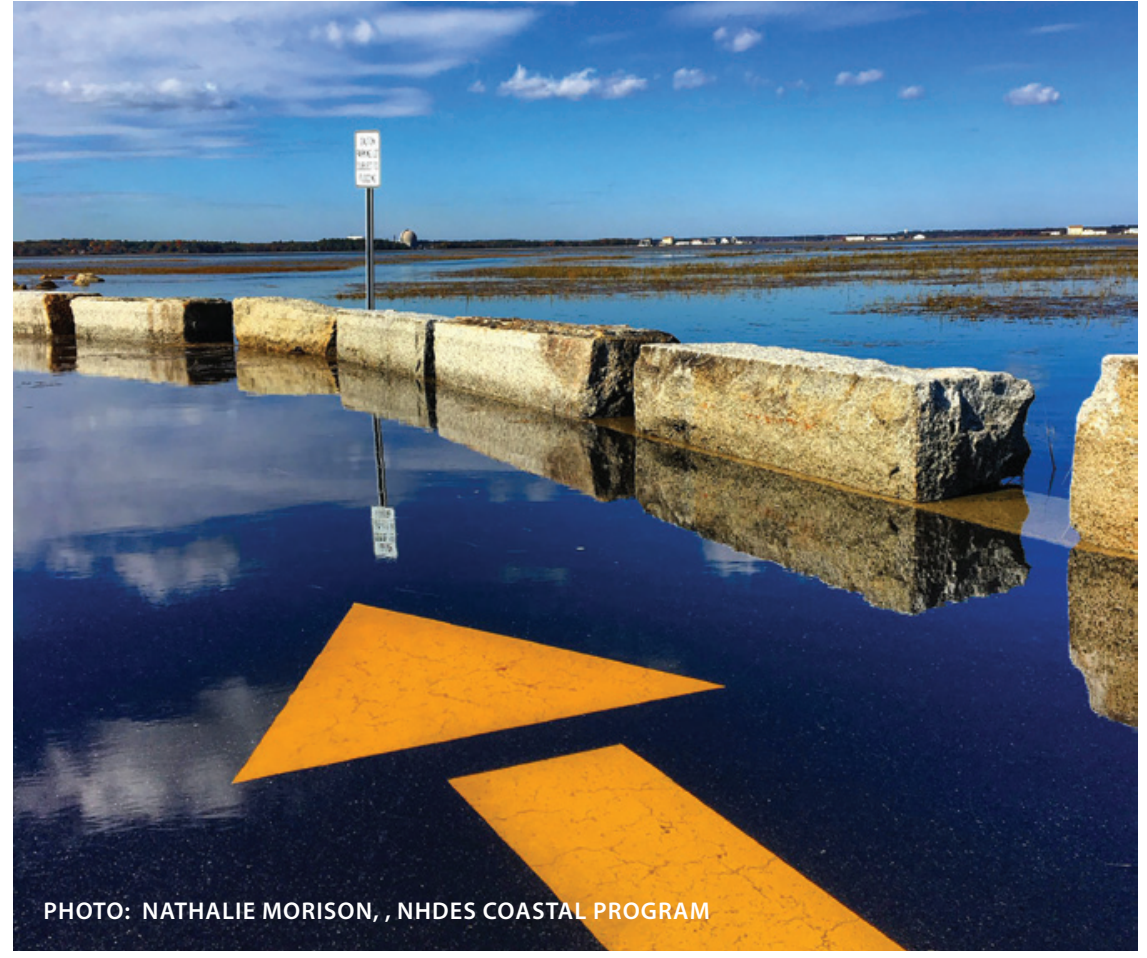

NH COASTAL FLOOD RISK SUMMARY PART II: GUIDANCE | STEP 7
$\mathbf{4}$ 
STEP 7 TABLE B. EXAMPLES OF TYPES OF ACTION TO MANAGE COASTAL FLOOD RISK.

There are multiple ways to develop and select preferred option(s) for planning, regulatory, and site-specific projects. Approaches will vary based on project goals and decision maker preferences. The following examples are intended to provide additional context and ideas for each project type, but do not necessarily represent recommended options and will not apply to all projects.

\begin{tabular}{|c|c|c|c|c|c|}
\hline & NO ACTION & AVOID & ACCOMMODATE & RESIST & RELOCATE \\
\hline $\begin{array}{l}\text { IN OTHER WORDS, } \\
\text { RECOGNIZE RISK AND.. }\end{array}$ & Don't change anything ${ }^{*}$ & $\begin{array}{c}\text { Prioritize investment out } \\
\text { of the water's way }\end{array}$ & $\begin{array}{l}\text { Live with } \\
\text { the water }\end{array}$ & $\begin{array}{l}\text { Keep the } \\
\text { water out }\end{array}$ & $\begin{array}{c}\text { Move assets or facilitate } \\
\text { migration }\end{array}$ \\
\hline $\begin{array}{l}\text { PLANNING } \\
\text { PROJECTS } \\
\text { Many planning projects will } \\
\text { incorporate multiple action } \\
\text { types from this framework. }\end{array}$ & $\begin{array}{l}\text { Public Park Master Plan } \\
\text { update determines no } \\
\text { need to take action to } \\
\text { address coastal flood risk. }\end{array}$ & $\begin{array}{l}\text { Economic Development } \\
\text { Plan update identifies } \\
\text { area with low coastal } \\
\text { flood risk to prioritize for } \\
\text { future development. }\end{array}$ & $\begin{array}{l}\text { Natural resource } \\
\text { management plan } \\
\text { identifies strategies } \\
\text { to facilitate habitat } \\
\text { adaptation. }\end{array}$ & $\begin{array}{l}\text { Local Hazard } \\
\text { Mitigation Plan } \\
\text { update identifies } \\
\text { necessary upgrades } \\
\text { to existing seawall } \\
\text { on critical local } \\
\text { evacuation route. }\end{array}$ & $\begin{array}{l}\text { State transportation plan } \\
\text { identifies transportation } \\
\text { routes that may be moved } \\
\text { or decommissioned if future } \\
\text { coastal flood conditions } \\
\text { reach an identified } \\
\text { threshold. }\end{array}$ \\
\hline $\begin{array}{l}\text { REGULATORY } \\
\text { PROJECTS } \\
\text { Some regulatory projects } \\
\text { might require use of the } \\
\text { Guidance steps by permit } \\
\text { applicants rather than } \\
\text { predetermine the action(s) } \\
\text { required of applicants. }\end{array}$ & $\begin{array}{l}\text { Local floodplain zoning } \\
\text { ordinance update } \\
\text { does not incorporate } \\
\text { new coastal flood risk } \\
\text { information because } \\
\text { existing ordinance } \\
\text { already requires adequate } \\
\text { RSLR-adjusted DFE. }\end{array}$ & $\begin{array}{c}\text { Transfer of development } \\
\text { rights regulation } \\
\text { provides incentives for } \\
\text { development in areas } \\
\text { with low coastal flood } \\
\text { risk. }\end{array}$ & $\begin{array}{l}\text { Local wetlands } \\
\text { conservation district } \\
\text { zoning ordinance adopts } \\
\text { new requirements } \\
\text { for substantial } \\
\text { improvements to be } \\
\text { elevated to adequate } \\
\text { RSLR-adjusted DFE on } \\
\text { open foundations. }\end{array}$ & $\begin{array}{l}\text { State wetlands } \\
\text { regulations allow } \\
\text { for construction of } \\
\text { new seawalls, only if } \\
\text { they protect public } \\
\text { infrastructure. }\end{array}$ & $\begin{array}{l}\text { Local floodplain } \\
\text { management program } \\
\text { provides incentives for } \\
\text { highly vulnerable properties } \\
\text { to participate in voluntary } \\
\text { buyouts. }\end{array}$ \\
\hline
\end{tabular}

*Be sure to understand the potential liability associated with not taking action despite understanding risk information. Justification for no action should be based on risk assessment results. ${ }^{55}$

\section{RESOURCES TO REFERENCE IN STEP 7}

${ }^{55}$ Climate Adaptation and Liability: A legal primer and workshop summary report. (2018). Published by the Conservation Law Foundation. https://www.clf.org/wp-content/uploads/2018/01/GRC_CLF_Report_R8.pdf

42 | STEP 7 | NH COASTAL FLOOD RISK SUMMARY PART II: GUIDANCE 


\section{SECTION D. GLOSSARY AND ACRONYMS}

Adaptation 56: A response or action that seeks to reduce the vulnerability of natural and human systems to the impacts of projected coastal flood risks.

Adaptability: The ability to alter a project or the ability of that project to naturally adapt in the future as conditions change.

Base Flood Elevation (BFE): The elevation to which floodwater is anticipated to rise during the base flood. Base Flood Elevations (BFEs) are shown on Flood Insurance Rate Maps (FIRMs) and on the flood profiles. The elevation of the 1\% annual chance flood.

Beneficiary: Any individual, community, or wildlife that benefits from a project.

Coastal storm: A disturbance of the atmosphere affecting coastal areas such as a nor'easter or tropical cyclone that is often accompanied by strong winds, heavy precipitation, and storm surge and results in coastal flooding.

Decision maker: Any project proponents, regulators, advisors, and stakeholders affected or served by a project.

Design Flood Elevation (DFE): The total flood elevation that a project is designed to protect for. DFE is typically at least "BFE" with freeboard, as required by building codes. "RSLR"-adjusted DFE is typically at least "BFE" with freeboard and "RSLR."

Design Life ${ }^{57}$ : The life expectancy of a project as determined during design, as opposed to a project's "useful life" (see definition in Glossary).

Design storm ${ }^{58}$ : The magnitude and temporal distribution of precipitation from a storm event defined by probability of occurrence (e.g., five-year storm) and duration (e.g., 24 hours), used in the design and evaluation of stormwater management systems.
Freeboard: Freeboard is a factor of safety usually expressed in feet above a flood level for purposes of floodplain management.

Maladaptation ${ }^{59}$ : Action taken ostensibly to avoid or reduce vulnerability to climate change that impacts adversely on, or increases the vulnerability of other systems, sectors or social groups, including but not limited to, actions that increase emissions of greenhouse gases, disproportionately burden vulnerable populations, have high opportunity costs, reduce incentives to adapt, and limit the choices available to future generations.

Project: Any private, local, state, or federal planning, regulatory, or site-specific effort that should consider and incorporate coastal flood risk projections.

Project value and replacement cost: Both the explicit economic and intrinsic social value of a project and the cost to replicate or replace the project.

Public function or safety: The implications of a project on the effective function of public services and safety of people.

\section{Representative Concentration Pathways (RCP) ${ }^{60}$.}

Representative Concentration Pathways (RCPs) are four greenhouse gas concentration (not emissions) trajectories adopted by the IPCC for its Fifth Assessment Report in 2014. The Representative Concentration Pathways (RCPs), which are used for making projections based on these factors, describe four different $21 \mathrm{st}$ century pathways of greenhouse gas emissions and atmospheric concentrations, air pollutant emissions and land use. The RCPs include a stringent mitigation scenario (RCP 2.6), two intermediate scenarios (RCP 4.5 and RCP 6.0) and one scenario with very high greenhouse gas emissions (RCP 8.5). 
Relative sea-level rise (RSLR) ${ }^{61}$ : The increase in elevation between the land and the sea surface at particular locations. Relative sea-level differs from Global Mean Sea Level due to processes operating on more regional scales, including vertical land motion, atmosphere/ocean dynamics, and changes in the height of the geoid (the gravitationally determined surface of the ocean in the absence of tides and ocean currents).

Resilience (coastal): The ability of a community or system to proactively prepare for and bounce back (better) from hazardous events such as hurricanes, coastal storms, and long-term sea-level rise and associated flooding, rather than simply react and respond.

Sea level-induced groundwater rise: The process by which groundwater rises as a result of sea-level rise.

Sea-level rise ${ }^{62}$ : The worldwide average rise in mean sea level, which may be due to a number of different causes, such as the thermal expansion of sea water and the addition of water to the oceans from the melting of glaciers, ice caps, and ice sheets; contrast with relative sea-level rise.

Sensitivity to inundation: Both the physical and social implications if the project were to experience flooding. Physical sensitivity refers to the implications on a site or structures while social sensitivity refers to the implications for the specific populations that depends on the project.

Storm surge ${ }^{63}$ : An abnormal rise in sea level accompanying a hurricane or other intense storm, whose height is the difference between the observed level of the sea surface and the level that would have occurred in the absence of the cyclone.

System: The social and ecological characteristics and linkages comprising coastal areas.
Tolerance for flood risk ${ }^{62}$. The willingness of decision makers to accept a higher or lower probability of flood impacts based on relevant project characteristics such as project value or replacement cost, modifiability or adaptive capacity, importance for public function or safety, and sensitivity to inundation.

Useful Life ${ }^{57}$ : The period over which a project is expected to be available for use by an entity. This depends on regular and adequate maintenance. This period of time typically exceeds a project's "design life."The combined effect of operational requirements and useful life is practical in assessing an investment in improving resilience.

\section{ACRONYMS}

ASCE American Society of Civil Engineers

BFE Base Flood Elevation

DFE Design Flood Elevation

FEMA Federal Emergency Management Agency

FIRM Flood Insurance Rate Map

HOTL Highest Observable Tide Line

NHCAW New Hampshire Coastal Adaptation Workgroup

NHDES NH Department of Environmental Services

NOAA National Oceanic and Atmospheric Administration

RCP Representative Concentration Pathway

RSLR Relative Sea-Level Rise

SERG State Environmental Resilience Group

STAP Science and Technical Advisory Panel

UNH University of New Hampshire

44 GLOSSARY AND ACRONYMS I NH COASTAL FLOOD RISK SUMMARY PART II: GUIDANCE 


\section{RESOURCES TO REFERENCE IN GLOSSARY}

${ }^{56}$ Preparing New Hampshire for Projected Storm Surge, Sea-Level Rise, and Extreme Precipitation. (2016). Published by the New Hampshire Coastal Risk and Hazards Commission. https://www. nhcrhc.org/wp-content/uploads/2016-CRHC-final-report.pdf

${ }^{57}$ Climate Resiliency Design Guidelines. (2019). By the New York City Mayor's Office of Recovery and Resiliency. https://www1.nyc.gov/assets/orr/pdf/NYC_Climate_ Resiliency_Design_Guidelines_v3-0.pdf

58 Philadelphia Stormwater Management Guidance Manual, Version 3.1. (2018). By the Philadelphia Water Department. https://www.pwdplanreview.org/manual/appendices/a.-glossary

${ }^{59}$ Maladaptation. (2010). By Barnett, J., O’Neill, S. Global Environmental Change, 20: 211-213.

http://dx.doi.org/10.1016/j.gloenvcha.2009.11.004
${ }^{60}$ Climate Change 2014: Synthesis Report. (2014). Intergovernmental Panel on Climate Change. https://www.ipcc.ch/site/assets/uploads/2018/05/SYR_AR5_ FINAL_full_wcover.pdf

${ }^{61}$ Mapping Sea-Level Change in Time, Space, and Probability. (2018). By Horton, B.P., et al. Annual Review of Environment and Resources. doi: https://doi.org/10.1146/annurevenviron-102017-025826

${ }^{62}$ State of California Sea-Level Rise Guidance. (2018). By the OPC. http://www.opc.ca.gov/webmaster/ftp/pdf/agenda_ items/20180314/Item3_Exhibit-A_OPC_SLR_Guidance-rd3.pdf

${ }^{63}$ Glossary - Storm Surge. (2009). National Weather Service. https://w1.weather.gov/glossary/index. php? word=storm+surge

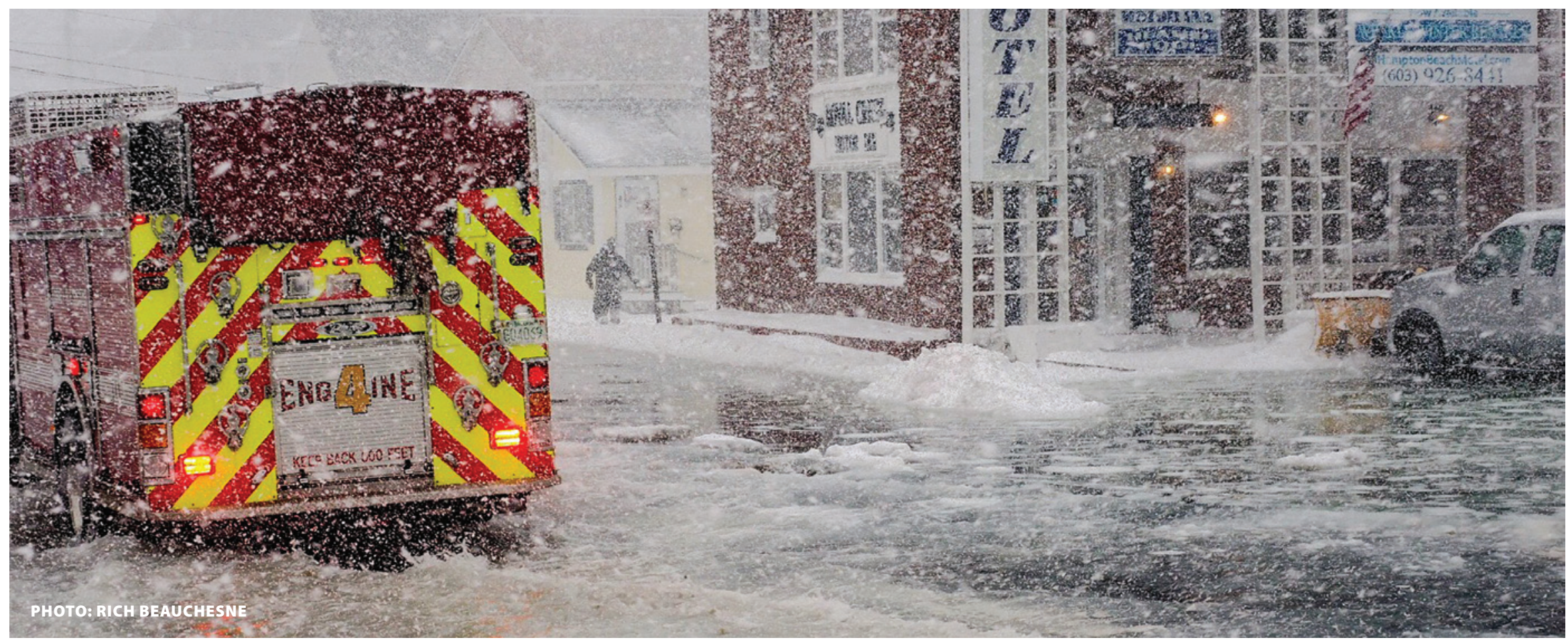

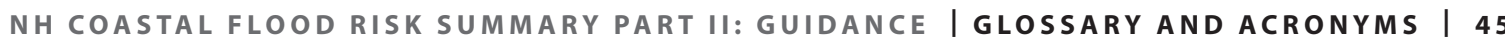


This Worksheet and Project Inventory Table is a companion resource to be used while referencing the New Hampshire Coastal Flood Risk Summary Part II: Guidance for Using Coastal Flood Risk Projections (Guidance). The purpose of the Worksheet is to help decision makers work through the seven step approach for incorporating coastal flood risk projections in multiple local, state, and federal projects, including planning, regulatory, or site-specific efforts. The Guidance provides principles, step-by-step instructions, and key resources needed to fill out this Worksheet. Use of the Worksheet is voluntary. For some projects, the Worksheet will be a useful tool for decision makers working through the seven step process. For other projects, decision makers may find that only part of the Worksheet is useful, that they need to adjust the worksheet to tailor it to their project, or that they prefer to apply the Guidance to their project without using the Worksheet. Decision makers are expected to acquire additional data about their project in order to use the Guidance and complete the Worksheet.

The seven step approach recommended in the Guidance is intended for private, local, state, and federal planning, regulatory, and site-specific projects affecting or taking place in New Hampshire's 17 coastal zone municipalities, including Dover, Durham, Exeter, Greenland, Hampton, Hampton Falls, Madbury, New Castle, Newfields, Newington, Newmarket,
North Hampton, Portsmouth, Rollinsford, Rye, Seabrook, and Stratham. The seven steps provide a framework to guide decision makers as they select appropriate coastal flood risk projections, begin assessing impacts of those projections, and consider actions to increase project resilience. The term "decision maker" refers broadly to project proponents, regulators, advisors, and stakeholders affected or served by a project. In the Guidance and Worksheet, project-specific considerations are provided for steps where Guidance application is likely to differ for planning, regulatory, or site-specific projects. Referenced resources that may be useful for completing the Worksheet appear at the end of each step in the Guidance. The Project Inventory Table is provided for decision makers working on detailed projects and/or projects that are broad in scale with multiple areas, facilities, structures, and/or resources to evaluate.

In order to fill out this worksheet, decision makers will need to reference the Guidance. Prior to beginning the worksheet, read the Guidance Section A Purpose and Intended Use, as well as Guidance Section B Guiding Principles for Enhancing Coastal Flood Resilience. Guidance Section C Step-by-Step Approach for Selecting and Incorporating Coastal Flood Risk Projections presents Steps 1-7 that are directly referenced throughout this Worksheet and Project Inventory Table.

\section{BACKGROUND}

B.1 Preparer name:

B.2 Preparer affiliation to the project:

B.3 Preparer contact information: Email Phone

B.4 Select the municipality or municipalities where the project takes place.

\begin{tabular}{|c|c|c|c|c|c|}
\hline$\square$ Dover & $\square$ Durham & $\square$ Exeter & $\square$ Greenland & $\square$ Hampton & $\square$ Hampton Falls \\
\hline$\square$ Madbury & $\square$ New Castle & $\square$ Newfields & $\square$ Newington & $\square$ Newmarket & $\square$ North Hampton \\
\hline Portsmouth & $\square$ Rollinsford & $\square$ Rye & $\square$ Seabrook & $\square$ Stratham & \\
\hline
\end{tabular}

B.5 Date: 


\section{STEP 1 DEFINE PROJECT GOAL, TYPE, LOCATION, AND TIMEFRAME(S)}

See Guidance Step 1, including Resources to Reference.

\section{STEP 1.1 DEFINE THE PROJECT GOAL AND PROJECT TYPE.}

1.1.1 Project name:

1.1.2 Project goal:

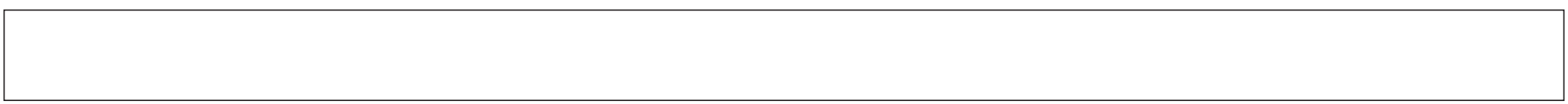

1.1.3 Identify the project beneficiaries.

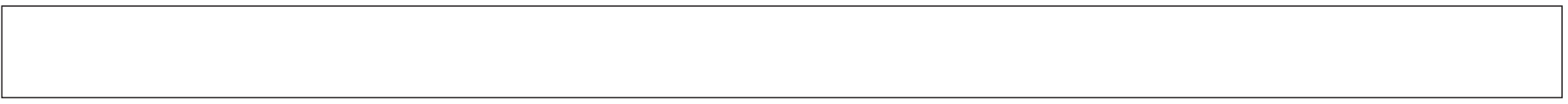

1.1.4 Select the project type:
$\square$ Planning
$\square$ Regulatory
$\square$ Site-specific
Other:

1.1.5 Briefly describe the project activities.

\section{STEP 1.2 DEFINE AND INVENTORY THE PROJECT AREA.}

1.2.1 Describe the project planning, regulatory, or site-specific area. If relevant (likely for site-specific projects) identify address and tax lot number

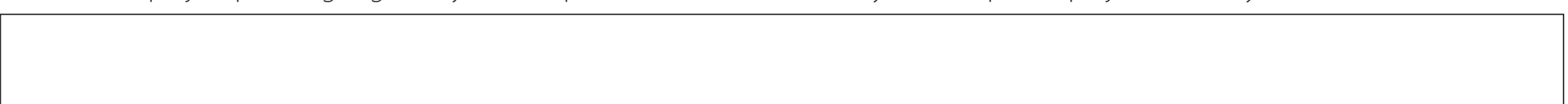

Optional: For detailed projects, use the Project Inventory Table, row 1, to list project sub-areas.

1.2.2 Identify important facilities, structures, and resources within the project area.

Optional: For detailed projects, use the Project Inventory Table, row 1, to list facilities, structures, and resources.

NH COASTAL FLOOD RISK SUMMARY PART II: GUIDANCE | WORKSHEET | 47 
STEP 1.3 DEFINE THE TIMEFRAME(S) FOR THE PROJECT.

Optional: For detailed projects, use the Project Inventory Table, rows 2-3, to identify multiple timeframes.

1.3.1 Identify the planning horizon, regulatory timeframe, or useful life of the project.

1.3.2 Identify the year when the project timeframe ends. Year:

1.3.3 Identify likely incremental action points over the course of the project timeframe.

\begin{tabular}{|l|l|}
\hline Incremental Action Point (Year) & Explanation \\
\hline & \\
\hline & \\
\hline
\end{tabular}

\section{STEP 2 DETERMINE TOLERANCE FOR FLOOD RISK}

See Guidance Step 2, including Step 2 Table and Resources to Reference.

\section{STEP 2.1 IDENTIFY PROJECT CHARACTERISTICS THAT INFLUENCE TOLERANCE FOR FLOOD RISK.}

2.1.1 Identify and rank characteristics of the overall project that influence tolerance for flood risk using the table provided.

\begin{tabular}{|l|c|c|c|c|c|c|}
\hline $\begin{array}{l}\text { Project Characteristics that } \\
\text { Influence Tolerance for Flood Risk }\end{array}$ & $\begin{array}{c}\text { Very } \\
\text { High }\end{array}$ & High & Medium & Low & N/A & Explanation \\
\hline Value or replacement cost & $\square$ & $\square$ & $\square$ & $\square$ & $\square$ & \\
\hline Capacity to adapt & $\square$ & $\square$ & $\square$ & $\square$ & $\square$ & \\
\hline Implication for public safety \& function & $\square$ & $\square$ & $\square$ & $\square$ & $\square$ & \\
\hline Sensitivity to inundation & $\square$ & $\square$ & $\square$ & $\square$ & $\square$ & \\
\hline Other, if applicable: & $\square$ & $\square$ & $\square$ & $\square$ & $\square$ & \\
\hline
\end{tabular}

Optional: For detailed projects, use the Project Inventory Table, rows 4-7, to describe tolerance for flood risk characteristics of multiple features.

48 WORKSHEET I NH COASTAL FLOOD RISK SUMMARY PART II: GUIDANCE 
STEP 2.2 DETERMINE TOLERANCE FOR FLOOD RISK APPLICABLE TO THE PROJECT.

2.2.1 The tolerance for flood risk applicable to the overall project is:
$\square$ High
$\square$ Medium
$\square$ Low
$\square$ Very Low

Explanation:

Optional: For detailed projects, use the Project Inventory Table, row 8, to determine tolerance for flood risk of multiple features.

2.2.2 Consider the tolerance for flood risk of important access and services identified in Step 1.2 and possible implications for the project.

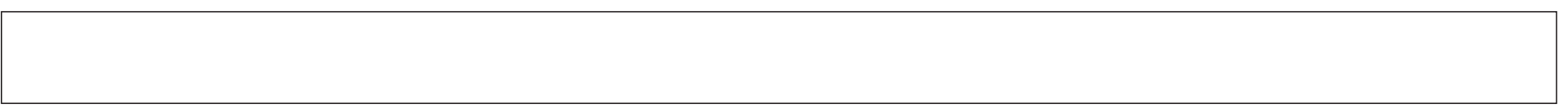

2.2.3 Consider how the project goal and use of the project area may change over the course of the project timeframe and resulting changes in tolerance for flood risk.

\section{STEP 3 SELECT AND ASSESS RELATIVE SEA-LeVEL RISE (RSLR) ESTIMATE(S)}

See Guidance Step 3, including Step 3 Table A or B and Resources to Reference.

\section{STEP 3.1 SELECT THE RSLR ESTIMATE(S) FOR THE PROJECT.}

3.1.1 Based on tolerance for flood risk and project timeframe, select the RSLR or range of RSLR estimate(s) that the project should plan to, regulate for, or design for: feet by year from 1.3.2

3.1.2 Based on tolerance for flood risk and incremental action points, select the RSLR or range of RSLR estimate(s) that the project should make incremental plans for. (Repeat for all incremental action point years).

\begin{tabular}{|l|l|}
\hline Incremental Action Point (Year from 1.3.3) & RSLR (feet) \\
\hline & \\
\hline & \\
\hline
\end{tabular}

Optional: For detailed projects, use the Project Inventory Table, row 9, to select RSLR estimate(s) for multiple, different features. 
STEP 3.2 ASSESS RSLR IMPACTS TO THE PROJECT.

Mapping tools listed in Guidance Step 3 may assist with Step 3.2.

3.2.1 Identify the tidal datum used for the project.
$\square$ NAVD88
$\square$ NGVD29
$\square$ Other:

3.2.2 Select the tidal (non-storm) water reference levels that are most relevant to the project overall.
$\square$ Mean Lower Low Water
$\square$ Mean Low Water
$\square$ Mean Sea Level

$\square$ Mean High Water

$\square$ Mean Higher High Water

$\square$ Highest Observable Tide Line

$\square$ Other:

3.2.3 Calculate RSLR-adjusted elevations for the relevant tidal water reference line(s).

\begin{tabular}{|l|l|l|}
\hline Tidal Water Reference Level & Present-Day Elevation (feet) & $\begin{array}{c}\text { RSLR-Adjusted Elevation } \\
\text { or Range of Elevations (feet) }\end{array}$ \\
\hline Mean Lower Low Water (MLLW) & & \\
\hline Mean Low Water (MLW) & & \\
\hline Mean Sea Level (MSL) & & \\
\hline Mean High Water (MHW) & & \\
\hline Mean Higher High Water (MHHW) & & \\
\hline Highest Observable Tide Line (HOTL) & & \\
\hline Other: & & \\
\hline
\end{tabular}

3.2.4 If relevant, describe present-day sediment deposition and/or erosion dynamics at the site. 
3.2.5 Evaluate risks to the project from RSLR-induced increases in tidal extent, water level, current velocities, and changes in sediment deposition and/or erosion using the table provided.

\begin{tabular}{|l|c|c|c|c|c|c|}
\hline Risks from RSLR-Induced: & $\begin{array}{c}\text { Very } \\
\text { High }\end{array}$ & High & Medium & Low & N/A & Explanation \\
\hline Increase in tidal extent & $\square$ & $\square$ & $\square$ & $\square$ & $\square$ & \\
\hline Increase in water level & $\square$ & $\square$ & $\square$ & $\square$ & $\square$ & \\
\hline Increase in current velocities & $\square$ & $\square$ & $\square$ & $\square$ & $\square$ & \\
\hline Changes in sediment deposition & $\square$ & $\square$ & $\square$ & $\square$ & $\square$ & \\
\hline Changes in erosion & $\square$ & $\square$ & $\square$ & $\square$ & $\square$ & \\
\hline Other: & $\square$ & $\square$ & $\square$ & $\square$ & $\square$ & \\
\hline
\end{tabular}

Optional: For detailed projects, use the Project Inventory Table, row 10, to evaluate risks from RSLR-induced impacts to project features.

3.2.6 Describe how nearby landscape features and infrastructure such as undersized culverts and bridges, as well as future land use change may affect risks to the overall project from RSLR in the future.

Project interactions with RSLR and nearby landscape features and infrastructure:

Project interactions with RSLR and future land use change: 
3.2.7 Evaluate the RSLR impacts on the overall project, natural resources, cultural and historic resources, public access, socially vulnerable populations, and other relevant project characteristics.

\begin{tabular}{|l|c|c|c|c|c|c|}
\hline RSLR Impacts on: & $\begin{array}{c}\text { Very } \\
\text { High }\end{array}$ & High & Medium & Low & N/A & Explanation \\
\hline Overall Project & $\square$ & $\square$ & $\square$ & $\square$ & $\square$ & \\
\hline Natural Resource & $\square$ & $\square$ & $\square$ & $\square$ & $\square$ & \\
\hline Cultural and Historic Resources & $\square$ & $\square$ & $\square$ & $\square$ & $\square$ & \\
\hline Socially Vulnerable Populations & $\square$ & $\square$ & $\square$ & $\square$ & $\square$ & \\
\hline Other: & $\square$ & $\square$ & $\square$ & $\square$ & $\square$ & \\
\hline
\end{tabular}

Optional: For detailed projects, use the Project Inventory Table, row 11, to evaluate RSLR impacts for multiple project features.

\section{STEP 4 IDENTIFY AND ASSESS RSLR-ADJUSTED COASTAL STORMS}

See Guidance Step 4, including Step 4 Table and Resources to Reference.

\section{STEP 4.1 DETERMINE RSLR-ADJUSTED DESIGN FLOOD ELEVATION (DFE).}

4.1.1 If relevant, identify the Flood Design Class or classes most closely associated with the project.
$\square$ Class 1
$\square$ Class 3
$\square$ Class 2
$\square$ Class 4

Not applicable

Optional: For detailed projects, use the Project Inventory Table, row 12, to identify Flood Design Class for multiple project features.

4.1.2 Identify the present-day coastal storm(s) relevant to the project.

$\square 1 \%$ annual chance storm (100-year)

$\square$ 0.2\% annual chance storm (500-year)

$\square$ Other: 
4.1.3 Identify present-day FEMA Flood Insurance Rate Map Special Flood Hazard Area(s) flood zone(s) for the project area.
$\square$ AE Zone
$\square$ AO Zone
Coastal A Zone
$\square$ VE Zone
$\square \times$ Zone
$\square$ Other:

4.1.4 If the project takes place in a FEMA Special Flood Hazard Area, identify the present-day Base Flood Elevation(s) (BFE) for the project area. feet or $\square$ NoBFE

Optional: For detailed projects, use the Project Inventory Table, rows 13-14, to identify Flood Zone and BFE for multiple project features.

4.1.5 Identify any freeboard requirements or recommendations associated with the project area related to present-day coastal flood protection.
$\square$ o feet
$\square 1$ foot
$\square 2$ feet
Other:

Optional: For detailed projects, use the Project Inventory Table, row 15, to identify freeboard for multiple project features.

4.1.6 Identify the present-day coastal storm DFE(s) for the project. For instructions on how to calculate DFE, see Guidance Step 4 Table. feet

Optional: For detailed projects, use the Project Inventory Table, row 16, to identify DFE for multiple project features.

4.1.7 For projects with no DFE or for which DFE is not applicable, describe how a present-day coastal storm might affect the project.

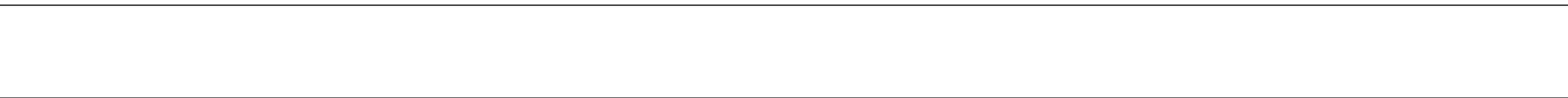

4.1.8 Identify RSLR-adjusted DFE(s) or range of DFE that the project should plan to, regulate for, or design for. For instructions on how to calculate RSLR-adjusted DFE, see Guidance Step 4 Table. feet

Optional: For detailed projects, use the Project Inventory Table, row 16, to identify RSLR-adjusted DFE for multiple project features.

NH COASTAL FLOOD RISK SUMMARY PART II: GUIDANCE | WORKSHEET I 53 
STEP 4.2 ASSESS RSLR-ADJUSTED COASTAL STORM IMPACTS TO THE PROJECT.

Mapping tools listed in Guidance Step 4 Resources to Reference may assist with Step 4.2.

4.2.1 Evaluate risks to the project from RSLR-adjusted coastal storm induced increases in tidal extent, water level, current velocities, and changes in sediment deposition and/or erosion using the table provided.

\begin{tabular}{|l|c|c|c|c|c|c|}
\hline $\begin{array}{l}\text { Risks from RSLR-Adjusted } \\
\text { Coastal Storms Resulting in: }\end{array}$ & $\begin{array}{l}\text { Very } \\
\text { High }\end{array}$ & High & Medium & Low & N/A & Explanation \\
\hline Increase in flood extent & $\square$ & $\square$ & $\square$ & $\square$ & $\square$ & \\
\hline Increase in flood water level & $\square$ & $\square$ & $\square$ & $\square$ & $\square$ & \\
\hline Increase in storm current velocities & $\square$ & $\square$ & $\square$ & $\square$ & $\square$ & \\
\hline Changes in sediment deposition & $\square$ & $\square$ & $\square$ & $\square$ & $\square$ & \\
\hline Changes in erosion & $\square$ & $\square$ & $\square$ & $\square$ & $\square$ & \\
\hline Other: & $\square$ & $\square$ & $\square$ & $\square$ & $\square$ & \\
\hline
\end{tabular}

Optional: For detailed projects, use the Project Inventory Table, row 18, to evaluate risks from RSLR-adjusted coastal storm impacts on project features.

4.2.2 Describe how nearby landscape features and infrastructure such as undersized culverts and bridges, as well as future land use change may affect risks to the project from RSLR-adjusted coastal storms in the future.

Project interactions with RSLR-adjusted coastal storms and nearby landscape features and infrastructure:

Project interactions with RSLR-adjusted coastal storms and future land use change: 
4.2.3 Assess the RSLR-adjusted coastal storm impacts on the overall project, natural resources, cultural and historic resources, public access, socially vulnerable populations, and other relevant project characteristics.

\begin{tabular}{|l|c|c|c|c|c|c|}
\hline $\begin{array}{l}\text { RSLR-Adjusted Coastal } \\
\text { Storm Impacts on: }\end{array}$ & $\begin{array}{l}\text { Very } \\
\text { High }\end{array}$ & High & Medium & Low & N/A & Explanation \\
\hline Overall Project & $\square$ & $\square$ & $\square$ & $\square$ & $\square$ & \\
\hline Natural Resources & $\square$ & $\square$ & $\square$ & $\square$ & $\square$ & \\
\hline Cultural and Historic Resources & $\square$ & $\square$ & $\square$ & $\square$ & $\square$ & \\
\hline Socially Vulnerable Populations & $\square$ & $\square$ & $\square$ & $\square$ & $\square$ & \\
\hline Other: & $\square$ & $\square$ & $\square$ & $\square$ & $\square$ & \\
\hline
\end{tabular}

Optional: For detailed approach, use the Project Inventory Table, row 19, to evaluate RSLR-adjusted coastal storm impacts for multiple project features.

\section{STEP 5 IDENTIFY AND ASSESS RSLR-INDUCED GROUNDWATER RISE}

See Guidance Step 5, including Step 5 Table and Resources to Reference.

\section{STEP 5.1 IDENTIFY RSLR-INDUCED GROUNDWATER RISE FOR THE PROJECT.}

5.1.1 Identify the groundwater rise mapping status for the communities associated with the project area.
$\square$ Mapped
$\square$ Unmapped
$\square$ Both

5.1.2 If the project area is mapped, identify the RSLR-induced groundwater rise estimate(s) or range of estimates. feet

5.1.3 If the project area is unmapped, identify the RSLR-induced groundwater rise estimates for the project.

Commit to manage to: feet and be prepared to adapt to: feet.

Optional: For detailed projects, use the Project Inventory Table, rows 20-21, to identify RSLR-induced groundwater rise for project features. 
STEP 5.2 ESTIMATE DEPTH TO PRESENT-DAY AND FUTURE GROUNDWATER FOR THE PROJECT AREA.

5.2.1 Estimate the present-day depth to Seasonal High Water Table (SHWT). feet

Optional: For detailed projects, use the Project Inventory Table, row 22, to estimate present-day depth to SHWT for project features.

5.2.2 Determine estimated depth or range of depths to projected SHWT. feet

Optional: For detailed projects, use the Project Inventory Table, row 23, to estimate depth to projected SHWT for project features.

STEP 5.3 EVALUATE IMPACTS OF RSLR-INDUCED GROUNDWATER RISE FOR THE PROJECT.

5.3.1 Describe risks to the overall project from RSLR-induced groundwater rise.
$\square$ Very High
$\square$ High
$\square$ Medium
Low
No Risk

Explanation:

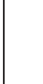

Optional: For detailed projects, use the Project Inventory Table, row 24, to describe risk from RSLR-induced groundwater rise on project features.

5.3.2 Assess the RSLR-induced groundwater rise impacts on the overall project, natural resources, cultural and historic resources, public access, socially vulnerable populations, and other relevant project characteristics.

\begin{tabular}{|l|c|c|c|c|c|c|}
\hline $\begin{array}{l}\text { RSLR-Induced Groundwater } \\
\text { Rise Impacts on: }\end{array}$ & $\begin{array}{c}\text { Very } \\
\text { High }\end{array}$ & High & Medium & Low & N/A & Explanation \\
\hline Overall Project & $\square$ & $\square$ & $\square$ & $\square$ & $\square$ & \\
\hline Natural Resources & $\square$ & $\square$ & $\square$ & $\square$ & $\square$ & \\
\hline Cultural and Historic Resources & $\square$ & $\square$ & $\square$ & $\square$ & $\square$ & \\
\hline Socially Vulnerable Populations & $\square$ & $\square$ & $\square$ & $\square$ & $\square$ & \\
\hline Other: & $\square$ & $\square$ & $\square$ & $\square$ & $\square$ & \\
\hline
\end{tabular}

Optional: For detailed projects, use the Project Inventory Table, row 25, to evaluate RSLR-adjusted coastal storm impacts for multiple project features. 


\section{STEP 6 IDENTIFY AND ASSESS EXTREME PRECIPITATION ESTIMATES.}

See Guidance Step 6, including Step 6 Table and Resources to Reference.

\section{STEP 6.1 ACCOUNT FOR PROJECTED INCREASES IN EXTREME PRECIPITATION.}

6.1.1 Based on tolerance for flood risk, identify the percent increase in extreme precipitation for the project.

$\square 15 \%$

$\square$ More than 15\% Specify: $\%$

Optional: For detailed projects, use the Project Inventory Table, row 26, to identify percent increase in extreme precipitation for multiple project features.

6.1.2 For projects involving hydrologic and/or hydraulic modeling, identify the following:

- Duration and recurrence interval(s) relevant to the project,

- Best available present-day extreme precipitation estimates for the selected duration and recurrence interval(s), and

- Projected extreme precipitation estimates for the selected duration and recurrence interval(s).

\begin{tabular}{|l|l|l|}
\hline Duration and Recurrence Interval & Present-day Precipitation Estimate & Projected Precipitation Estimate \\
\hline & & \\
\hline & & \\
\hline & & \\
\hline & & \\
\hline & & \\
\hline
\end{tabular}


STEP 6.2 ASSESS PROJECTED EXTREME PRECIPITATION IMPACTS TO THE PROJECT.

For projects not involving hydrologic and/or hydraulic modeling, qualitatively assess projected extreme precipitation impacts.

For projects conducting hydrologic and/or hydraulic modeling, use modeling results to analyze projected extreme precipitation impacts.

6.2.1 Evaluate risks to the project from projected extreme precipitation using the following table.

\begin{tabular}{|l|c|c|c|c|c|c|}
\hline $\begin{array}{l}\text { Risks from Projected Extreme } \\
\text { Precipitation Resulting in: }\end{array}$ & $\begin{array}{c}\text { Very } \\
\text { High }\end{array}$ & High & Medium & Low & N/A & Explanation \\
\hline Increase in flood extent & $\square$ & $\square$ & $\square$ & $\square$ & $\square$ & \\
\hline Increase in flood water level & $\square$ & $\square$ & $\square$ & $\square$ & $\square$ & \\
\hline Increase in storm current velocities & $\square$ & $\square$ & $\square$ & $\square$ & $\square$ & \\
\hline Changes in sediment deposition & $\square$ & $\square$ & $\square$ & $\square$ & $\square$ & \\
\hline Changes in erosion & $\square$ & $\square$ & $\square$ & $\square$ & $\square$ & \\
\hline Other: & $\square$ & $\square$ & $\square$ & $\square$ & $\square$ & \\
\hline
\end{tabular}

Optional: For detailed projects, use the Project Inventory Table, row 27, to evaluate risks from projected extreme precipitation for multiple project features.

6.2.2 Describe how nearby landscape features and infrastructure such as undersized culverts and bridges, as well as future land use change may affect risks to the project from projected extreme precipitation.

Project interactions with projected extreme precipitation and nearby landscape features and infrastructure:

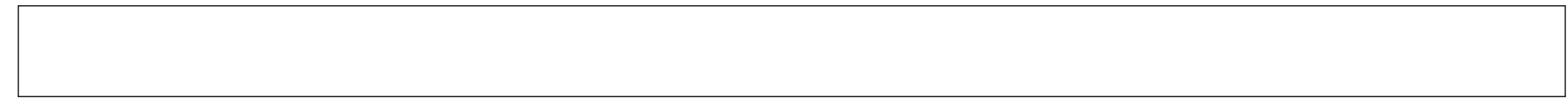

Project interactions with projected extreme precipitation and future land use, including possible changes in impervious cover: 
6.2.3 Assess the projected extreme precipitation impacts on the overall project, natural resources, cultural and historic resources, public access, socially vulnerable populations, and other relevant project characteristics.

\begin{tabular}{|l|c|c|c|c|c|c|}
\hline $\begin{array}{l}\text { Projected Extreme } \\
\text { Precipitation Impacts on: }\end{array}$ & $\begin{array}{c}\text { Very } \\
\text { High }\end{array}$ & High & Medium & Low & N/A & Explanation \\
\hline Overall Project & $\square$ & $\square$ & $\square$ & $\square$ & $\square$ & \\
\hline Natural Resources & $\square$ & $\square$ & $\square$ & $\square$ & $\square$ & \\
\hline Cultural and Historic Resources & $\square$ & $\square$ & $\square$ & $\square$ & $\square$ & \\
\hline Socially Vulnerable Populations & $\square$ & $\square$ & $\square$ & $\square$ & $\square$ & \\
\hline Other: & $\square$ & $\square$ & $\square$ & $\square$ & $\square$ & \\
\hline
\end{tabular}

Optional: For detailed projects, use the Project Inventory Table, row 28, to assess projected extreme precipitation impacts on multiple project features.

\section{STEP 7 ASSESS CUMULATIVE RISK AND EVALUATE ADAPTATION OPTIONS}

See Guidance Step 7, including Step 7 Tables A and B and Resources to Reference.

\section{STEP 7.1 ASSESS CUMULATIVE COASTAL FLOOD RISK TO THE PROJECT.}

7.1.1 Specify, based on responses to Steps 3-6, projected coastal flood risk impacts to the overall project.

\begin{tabular}{|l|c|c|c|c|c|}
\hline $\begin{array}{l}\text { Overall future coastal flood risk } \\
\text { impacts to the project: }\end{array}$ & Very High & High & Medium & Low & N/A \\
\hline RSLR (3.2.7) & $\square$ & $\square$ & $\square$ & $\square$ \\
\hline RSLR-adjusted coastal storms (4.2.3) & $\square$ & $\square$ & $\square$ & $\square$ & $\square$ \\
\hline RSLR-induced groundwater rise (5.3.2) & $\square$ & $\square$ & $\square$ & $\square$ & $\square$ \\
\hline Projected extreme precipitation (6.2.3) & $\square$ & $\square$ & $\square$ & $\square$ & $\square$ \\
\hline
\end{tabular}

7.1.2 Describe how the cumulative impact of multiple coastal flood risks occurring together may affect the project. 
$\square$ RSLR

$\square$ Projected extreme precipitation

Explanation:

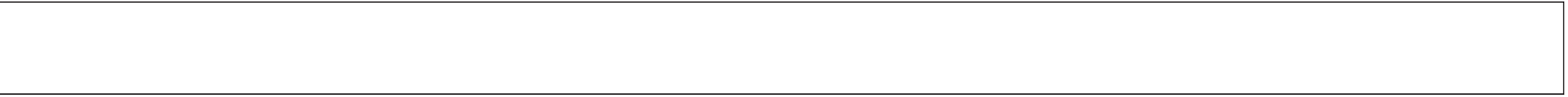

Optional: For detailed projects, use the Project Inventory Table, row 29, to specify coastal flood risks that are most impactful for multiple project features.

STEP 7.2 IDENTIFY AND EVALUATE POSSIBLE ADAPTATION OPTIONS TO MITIGATE COASTAL FLOOD RISK.

7.2.1 Identify adaptation options and select relevant action category(ies) for each option. Insert more rows if needed.

\begin{tabular}{|c|c|c|c|c|c|c|}
\hline \multirow{2}{*}{$\begin{array}{c}\text { Option } \\
\text { ID\# }\end{array}$} & \multirow{2}{*}{ Option } & \multicolumn{5}{c|}{ Action Category } \\
\cline { 3 - 7 } & & No Action & Avoid & Accommodate & Resist & Relocate \\
\hline 1 & & $\square$ & $\square$ & $\square$ & $\square$ \\
\hline 2 & $\square$ & $\square$ & $\square$ & $\square$ & $\square$ \\
\hline 3 & $\square$ & $\square$ & $\square$ & $\square$ & $\square$ & $\square$ \\
\hline 4 & & $\square$ & $\square$ & $\square$ & $\square$ & $\square$ \\
\hline 5 & & $\square$ & $\square$ & $\square$ & $\square$ & $\square$ \\
\hline
\end{tabular}

Use the table "Framework for Evaluating Adaptation Options" on the following page to complete Steps 7.2.2-7.2.3. Insert more rows if needed.

7.2.2 Identify additional "custom" criteria to evaluate adaptation options.

7.2.3 Evaluate adaptation options against each "effectiveness," "guiding principles," and "custom" criteria. 


\begin{tabular}{|c|c|c|c|c|c|c|c|c|c|c|c|c|}
\hline \multirow{3}{*}{$\begin{array}{l}\text { Option } \\
\text { ID\# } \\
\text { from } \\
7.2 .1\end{array}$} & \multirow{3}{*}{$\begin{array}{c}\text { Action } \\
\text { Categories } \\
\text { from } \\
7.2 .1\end{array}$} & \multicolumn{3}{|c|}{ EFFECTIVENESS } & \multicolumn{6}{|c|}{ GUIDING PRINCIPLES } & \multicolumn{2}{|c|}{ CUSTOM } \\
\hline & & $\begin{array}{l}\text { Mitigation } \\
\text { of Flood } \\
\text { Risk }\end{array}$ & $\begin{array}{c}\text { Meets } \\
\text { Project Goal }\end{array}$ & $\begin{array}{l}\text { Short-Term } \\
\text { or Long- } \\
\text { Term }\end{array}$ & Cost & $\begin{array}{l}\text { Contributes } \\
\text { to Mal- } \\
\text { Adaptation }\end{array}$ & $\begin{array}{l}\text { Effect on } \\
\text { Socially } \\
\text { Vulnerable } \\
\text { Populations }\end{array}$ & $\begin{array}{l}\text { Effect on } \\
\text { Natural } \\
\text { Resources }\end{array}$ & $\begin{array}{l}\text { Effect on } \\
\text { Cultural } \\
\text { and Historic } \\
\text { Resources }\end{array}$ & $\begin{array}{l}\text { Effect on } \\
\text { Public } \\
\text { access }\end{array}$ & $\begin{array}{l}\text { Custom } \\
\text { Criteria }\end{array}$ & $\begin{array}{l}\text { Custom } \\
\text { Criteria }\end{array}$ \\
\hline & & $\begin{array}{l}\text { High } \\
\text { Medium } \\
\text { Low }\end{array}$ & Yes/No & ST/LT & $\$ / \$ \$ / \$ \$ \$$ & Yes/No & $\begin{array}{l}\text { Positive } \\
\text { Neutral } \\
\text { Negative }\end{array}$ & $\begin{array}{l}\text { Positive } \\
\text { Neutral } \\
\text { Negative }\end{array}$ & $\begin{array}{l}\text { Positive } \\
\text { Neutral } \\
\text { Negative }\end{array}$ & $\begin{array}{l}\text { Positive } \\
\text { Neutral } \\
\text { Negative }\end{array}$ & & \\
\hline 1 & & & & & & & & & & & & \\
\hline 2 & & & & & & & & & & & & \\
\hline 5 & & & & & & & & & & & & \\
\hline
\end{tabular}

Optional: For detailed projects, fill out this framework for each relevant column (project feature) in the Project Inventory Table.

\section{STEP 7.3 SELECT PREFERRED OPTION(S) AND PROCEED WITH PROJECT OR REVISIT AND REVISE PREVIOUS STEPS.}

7.3.1 Describe adaptation option(s) selected for the project and considerations to ensure transparent disclosure of flood risk and future actions that may be necessary to further mitigate flood risk, particularly if a flexible adaptation approach is followed.

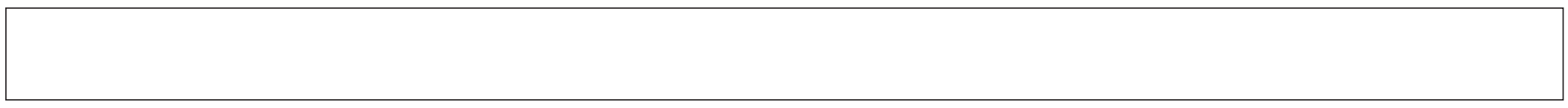

Optional: For detailed projects, use the Project Inventory Table, row 30, to describe preferred option(s) for multiple project features.

7.3.2 Should the project proceed with the adaptation options selected, revisit and revise previous steps, or not proceed?
$\square$ Proceed
$\square$ Revisit and revise
$\square$ Do not proceed

NH COASTAL FLOOD RISK SUMMARY PART II: GUIDANCE | WORKSHEET | 61 


\section{PROJECT DEFINITION}

\section{TOLERANCE FOR} FLOOD RISK

RELATIVE SEA-LEVEL RISE (RSLR)

RSLR-ADJUSTED

COASTAL STORMS

RSLR-INDUCED GROUNDWATER RISE

\section{PROJECTED EXTREME PRECIPITATION}

CUMULATIVE IMPACTS

9 RSLR estimate (in feet)

10 Notes about RSLR impacts to the project from changed tidal extent, water level, current velocities, sediment deposition, erosion

11 RSLRimpact (very high, high, medium, or low)

12 Flood Design Class $(1,2,3,4)$

13 FEMA Flood Zone (AE, AO, Coastal A, VE, X)

\begin{tabular}{l|l}
14 & BFE (in feet) \\
\hline 15 & Freeboard (in feet)
\end{tabular}

15 Freeboard (in feet)

16 DFE (in feet)

17 RSLR-adjusted DFE (in feet)

18 Notes about RSLR-adjusted coastal storm impacts from changed tidal extent, water level, current velocities, sediment deposition, erosion

19 Coastal storm impact (very high, high, medium, or low)

20 Map status (mapped, unmapped)

21 RSLR-induced groundwater rise estimate (in feet)

22 Present-day depth to SHWT (in feet)

23 Projected depth to RSLR-adjusted SHWT (in feet)

24 Notes about RSLR-induced groundwater rise impacts

25 Groundwater rise impact (very high, high, medium, or low)

26 Percent increase in extreme precipitation (15\% or greater)

27 Notes about projected extreme precipitation impacts

28 Projected extreme precipitation impact (very high, high, medium, or low)

29 Which, if any, projected coastal flood risks outweigh others in terms of impacts to the project? (RSLR, RSLR-

adjusted coastal storms, RSLR-induced groundwater rise, projected extreme precipitation)

Use framework in worksheet (Step 7.2.3) to identify and evaluate adaptation options for each structure, facilitiy, or resource, as needed.

62 PROJECT INVENTORY TABLE | NH COASTAL FLOOD RISK SUMMARY PART II: GUIDANCE 


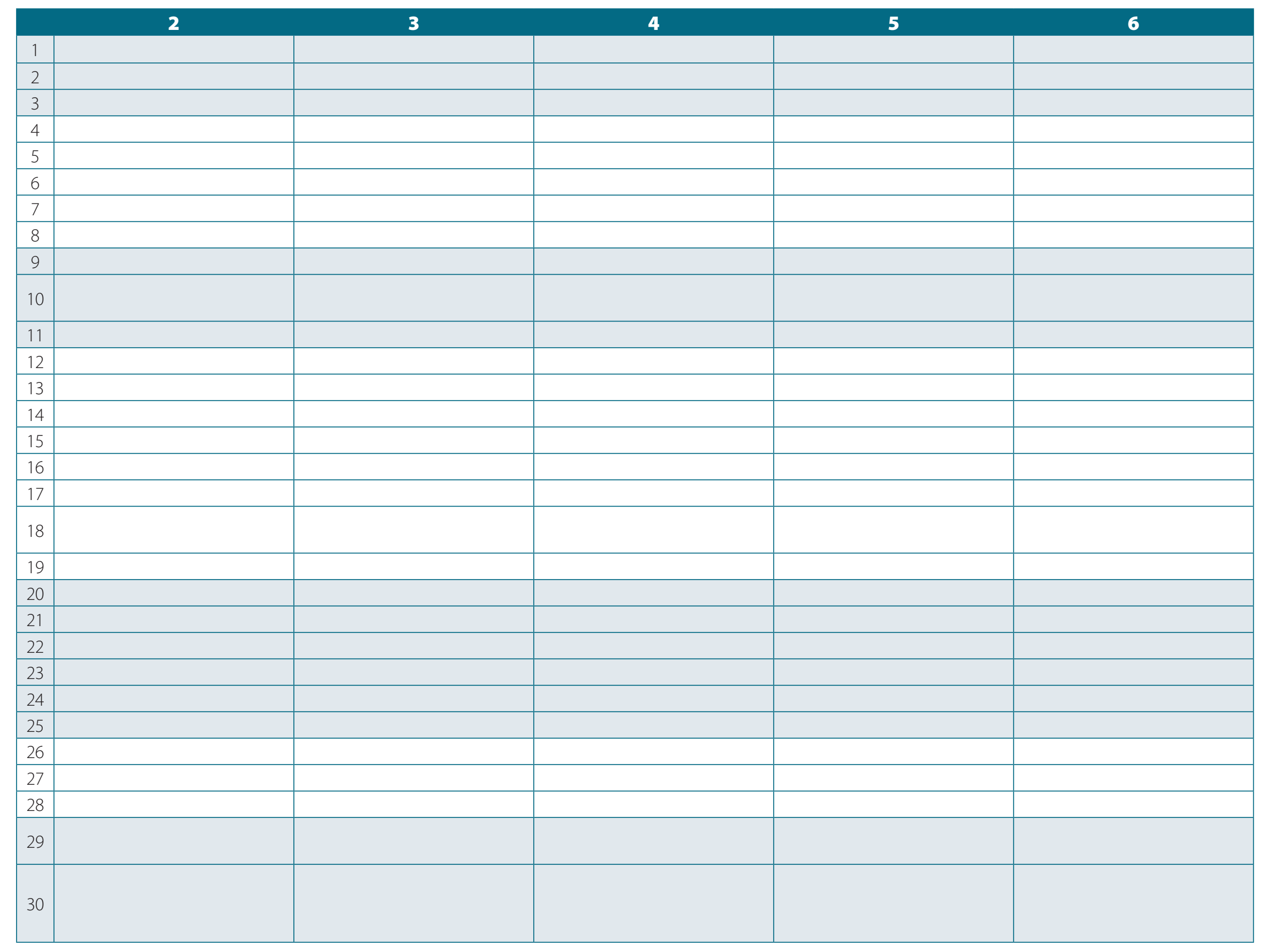


